\title{
Colonial Representations of British India: A Description and Analysis of the First Twenty-Four Issues of The Indian Amateur's Photographic Album
}

\author{
by \\ Stuart Macmillan \\ B.F.A. Ryerson University, Toronto, ON, 2004 \\ B.Sc. University of Toronto, Toronto, ON, 1996 \\ A thesis presented to Ryerson University and \\ George Eastman House International Museum of Photography and Film \\ In partial fulfillment of the requirements for the degree of \\ Master of Arts \\ In the Program of \\ Photographic Preservation and Collections Management
}

Toronto, ON, Canada, and Rochester, NY, USA, 2011

(C) Stuart Macmillan 2011 



\section{Author's Declaration}

I hereby declare that I am the sole author of this thesis.

I authorize Ryerson University to lend this thesis to other institutions or individuals for the purpose of scholarly research.

I further authorize Ryerson University to reproduce the thesis by photocopying or by other means, in total or in part, at the request of other institutions or individuals for the purpose of scholarly research. 



\title{
Colonial Representations of British India: A Description and Analysis of the First Twenty-Four Issues of The Indian Amateur's Photographic Album
}

By Stuart Macmillan

\author{
M. A. Photographic Preservation and Collections Management
}

Ryerson University, Toronto, 2011

\begin{abstract}
This thesis provides a description and analysis of the first twenty-four issues of The Indian Amateur's Photographic Album (IAPA), serially published between 1856 and 1858, in the collection of George Eastman House International Museum of Photography and Film (GEH). The thesis traces the origins of the publication to the creation of the Bombay Photographic Society, and considers its relationship with European photographic societies and a similar publication in Europe. It contains an extensive literature survey summarizing the current state of research on the IAPA within the framework of colonialist photography in British India; a detailed description of the publication and an analysis of the photographic and written components of the IAPA; and a consideration of the IAPA's contributions to and its role in the visual culture of nineteenth century India. Three appendices accompany the thesis, including an annotated and fully illustrated catalogue of the seventy-two photographs in GEH album.
\end{abstract}





\section{Acknowledgments}

I would like to thank my thesis advisor David Harris for his guidance and assistance throughout this project. His insightful and thorough analysis of the work in its various embryonic stages was essential to the project's completion. Marta Braun also provided enthusiastic support and many helpful suggestions as the second reader of my thesis.

From George Eastman House I would like to thank Alison Nordström for her inspiring words, Jamie Allan and Joseph Struble for their assistance with the photographic collection and archive, Jessica Johnston and Barbara Galasso for providing the images, and James Bellucci for help researching the museum's acquisition records.

Many people offered their time and expertise, and contributed in some way to this project: Phillip Block at the International Centre of Photography, Esa Epstein at Sepia Eye, Deepali Dewan at the Royal Ontario Museum, Sophie Gordon, Rahaab Allana at the Alkazi Foundation for the Arts, Janet Dewan, Autumn L. Mather at the Newberry Library, and Leah Hamilton at the University of Rochester.

My family all helped and contributed in their own way, and it would have been impossible to complete this project without them.

Finally I would like to thank Laurel Waterman for her essential eleventh-hour editing and support, and Shanti, the dog, who provided unconditional love no matter what was happening. 



\section{Contents}

Author's Declaration iii

Abstract $\quad v$

Acknowledgements vii

Contents $\quad$ ix

List of Illustrations $\quad x i$

List of Appendices $\quad$ XV

Introduction 1

Literature Survey 4

Setting the Scene: Photography in 1850s Bombay and the Origins of the IAPA

British Photographic Societies and Amateur Organizations 14

The Bombay Photographic Society 16

Journal of the Photographic Society of Bombay 18

$\begin{array}{ll}\text { Photographic Exhibitions } & 20\end{array}$

The Birth of the IAPA 20

Connection to the Amateur's Photographic Album 22

Description of the IAPA

The GEH Album as a Physical Object 25

Identification of the Photographs 28

A note on the Photographs 30

A Note on the Letterpress 31

Analysis I: Introduction

The IAPA as a Record of the Colonial Experience 33

Analysis of a 'Typical' Issue of the IAPA 35

Analysis II: Ethnographic Portraiture

Introduction 38

Pre-Existing Visual Conventions $\quad 39$

The Johnson and Henderson Style 43

Inside the Studio/Out in the Street 44

Costumes and Characters of Western India 47

Castes $\quad 50$

Professions and Occupations 56

Physiognomy 58

Conclusion 60

Analysis III: Architecture and Views

$\begin{array}{ll}\text { Introduction } & 61\end{array}$

The Picturesque Aesthetic 62

Stern Fidelity: the "Pencil of the Sun" 63 


\section{Photographing Bombay City}

British Bombay: Sites of Familiarity and Colonial Growth 67

Imperial Economies: Sites of Commerce 69

$\begin{array}{ll}\text { Picturesque City } & 71\end{array}$

Native Bombay

Protestant Architecture 74

Photographing Bombay Presidency

Mapping Traces of Empire and Sites of Decay 76

Amarnath and Gokak: Picturesque Indian Antiquities 76

Bassein: Picturesque Ruins, Faded Colonial Splendour 78

$\begin{array}{ll}\text { The Colonial Occupier as Photographer } & 79\end{array}$

Documenting the Emergence of the New Empire 81

Conclusion 83

After the IAPA: Professional Aspirations and Nineteenth Century Visual Culture Introduction 84

Professional Aspirations $\quad 85$

The IAPA in Nineteenth Century Visual Culture 88

Conclusion $\quad 92$

Appendix A Catalogue of Photographs in the GEH Album 95

Appendix B The IAPA by Issue Number 121

Appendix C The IAPA by Series 124

Bibliography and Works Consulted 127 


\section{List of Illustrations}

All illustrations are reproductions of photographs from the collection of George Eastman House International Museum of Photography and Film, Rochester NY, unless otherwise indicated.

Fig. 1 Example of the paper sleeve used to contain the IAPA. British Library, Photo 140. 25

Fig. 2 Descriptive letterpress sheet for IAPA no. 4.

$\begin{array}{lll}\text { Fig. } 3 & \text { Page spread for IAPA no. 11. } & 27\end{array}$

Fig. $4 \quad$ Unidentified Photographer, Tomb of Mubarak Sayyid, near Mahmudabad, mounted albumen 29 silver print (Catalogue 49).

Fig. $5 \quad$ Unidentified engraver, Tomb of Mubarak Sayyid, near Mahmudabad. (From a Photograph.), wood engraving. Page 244 in James Fergusson, History of Indian and Eastern Architecture (London: John Murray, 1910). University of Toronto.

Fig. 6 Henry H. Hinton, Bombay no. 5-Jooma Musjid, mounted albumen silver print (Catalogue 10).

Fig. 7 Arthur A. Jacob, View on the Taptee River, The Site of the Proposed Railway Bridge Near Surat, mounted albumen silver print (Catalogue 11).

Fig. $8 \quad$ Unidentified artist, A couple of the Lambadi caste, a basket-maker and his wife, and a tankdigger and his wife, Company painting from a volume containing thirty folios depicting castes, occupations, methods of cultivation, and procession scenes, gouache and watercolour. Victoria and Albert Museum, London.

Fig. 9 Johnson and Henderson, Costumes and Characters of Western India no. 5-Parsee Lady and Child, mounted albumen silver print (Catalogue 15).

Fig. 10 Johnson and Henderson, Costumes and Characters of Western India no. 6-Comfortable Gosavis, mounted albumen silver print (Catalogue 18).

Fig. 11 Unidentified Photographer, Costumes and Characters of Western India no. 19-Mehtas, or Native Writers, mounted albumen silver print (Catalogue 67).

Fig. 12 Unidentified Photographer, Costumes and Characters of Western India no. 20-Naka-Dole Waidyas, mounted albumen silver print (Catalogue 70).

Fig. 13 William Johnson, Costumes and Characters of Western India no. 1-The Gosayins, mounted albumen silver print (Catalogue 3).

Fig. 14 Johnson and Henderson, Costumes and Characters of Western India no. 2-A Group of Persians, mounted albumen silver print (Catalogue 6).

Fig. 15 Johnson and Henderson, Costumes and Characters of Western India no. 3-Parwari Women, mounted albumen silver print (Catalogue 9).

Fig. 16 Johnson and Henderson, Costumes and Characters of Western India no. 7-Group of Maratha Ghatis, mounted albumen silver print (Catalogue 25).

Fig. 17 Johnson and Henderson, Costumes and Characters of Western India no. 8-Maratha Women of the Labouring Class, mounted albumen silver print (Catalogue 29).

Fig. 18 Johnson and Henderson, Costumes and Characters of Western India no. 11-Brahmani Ladies, mounted albumen silver print (Catalogue 38). 
Fig. 19 Johnson and Henderson, Costumes and Characters of Western India no. 12-Brahmin Students of English Literature, mounted albumen silver print (Catalogue 15).

Fig. 20 Johnson and Henderson, Costumes and Characters of Western India no. 14-Smarta Brahmans, mounted albumen silver print (Catalogue 46).

Fig. 21 Johnson and Henderson, Costumes and Characters of Western India no. 4-Group of Pinjaras, or Cotton-Carders, mounted albumen silver print (Catalogue 12).

Fig. 22 William Johnson, Costumes and Characters of Western India no. 15-Bengali Hamals, mounted albumen silver print (Catalogue 47).

Fig. 23 Unidentified Photographer, Costumes and Characters of Western India no. 17-The Brahmachari Bawa, Vishnu Bhiku, mounted albumen silver print (Catalogue 52).

Fig. 24 Map of Bombay ca. 1856, indicating the locations of photographs in the IAPA. Illustration by author.

Fig. 25 Dr. G. R. Ballingall, Bombay no. 1-Bird's Eye View of the Church Gate and the Esplanade, from the Bank of Bombay, mounted albumen silver print (Catalogue 53).

Fig. 26 An Amateur, Bombay no. 9-A Wee Bit of the Castle, mounted albumen silver print (Catalogue 30).

Fig. 27 A. Z. (Albert Zorn?), Bombay no. 3-Monument to the Late Marquis of Cornwallis, Governor General of India, mounted albumen silver print (Catalogue 5).

Fig. 28 Johnson and Henderson, Bombay no. 2-Bombay Green from the Town Hall, mounted albumen silver print (Catalogue 4).

Fig. 29 Johnson and Henderson, Bombay no. 6-The Cotton Ground, Colaba, mounted albumen silver print (Catalogue 13).

Fig. 30 Johnson and Henderson, Bombay no. 11-Panoramic View of the Fort from Colaba, mounted albumen silver print (Catalogue 2).

Fig. 31 Johnson and Henderson, Bombay no. 12-Back Bay, from Malabar Hill, mounted albumen silver print (Catalogue 33).

Fig. 32 Johnson and Henderson, Bombay no. 15-Malabar Point, mounted albumen silver print (Catalogue 39).

Fig. 33 Johnson and Henderson, Bombay no. 14-Temples at Walakeshwar, mounted albumen silver print (Catalogue 37).

Fig. 34 William Johnson, Bombay no. 17-The Colaba Memorial Church, mounted albumen silver print (Catalogue 44).

Fig. 35 Henry H. Hinton, St. Mary’s Church, Poona, mounted albumen silver print (Catalogue 54). 74

Fig. 36 Map of Bombay Presidency ca. 1856, indicating locations of photographs published in the 75 IAPA. Illustration by author.

Fig. 37 Archibald Robertson, The Temple of Amarnath, mounted albumen silver print. Newberry Library Collection.

Fig. 38 A. Z. (Albert Zorn?), Ancient Temple at Gokak, mounted albumen silver print (Catalogue 48). 77

Fig. 39 William Johnson, Bassein no. 2-The Church of St. Paul, mounted albumen silver print 78 (Catalogue 60).

Fig. 40 William Johnson, Bassein no. 3-The Main Entrance into the Inner Fort, mounted albumen silver print (Catalogue 62). 
Fig. 41 H. D. Rae, Ahmadabad no. 1-The Masjid of Alimpura, mounted albumen silver print (Catalogue 59).

Fig. 42 H. D. Rae, Ahmadabad no. 2-The Gambaj of Ganj Bakshi, mounted albumen silver print (Catalogue 63).

Fig. 43 J. N. S. (Capt. Allan N. Scott?), Entrance to the Monolithic Temple of Kailas at Elora, mounted albumen silver print (Catalogue 17).

Fig. 44 Capt. Allan N. Scott, Entrance to One of the Smaller Excavations at Elora, mounted albumen silver print (Catalogue 31).

Fig. 45 Unidentified Photographer, Campoolee, mounted albumen silver print (Catalogue 68).

Fig. 46 Henry H. Hinton, Poona no. 2-The Jamsetjee Bund, mounted albumen silver print (Catalogue 56).

Fig. 47 William Johnson, Owdich Brahmins, mounted albumen silver print. Page 171 in William Johnson, The Oriental Races and Tribes, Residents and Visitors of Bombay vol. 1 (W. J. Johnson, Bolton and Barnitt, 1863). University of Rochester.

Fig. 48 William Johnson, Bombay no. 18-Temple of Shiva at Walakeshwar, mounted albumen silver print (Catalogue 14).

Fig. 49 Capt. Allan N. Scott, Very Ancient Jain Temple at Mucktagherry, Near Ellichpoor, mounted albumen silver print. Plate 13 in Capt. Allan N. Scott, Sketches in India: Taken at Hyderabad and Secunderbund, in the Madras Presidency, edited by Charles Richard Weld (London: Lovell Reeve, 1862).

Fig. 50 Unidentified engraver, Brahmin Students. Wood engraving and letterpress. Page 179 in The Illustrated London News (August 21, 1858). University of Toronto.

Fig. 51 Johnson and Henderson, Costumes and Characters of Western India no. 12-Brahmin Students of English Literature, mounted albumen silver print (Catalogue 41).

Fig. 52 Johnson and Henderson, Costumes and Characters of Western India no. 8-Maratha Women of the Labouring Class, mounted albumen silver print (Catalogue 29).

Fig. 53 Unidentified engraver, Femmes du Peuple, after a photograph by Johnson and Henderson. Page 11 in Louis Rousselet, L'Inde des Rajahs: Voyage dans L'Inde Central et dans Les Présidences de Bombay et du Bengal (Paris: Librairie Hachette et Co., 1877). University of Toronto. 



\section{List of Appendices}

Appendix A Catalogue of Photographs in the GEH Album

Appendix B The IAPA by Issue Number

121

Appendix C The IAPA by Series

124 



\section{Introduction}

This thesis is a description and analysis of The Indian Amateur's Photographic Album (IAPA) found in the collection at George Eastman House International Museum of Photography and Film (GEH) in Rochester, New York. Considered to be the earliest photographic publication in India, the IAPA was published monthly from November 1856 to October 1859 under the patronage of the Bombay Photographic Society. ${ }^{1}$ Sold by subscription, each issue contained three unmounted albumen prints and a descriptive letterpress sheet that accompanied the photographs. GEH has the first twenty-four issues of the IAPA (of the thirty-six published), and the photographs and the letterpress have been bound together in a single volume. The IAPA is extremely rare, and although the GEH album does not form a complete set, this collection provides a valuable record of British India at a critical moment in its photographic history.

This study examines both the photographic and printed content of the GEH collection of the IAPA. These two distinct forms of representation work together to produce a vision and impression of India that reflects the British colonialist view in the mid-nineteenth century. The selection of imagery, the depiction of the subjects, and their treatment in the written text contribute to the way India was conceived of and viewed by the West. Although the IAPA has been briefly mentioned in nearly every piece of scholarly writing on nineteenth century photography in India since the 1970s, it is only within the last ten years that it has started to receive significant attention. Partly due to its scarcity, the IAPA has yet to receive an extensive in-depth description and analysis that contextualizes it within the framework of nineteenth century British photography in India.

In India, as in Europe, the 1850s represents a transitional time in the history of photography as a field dominated by a loose assortment of amateurs became increasingly commercialized and professionalized. As an early photographic publication from the first two decades of photography's existence, the IAPA is an important artifact of early photography, and was the first attempt to produce and distribute a photographic

\footnotetext{
${ }^{1}$ Although the organization is officially named the 'Photographic Society of Bombay' and its publication is called the Journal of the Photographic Society of Bombay, within the journal and elsewhere the name appears to be used frequently and interchangeably with the 'Bombay Photographic Society.'
} 
publication in India. British amateurs living in India, mainly clerks and officers working for the British East India Company and associated with the Bombay Photographic Society contributed the photographic and written content of the IAPA. The subject matter is the burgeoning city of Bombay, the temples, ruins, and antiquities of the Bombay Presidency, ${ }^{2}$ and its resident "Costumes and Characters," who appear in a series of genre and group portraits. At the time photographic experimentation served as a form of exploration, and these photographs functioned to shape perceptions and perpetuate cultural stereotypes of an exotic country that formed the centre of Britain's expanding empire.

As local Bombay amateurs practiced the emerging art and science of photography in the 1850s, their choice of subject matter and modes of representation reflected a conscious 'mapping'3 of the unfamiliar terrain and culture within which they found themselves situated. The colonial politics and the imperial economic views of the British residents are inevitably represented in both the choice of subject matter and the manner in which these subjects are depicted and described. These texts now serve as valuable historical documents, revealing early uses of the camera to produce anthropological, topographical, architectural, and archeological photographs. Colonialist photography can be seen as a process of documenting, accumulating, sorting, and mapping exotic sights and locations that resulted in the formation of a visual record representing what has come to be described as the imperial project. As a collection of colonial representations of India created and compiled in the nineteenth century, the IAPA photographs embody aspects of the formation of this visual record, and the analysis of the GEH album provides an opportunity to explore a specific instance of the cultural, political, and economic realities of British involvement in India.

\footnotetext{
${ }^{2}$ The British East India Company administration divided the country up into three 'Presidencies,' Bombay, Madras, and Bengal. The areas defined by these Presidencies changed constantly throughout the eighteenth and nineteenth centuries as the areas under British control expanded, but roughly corresponded to the west, south and northeast, respectively.

${ }^{3}$ By mapping I do not mean to imply a rigorous and systematic attempt at defining a terrain, as in cartography, but rather the placement of landmarks and touchstones with which to familiarize a foreign and unknown place. I will argue that the imaging techniques utilized by the IAPA photographers apply familiar visual conventions consistent with the colonial viewpoint in order to do so.
} 
The IAPA was published in thirty-six installments over three years, and contained 108 photographs. Although the GEH album is incomplete-representing about two-thirds of the entire publication-it embodies the general themes, attitudes, and concerns of the publishers. ${ }^{4}$ By examining the circumstances that led to its creation, and describing and analyzing its contents, this thesis argues that the IAPA can be viewed as part of the colonial visual record.

In order to develop and support this argument the thesis is organized into seven sections. It begins with a literature survey that describes the current state of research on the IAPA, and summarizes the critical writing that has significantly advanced knowledge of the IAPA and that has informed contemporary thinking on nineteenth century British colonialist photography. This is followed by a discussion of the origins of the IAPA, its relation to the Bombay Photographic Society and British amateur photographic organizations, and the connection to a model for the publication and distribution of photographs that was being attempted in Europe. The following section provides a description of the GEH album as a material object, including its content and organization, what is known of its provenance, and notes on the methodology used in the description and analysis of the album. This leads into three sections of analysis, beginning with an introduction explaining the approach. After a brief analysis of a 'typical' issue of the IAPA, the ethnographic portraits and architectural and landscape views are considered separately with a thorough analysis that considers the visual material in relation to the letterpress descriptions. Following a brief section considering the work of IAPA photographers after publication ceased and the use of IAPA photographs in nineteenth century visual culture, a concluding section summarizes the findings and presents suggestions for future research. Finally, the thesis is supported by three appendices that present the material in the IAPA. Appendix $A$ is an illustrated and annotated catalogue of the seventy-two photographs found in the GEH album, Appendix B provides a list of the contents of each issue of the $I A P A$, and Appendix $C$ provides a summary of the various photographic series presented in the IAPA throughout its run.

\footnotetext{
${ }^{4}$ Although the role played by Johnson and Henderson in the production of the IAPA appears to resemble that of editors rather than publishers, they consistently refer to themselves as "the publishers" throughout the text and I have maintained this convention.
} 


\section{Literature Survey}

\section{Introduction}

Recent scholarly writing on the subject of photography in nineteenth century India has consistently included references to The Indian Amateur's Photographic Album. Although its importance in this context is widely acknowledged, the brevity and indirect nature of many of these references suggests that few of the authors have firsthand knowledge of the IAPA, and are basing their information on previous writings about the subject. This survey of literature is a descriptive and roughly chronological discussion of sources relevant to the understanding of the IAPA, colonialism and photography in nineteenth century India, and how each source has advanced our knowledge of these subjects.

\section{The Literature}

Following a long period of silence, academic interest in photography in nineteenth century India was rekindled in the 1970's with the publication of Ray Desmond's pioneering article "Photography in India during the Nineteenth Century," published in the India Office Library and Records Annual Report for the Year 1974. Desmond drew upon the resources at his disposal as Deputy Librarian at the India Office Library and Records to compile the earliest comprehensive overview of photography in nineteenth century British India. In the section entitled "Early Days of Photography" Desmond makes a minor reference to the IAPA as a publication by Messrs. Johnson and Henderson, "commercial photographers in Bombay," but erroneously states that it commenced publication in $1857 . .^{5}$ He acknowledges the uncertainty regarding the publication dates of the IAPA, stating that "it has not been established when this periodical ceased publication but the IOL has 13 issues." ${ }^{\circ}$ Although he mentions The Oriental Races and Tribes, Residents and Visitors of Bombay (2 volumes, 1863 and 1866) in the section "Photographing People," making note of its "not too skillful use of photomontage," it is unclear whether Desmond was aware that the author, William Johnson "of the Bombay Civil Service," was one of the commercial photographers

\footnotetext{
${ }^{5}$ The Indian Amateur's Photographic Album no. 1 was published in November 1856.

${ }^{6}$ Ray Desmond, "Photography in India During the Nineteenth Century," India Office Library and Records, Annual Report for the Year 1974 (London: Her Majesty's Stationary Office, 1976), 9.

7 Desmond, "Photography in India," 12.
} 
responsible for the IAPA. Whether this is an oversight on Desmond's part or simply reflects the state of research at the time is unclear, but by 1976 Clark Worswick makes the connection explicit in an essay included in The Last Empire: Photography in British India, $1855-1911.8$

In 1981, during his tenure as the photographic cataloguer at London's Royal Commonwealth Society (RCS), John Falconer contributed the article "The Photograph Collection of The Royal Commonwealth Society," which makes the connection between the IAPA and another work, Frith Series India vol. I, found in the collection of the RCS. The Frith album, bound by Thacker \& Co. of Bombay, contains 150 albumen prints by Johnson and Henderson consisting of "a series of landscapes and portraits of Indian types, some of which also appear in The Indian Amateur's Photographic Album which ran for twenty-four numbers between December 1856 and October 1858." Although Francis Frith (1822-1898) never traveled to India, the Frith Co. did sell Indian photographs, and Falconer suggests that Frith obtained the negatives from William Johnson in the late 1860s, and notes that several of the prints have "had the backgrounds painted out on the negatives in preparation for [the] montaging process" in Johnson's The Oriental Races and Tribes, Residents and Visitors of Bombay. Although Falconer misstates the initial publication date of the IAPA and the length of its run, his findings expand on Desmond's research, contribute biographical information about Johnson and Henderson, and speculate on the nature of their partnership. Falconer notes that Johnson's firm operated in Bombay from 1852 to around 1864, and Henderson's from 1855 to around 1868, but he postulates that both men sold their interests in the businesses that bore their names and left Bombay before these dates, Henderson around 1858, and Johnson around 1861. Falconer downplays the suggestion that the men were involved in a commercial studio together, citing minimal supporting evidence, and postulates "the partnership of these two photographers was short-lived and

\footnotetext{
${ }^{8}$ Clark Worswick, "Notes on photography in Nineteenth-Century India," in The Last Empire: Photography in British India, 1855-1911, Clark Worswick and Ainslee Embree, ed. (Millerton NY: Aperture, 1976), 4-5. Despite the clarification afforded by Worswick regarding the connection to The Oriental Races and Tribes..., his research is based on Desmond's (as indicated in the acknowledgements to The Last Empire) and contributes little else to our knowledge of the IAPA. He states that the IAPA published "at least thirteen issues," and mis-attributes the photographs to "W. Johnstone" in the captions in the plate section, suggesting that he relied upon Desmond's work without extending it.
} 
confined to their contributions to The Indian Amateurs..." In addition to its contribution of knowledge concerning the IAPA, Falconer's article is also significant for its larger cultural context, by connecting military conquest and colonial settlement with photography. Addressing the connections between colonialism and the photography it produced was to become a growing academic consideration from the 1980s on.

Falconer's serious research into nineteenth century photography in British India continued throughout the 1980s, as he emerged as one of the very few museum curators specializing in Indian photography. His 1984 article "Ethnographical Photography in India 1850-1900"10 contributes to the body of knowledge surrounding the IAPA and expands on the discussion of colonialist photography that began in "The Photographic Collection of the RCS," although it re-states the misinformation regarding the IAPA's publication dates. Falconer discusses the ethnographic work from the IAPA within the framework of the history and development of ethnographic photography in India, and argues that the use of this type of photography by the British Government was intended to maintain order and control by "obtaining a 'moral hold' on the population." ${ }^{11}$

By the 1980s photography from British India was starting to be of interest outside of the academy and the museum, and was attracting the attention of private collectors as well. Howard Ricketts, formerly a partner at Sotheby's, proudly includes the IAPA as part of his collection of early Indian material in a 1982 article describing the first major British

9 John Falconer, "The Photograph Collection of the Royal Commonwealth Society," The Photographic Collector 2, no. 1 (Spring 1981): 36. Falconer's article provides an illustration from the Frith series (Figure 4, pg. 37), which is a solo portrait of the central figure from Costumes and Characters no. 2-A Group of Persians (catalogue 6), dressed in variant costume.

${ }^{10}$ John Falconer, "Ethnographical Photography in India 1850-1900," The Photographic Collector 5 , no. 1 (1984): 16-46. Falconer's article provides several illustrations of Johnson and Henderson's work: the cover image is Costumes and Characters no. 13-Bene-Israel Teachers (catalogue 42), figure 5 is Costumes and Characters no. 16-The Native Knife Grinder and His Assistant (catalogue 55), and figures 6 and 7 are from Frith Series vol. I. Falconer seems to indicate that figure 4 is from the IAPA, but the photograph does not appear in the GEH album. Labeled by Falconer as Mussulman, Bombay, ca. 1856, this photograph is a solo portrait of the prominent Hindu speaker Vishnu Bhiku, who appears in IAPA no. 18 in the photograph Costumes and Characters no. 17The Brahmachari Bawa, Vishnu Bhiku (catalogue 52).

${ }^{11}$ Falconer, "Ethnographical Photography," 34. 
exhibition of Indian photographs, which was based on his holdings. ${ }^{12}$ Ricketts and his wife Jane were amongst the earliest collectors of nineteenth century Indian photographs, and began their collection as early as 1974, although it seems they acquired their set of the IAPA sometime after 1976. ${ }^{13}$ By 1984 the work of Johnson and Henderson had also attracted the attention of historians beyond the realm of specialists in Indian or colonial photography. Helmut Gernsheim included the IAPA in his Incunabula of British Photographic Literature, ${ }^{14}$ and Naomi Rosenblum featured work from the IAPA in the "Documentation: Daily Life and Ethnic Customs" and "Early Social Documentation" sections of her $A$ World History of Photography. ${ }^{15}$

Janet Dewan, an independent photographic historian, wrote a 1992 article, "Delineating Antiquities and Remarkable Tribes: Photography for the Bombay and Madras Governments 1855-70" that addresses the relationship between ethnographic and architectural photography and the British administration in India. This article is primarily concerned with the government-supported documentation of Indian monuments and antiquities, and the systematic collection of ethnographic data. Dewan discusses the contributions of amateur photographers to the field of ethnography and the role they played in the official program of architectural documentation that was underway. She briefly mentions the IAPA and The Oriental Races and Tribes, Residents and Visitors of Bombay as examples of amateur

\footnotetext{
${ }^{12}$ Howard Ricketts, "Early Indian Photographs at the Graves Art Gallery, Sheffield: From the Howard Ricketts Collection," Creative Camera 208 (April 1982): 477. Although Ricketts describes his IAPA collection as "a very rare set," he gives the publication dates as 1856-1858, indicating that he did not have a complete run.

${ }^{13}$ Ricketts, "Early Indian Photographs," 476-477.

${ }^{14}$ Helmut Gernsheim, Incunabula of British Photographic Literature: A Bibliography of British Photographic Literature 1839-75, and British Books Illustrated with Original Photographs (London: Scholar Press, 1984), 24. Gernsheim's information appears to be based on the India Office Library holdings, but he erroneously states that the photographs are salt prints (they are albumen prints), that the IOL has twelve issues (Desmond states that the IOL had thirteen issues in 1975), and that the publication "may have discontinued some time in 1858."

${ }^{15}$ Naomi Rosenblum, A World History of Photography (New York: Abbeville Press, 1984), 172, 344. Rosenblum includes an illustration from the IAPA on page 173, Costumes and Characters no. 4Group of Pinjaras, or Cotton-Carders (catalogue 12), reproduced from the India Office and Records Department. She reproduced the same image in the subsequent editions of her history.
} 
photographers showing an "increased interest in ethnographical photography." 16 The architectural work and publications of IAPA photographers Henry Hinton and Capt. Allan N. Scott are discussed, as well as the ethnographic photography of H.D. Rae, ${ }^{17}$ although Dewan does not mention that they were contributors to the IAPA, and may have been unaware of this at the time of writing. William Johnson's contribution of work to John Wilson's 1861 publication The Caves of Karla Illustrated: In a Series of Photographs, by W. Johnson, F.L.P.S. with Descriptive and Historical Remarks on the Buddhist Excavations of Western India is discussed, although she mentions that there is "no record that Johnson sought government patronage of this work, despite Bombay Castle's long-standing interest in the cave temples of India." 18

In 1997 Dewan contributed the essay "Sun Pictures from the City of Gold: Early Photography in Bombay," to Bombay to Mumbai: Changing Perspectives. ${ }^{19}$ Her discussion of photography in the burgeoning city of Bombay provides what appears to be the first indepth consideration of the IAPA as a whole. Dewan's treatment is thorough, but appears to have received little attention outside of India. Contextualizing the IAPA in terms of the budding commercial photography scene in 1850s Bombay, Dewan addresses the role played by the Bombay Photographic Society in centralizing local photography and the contributions of its members to the IAPA. Using information gleaned from the Bombay Almanac and Directory, she assembles brief biographies for contributors to the IAPA and provides details about their commercial practice. Dewan supplies information about the locations depicted in some of the photographs featured in the IAPA, identifying key landmarks and geographical features. She raises the question of attribution and authorship in the IAPA, and points out several inconsistencies in the way some of the work is

\footnotetext{
${ }^{16}$ Janet Dewan, "Delineating Antiquities and Remarkable Tribes: Photography for the Bombay and Madras Governments 1855-70," History of Photography 16 (1992): 305. Dewan indicates that the IAPA published twenty-four issues between "late 1856 and late 1858," and her references indicate that her information source was Falconer, "The Photograph Collection," and Falconer, "Ethnographical Photography."

${ }^{17}$ Referred to in the text as "Mr. Rae, Assistant Superintendent, Revenue Survey."

${ }^{18}$ Dewan, "Delineating Antiquities," 311.

19 Janet Dewan, "Sun Pictures from the City of Gold: Early Photography in Bombay," in Bombay to Mumbai: Changing Perspectives, ed. Pratapaditya Pal (Mumbai: Marg Publications, 1997), 112-127.
} 
credited. ${ }^{20}$ Her statement that the IAPA "appeared monthly for three years from November 1856 to October $1859 " 21$ seems to be the first time that accurate publication dates were given.

The 1990s yielded increased interest in the relationship between colonialism and photography, and what has come to be known as post-colonialism and the imperial gaze. Although the IAPA is not mentioned specifically, James Ryan's Picturing Empire: Photography and the Visualization of the British Empire ${ }^{22}$ summarizes the approach favored by contemporary scholars, addressing the role that photographic visuality plays in colonialism and empire building, and the corresponding power dynamics they establish. Christopher Pinney's Camera Indica: The Social Life of Indian Photographs, ${ }^{23}$ traces the development of photography in India from its roots as an instrument of measurement and control during British rule to its current use in the post-colonial visual culture that exists there today. Pinney's background in anthropology provides valuable cross-disciplinary insight into the IAPA. Although Camera Indica does not contribute any new historical information about the $I A P A,{ }^{24}$ it is significant because it examines the practice of photography in India from the point of view of both the colonizer and the colonized.

In the 1990s and 2000s a number of exhibitions highlighted nineteenth century photography in India, and large illustrated catalogues with accompanying essays supplemented these exhibitions. These exhibitions and their catalogues both raised interest in Indian photography and reflected contemporary approaches to the scholarship of the

\footnotetext{
${ }^{20}$ Dewan notes that although catalogues 4 and 5 appear to be companion images and provide a panoramic view of Bombay green when viewed together, they are each attributed to separate photographers. She also indicates that a variant of catalogue 15, in which the "Parsee woman" forming the main subject is posed with a different child, was acquired by the India Office at the 1867 Paris Exhibition as part of an acquisition of the work of Hurrichind Chintamon, although catalogue 15 is attributed in the IAPA to Johnson and Henderson. See Dewan, "Sun Pictures," 121-122.

${ }^{21}$ Dewan, "Sun Pictures," 120.

22 James R. Ryan, Picturing Empire: Photography and the Visualization of the British Empire (London: Reaktion Books), 1997.

${ }^{23}$ Christopher Pinney, Camera Indica: The Social Life of Indian Photographs (Chicago: The University of Chicago Press, 1997), 28-29.

${ }^{24}$ Although Pinney appears to have had some access to the IAPA, he lists the publication dates as December 1856-October 1858, following Falconer.
} 
history of British photography in India. ${ }^{25}$ The IAPA is often seen to be an important part of these histories, but it is rarely addressed directly or in depth. The text that accompanies India Though the Lens: Photography 1840-1911, an ambitious 2000-2001 exhibition at Washington DC's Arthur M. Sackler Gallery, contains multiple references to the IAPA but there are inconsistencies in the text. Despite an essay by John Falconer that correctly articulates the origins of the IAPA and indicates the length of its run, ${ }^{26}$ the introductory essay suggests that there were only twenty-four issues, and that the IAPA was published directly by the Bombay Photographic Society, rather than under its patronage. ${ }^{27}$ Although India Through the Lens does not contribute significantly to our understanding of the IAPA, its inconsistencies encapsulate the current state of confusion and uncertainty about the IAPA, particularly regarding the publication dates.

India: Pioneering Photographers 1850-1900, ${ }^{28}$ drawn from the holdings of the British Library and the Howard and Jane Ricketts collection, includes three photographs that

\footnotetext{
${ }^{25}$ One such exhibition, The Raj: India and the British 1600-1947, at the National Portrait Gallery in London in 1990, examines the relationship between imperial politics, visual culture, and the portrayal of India during the period of British control. The accompanying catalogue includes essays by Christopher Pinney and John Falconer. Pinney's contribution addresses the British attempt to construct a colonial sociology of knowledge, while Falconer's essay is a scholarly overview of the history of nineteenth century photography in British India, which greatly expands upon Desmond's earlier work and reflects the current understanding of the subject matter.
}

See Christopher Pinney, "Colonial Anthropology in the 'Laboratory of Mankind," in The Raj: India and the British 1600-1947, ed. C. A. Bayly (London: National Portrait Gallery, 1990), 252-263, and John Falconer, "Photography in Nineteenth-Century India," in The Raj: India and the British 16001947, ed. C. A. Bayly (London: National Portrait Gallery, 1990), 264-277.

Traces of India: Photography, Architecture, and the Politics of Representation, 1850-1900, which accompanied a 2003 exhibition originating at Montreal's Canadian Centre for Architecture (CCA), is a comprehensive work on photography and architecture in nineteenth century India that addresses the British concern with the documentation of empire and the role of photography in constructing memories of past events.

See Maria Antonella Pelezzari, ed., Traces of India: Photography, Architecture, and the Politics of Representation, 1850-1900 (New Haven: Yale University Press, 2003).

${ }^{26}$ John Falconer, "A Passion for Documentation: Architecture and Ethnography," in India Though the Lens: Photography 1840-1911, ed. Vidya Dehejia (Washington DC: Freer Gallery of Art and Arthur M. Sackler Gallery with Mapin, Ahmedabad, 2000), 80.

${ }^{27}$ Vidya Dehejia, "Fixing a Shadow," in India Though the Lens: Photography 1840-1911, ed. Vidya Dehejia (Washington DC: Freer Gallery of Art and Arthur M. Sackler Gallery with Mapin, Ahmedabad, 2000), 15.

28 John Falconer, India: Pioneering Photographers 1850-1900 (London: The British Library), 2001. 
originally appeared in the IAPA. ${ }^{29}$ In the catalogue accompanying the exhibition John Falconer includes an appendix with brief biographies of photographers practicing in India in the nineteenth century, including William Johnson, William Henderson, and Capt. Allan N. Scott. These biographies appear to have been assembled primarily with information drawn from publications such as the Bombay Almanac, and likely reflect Falconer's access to period records at the India Office Library and Records.

Divia Patel, a curator in the Indian and South-East Asian Department of the Victoria and Albert Museum in London contributed a very recent (2008) article "The Formation of an Imperial Vision: The Indian Amateur's Photographic Album," to The Asian Arts Society of Australia Review. ${ }^{30}$ Significant for being the only article to date dedicated to the IAPA exclusively, and based on a complete set in the collection of the Victoria and Albert Museum, Patel considers the IAPA as an antecedent to future uses of photography by the British to systematically order, understand, and control India. Unlike previous discussions of the IAPA, Patel specifically addresses the role the letterpress plays in contributing to the understanding of the work, and recognizes the importance of the photographs of the changing infrastructure of the young city of Bombay, a city far removed from the current metropolis of Mumbai. Patel's treatment is exemplary but very brief, providing summary statements rather than a complete discussion of the IAPA, suggesting that there is a need for a more thorough analysis of the IAPA.

\section{Conclusion}

In the last two decades colonialist photography and photography in British India have received considerable scholarly attention, and many writers have acknowledged the IAPA's role in the history of photography. They have primarily focused on small parts of the publication, often the ethnographic images, and in particular the IAPA's role as an antecedent to the ethnographic photography and visual anthropology that subsequently

\footnotetext{
${ }^{29}$ The exhibition catalogue reproduces Costumes and Characters of Western India no. 9-An Eastern Bishop (catalogue 32), and Weighing Cotton, Bombay (from IAPA no. 26, does not appear in the GEH album), as well as Ghur-Bareee (Householding) Gosaees from The Oriental Races and Tribes, which utilizes part of Costumes and Characters of Western India no. 6-Comfortable Gosavis (catalogue 18).

${ }^{30}$ Divia Patel, "The Formation of an Imperial Vision: The Indian Amateur's Photographic Album," The Asian Arts Society of Australia Review 17, no. 3 (Sept. 2008): 4-6.
} 
developed in the nineteenth century. Although the ethnographic work in the IAPA is important, photographs of people form only a small percentage of the total material included in the IAPA, with the bulk of the content consisting of photographs of the emerging city of Bombay, landscape views, British imperial infrastructure, and photographs of antiquities and temples. The relationship between the work of the IAPA amateurs and architectural photography in India has not been thoroughly explored. To date there has been little attention paid to the letterpress that accompanies the IAPA photographs, although the interaction between image and text is significant and worthy of consideration.

Despite the frequency with which the IAPA has appeared in the literature of the last few decades, the only two articles to address the IAPA in any depth have been Janet Dewan's "Sun Pictures from the City of Gold," and Divia Patel's "The Formation of the Imperial Vision."

The focus of Dewan's article is specifically the emergence of photography in Bombay, and while she addresses the documentation of antiquities in India in her other work, ${ }^{31}$ she does not address this specifically in relation to the IAPA. Although Dewan raises questions concerning the proper attribution of some of the IAPA's photographs, pointing out inconsistencies in the way some of the work is titled and authored, she does not address the significance this may have for attribution in the IAPA overall. If some of the photographs previously attributed to Johnson and Henderson are revealed to be the work of other photographers, then this appears to question the authorship of any photograph attributed to Johnson and Henderson in the IAPA. ${ }^{32}$

Patel's exemplary treatment of the IAPA is significant, as it is the first time in the nearly 35 years that it has been discussed in academic circles where all of its components are addressed in some way. Patel's summary of the IAPA, made possible by her access to a

\footnotetext{
${ }^{31}$ See Janet Dewan, "Captain Biggs and Doctor Pigou: Photographers to the Bombay Government 1855-1858," Photoresearcher 5 (December 1993): 6-13, and Dewan, "Delineating Antiquities," 302317.

${ }^{32}$ The catalogue record for the photograph central to Dewan's argument, a portrait of a Parsi woman and child in the British Library collection, states "this photograph is probably by [William] Johnson, despite the crediting of the image to [Hurrichund] Chintamon."
} 
rare complete set, is thorough but extremely brief. It is similar to the approach taken in this thesis, which provides a much fuller discussion of each component part of the GEH album. 


\section{Setting the Scene: Photography in 1850s Bombay and the Origins of the IAPA}

The Indian Amateur's Photographic Album is the first photographically illustrated publication of its kind in India, and represents a method for the distribution of work by amateurs and members of photographic societies that emulates similar subscription models in Europe. How the IAPA came into existence and how it came to take the form that it did are still not entirely clear, however it can be directly linked to the Bombay Photographic Society, which in turn reflects developments in photographic organizations in Europe. This section considers the formation of the Bombay Photographic Society and its connection with the London Photographic Society and British amateur organizations in general. It then proceeds to a discussion of the methods that amateur societies used to exchange and distribute prints, and how this relates to budding commercial models for the dissemination of photographic work.

\section{British Photographic Societies and Amateur Organizations}

In England, the amateurs of the 1840s had operated alone and had been content to share their results within their social groups, discussing photography with friends and relatives. The formation of The Photographic Society of London in 1853 facilitated communication among photographers through regular society meetings and exhibitions; the publication of a journal enabled members to publicize their findings and to increase awareness of the medium. Small groups of individual members would meet for formal dinners at which they would exchange photographic prints. ${ }^{33}$ Members of the Photographic Society Club (established in 1853) and the Photographic Exchange Club (established in 1855), both offshoots of the Photographic Society, ${ }^{34}$ felt that sharing prints was an effective way to communicate ideas about the medium by allowing participants to "examine at their leisure the work of others, learning from their technical example and their aesthetic judgments." ${ }^{35}$ In these photographic exchange clubs, members submitted a stipulated number of prints

\footnotetext{
${ }^{33}$ Grace Sieberling, Amateur's, Photography, and the Mid-Victorian Imagination (Chicago: University of Chicago Press, 1986), 9.

${ }^{34}$ For a more in depth discussion of this see Roger Taylor, Impressed by Light: British Photography from Paper Negatives, 1849-1860 (New York: The Metropolitan Museum of Art, 2007), 81-85.

35 Taylor, Impressed by Light, 83.
} 
to a secretary, along with a description of the subject and the process utilized. The prints were then exchanged and distributed to the members to be bound into albums. Members of the Photographic Society Club, for example, produced the Photographic Album for the Year 1855 and the Photographic Album for the Year 1857. ${ }^{36}$

Such clubs and exchange societies had a very narrowly defined aesthetic, and there were well-defined guiding principles that determined the choice of subject matter. Primarily focused on pastoral and rural subjects, the Victorian attitude towards the outdoors was shaped by earlier writers, such as the Reverend William Gilpin's concept of the 'picturesque,' a visual approach that prioritized certain motifs in nature and imposed an aesthetic order on its elements. ${ }^{37}$ The Victorian preoccupation with classification and cataloguing combined with Gilpin's aesthetic method resulted in the accumulation of photographs embodying this studied approach to the enjoyment and depiction of nature and scenery. The intellectual demands of photography as a combined scientific and artistic exercise appealed to the classes that could afford the time and money to engage them.

Photographic exchange clubs facilitated two fundamental goals of Victorian thoughtaccumulating collections and trading in specimens. An exchange proposal notice in the Journal of the Photographic Society in April 1853 addresses this connection:

It is evident that Amateurs, who have only a portion of their leisure to devote to photography, must be content with a limited collection of carefully prepared negatives of their own production. But if the large numbers of positives capable of being obtained from these negatives can be exchanged among photographers, the portfolios of Amateurs may be enlarged indefinitely and artists' collections of Photographic studies rendered very complete.

Most valuable results would also be reaped from a system of exchange of positives, by applying the art to Architectural and Archeological subjects; they would derive from it advantages similar to those which naturalists now experience from the interchange from local natural productions, and it is scarcely too much to say, that

\footnotetext{
${ }^{36}$ Sieberling, Amateur's, 10. See also Taylor, Impressed by Light, 83, 86-87.

${ }^{37}$ Taylor, Impressed by Light, 76.
} 
when once adopted exchange photographs will become as indispensible to antiquaries as the exchange of plants is to botanists. ${ }^{38}$

\section{The Bombay Photographic Society}

Bombay in the 1850s was a semi-rural trading centre that had recently built its first railway line and first cotton mill, and was poised to undergo a massive transformation and expansion. As business became more successful the East India Company hired thousands of civil servants and clerks to administer its trade, and housed a large military to protect its interests. Some of these civil servants and army officers spent their spare time practicing the burgeoning field of photography, a "culturally and technologically defined practice that initially carried both artistic pretensions and scientific credentials, but which ultimately, became a means by which people came to know the world and situate themselves in it." ${ }^{39}$ Soon there was sufficient interest to justify an organization to facilitate the exchange of ideas and photographic knowledge.

The Bombay Photographic Society held its first meeting on October 3, 1854 in the Rooms of the Geographical Society, located in the Bombay Town Hall. Established only one year after the formation of The Photographic Society of London ${ }^{40}$ and intended to enable "the advancement and promotion of the Science and Art of Photography, by the formation of a medium for the interchange of the experiences, modes of manipulation with their results, and the ideas of various Photographers," ${ }^{41}$ the Bombay Photographic Society predates similar societies in Calcutta and Madras. The society boasted of over 200 members within the first year, and was quick to publish a journal to communicate their ideas to other society members and to interested parties in India, and in England.

\footnotetext{
38 "Notice to Members: Exchange of Positive Pictures," Journal of the Photographic Society 1 (April 1, 1853): n.p., cited in Sieberling, Amateur's, 10. (Emphasis is in the original.)

39 Joan M. Schwartz, "'Records of Simple Truth and Precision': Photography, Archives, and the Illusion of Control," Archivaria 50: 6.

${ }^{40}$ The first meeting of The Photographic Society was held in January 1853. In 1894 it changed to its current name, The Royal Photographic Society of Great Britain.

${ }^{41}$ Journal of the Photographic Society of Bombay no. 6 (July, 1855): 90.
} 
In his introductory address at the first meeting of the Bombay Photographic Society the newly appointed president Capt. Harry Barr outlined the merits of India to the photographic amateur:

India, I need hardly point out to you, offers a vast field to the Photographer. Its magnificent Scenery - its Temples - Palaces - Shrines - and Ruins, dating back, as many of them do, to the remotest antiquity - the varied costumes, characters, and physiognomies of its millions of inhabitants; its religious and other processions, and all the other endless objects of attraction or of curiosity which present themselves to us - each and all should incite us to the practice of an Art, of which beauty and utility are only surpassed by its truthfulness; and where, I would ask, can that art be more advantageously studied than under the sunny skies of Ind? ${ }^{42}$

Barr's address practically reads like a blueprint for photography in British India and describes an approach that would guide the practice for another half century. Although Barr's address predates the creation of the IAPA by almost two years, it effectively describes the IAPA's content and the approach taken by its contributors.

By the time the first issue of the Journal of the Photographic Society of Bombay was published in early 1855, the society proudly claimed to have "upwards of one hundred members, the greater part of whom are Residents and men of influence." 43 Although the large number of members seems to indicate significant interest in the burgeoning field of photography and suggests that there were many photographic practitioners in Bombay at the time, it should be noted that not all members were actually photographers, and that the membership in the society overlapped significantly with other social clubs. The society's president, Capt. Barr, for example, also participated in several other clubs and societies, either as a member or on the board, including the Agri-Horticultural Society of Western India, The Bombay Yacht club, and the Bombay Education Society. ${ }^{44}$ Due to the social

\footnotetext{
42 "Introductory Address," JPSB no. 1 (January 15, 1855): 2-3.

43 "Introductory Address," JPSB no. 1 (January 15, 1855): ii.

${ }^{44}$ Bombay Calendar and Almanac for 1856. (Bombay: Times' Press, 1856), 362, 415, 427, 433, 436.
} 
nature of such clubs and societies, it was not unusual for members of one club to be active in other elite societies.

The pursuit of photography in the earliest years of its development required an adequate education and sufficient leisure time, which implied a certain social standing, and the purely amateur tradition was strongly connected with the upper classes and with "ideas of the proper way to live." 45 This association of photography and high social standing had existed since the earliest amateur organizations, which consisted of "a mixture of aristocrats and professionals who had the requisite time and money to engage in the new art." ${ }^{46}$ However, the increased popularity of photography was making it accessible to an audience that previously would not have been involved in it. The Photographic Society of London attempted to maintain this connection with the higher classes by drawing a clear distinction between photographers 'in trade' and photographers 'in society,' an expression of class anxiety reflecting the developing popularity of photography across all social strata and the increasing commercialization of the medium. ${ }^{47}$ Although there was definitely a connection between the Bombay Photographic Society and the upper levels of Bombay society overall, it was not confined exclusively to 'gentlemen amateurs,' as evidenced by the inclusion of civil servants, professional military officers, and commercial photographers in its membership.

\section{Journal of the Photographic Society of Bombay}

While the Photographic Society of Bombay was created to facilitate the exchange of ideas and to advance the "art and science of photography," it was generally felt that a medium was needed to disperse these ideas beyond the immediate circle of attendees. The Journal of the Photographic Society of Bombay (JPSB) was created to place a "record in

\footnotetext{
${ }^{45}$ Sieberling, Amateur's, 4.

${ }^{46}$ Elizabeth Anne McCauley, "Evasion in Victorian Landscape Photography: The Amateur Photographic Association Album," Bulletin, University of New Mexico Art Museum 12 (1978-1979): 3.

${ }^{47}$ Geoffrey Batchen, "Latent History," Art in America 96, no. 2 (Fall 2008): 57. In this article, one of Batchen's criticisms of Taylor's Impressed by Light is that Taylor "erases any signs of commerce or labour from the historical record, leaving the impression that the calotype was the preserve of the independently wealthy."
} 
the hands of each Member, and the interested public, of our periodical meetings." ${ }^{48}$ The journal contained the minutes of the preceding gathering, along with articles pertaining to photographic technique, the difficulties in acquiring photographic materials and chemicals in India, and the peculiarities of photography in India's extreme climate. The journal provides a valuable record of the thoughts and motivations of the Photographic Society of Bombay, as well as providing information about its most important members and indicating who attended the meetings. The JPSB mentions the most prominent members of the society by name, and the membership includes Indians as well as Englishmen. Many of these photographers would later have their work featured in the IAPA. The JPSB indicates that leading photographers working in the service of the Government to document antiquities, such as Capt. (later Col.) Thomas Biggs (1822-1905) and Maj. Robert Gill (1804-1879) as well as photographers known for their pioneering efforts in the field, such as Dr. John McCosh (1805-1885), were in regular communication with the society, and displayed work at society meetings.

William Johnson was present from the very first meeting, and served as the society's Joint Secretary from the outset, as well as co-editing its journal. Finding that he had "so many claims upon his leisure that he could not devote the attention and care to the work which a newly formed Society demanded," he retired from the duties of Joint Secretary in February 1855, but continued as Joint Editor of the journal. ${ }^{49}$ William Henderson was also a society member, but does not appear to have been a founding member. He is first mentioned in the JPSB as attending the general meeting on June $13,1855 . .^{50}$

Soon after its formation, the Bombay Photographic Society received recognition and support from the other Presidencies, and from abroad. The JPSB for July 1855 mentions, "we have letters from Officers of both the Bengal and Madras Armies, congratulating the Bombay Presidency in having 'taken the lead in India' with regard to the Photographic Art, 'by the establishment of a well-organized Photographic Society;' and both London and

\footnotetext{
48 JPSB no. 6 (July, 1855): 90.

49 “General Meeting-February 6, 1855," JPSB no. 2 (February 15, 1855): 28.

50 “General Meetiing-June 13, 1855," JPSB no. 6 (July, 1855): 95.
} 
Liverpool join also in very flattering and encouraging encomia." ${ }^{51}$ The next year would see the formation of photographic societies in both Calcutta and Madras.

\section{Photographic Exhibitions}

The Bombay Photographic Society organized early exhibitions of photographs at Bombay, showing work by society members alongside work by English photographers from home such as Roger Fenton. They held their first exhibition of photographs at the Town Hall in January 1855. The exhibition appealed to all strata of Bombay society, not exclusively photographers, and was attended by "the youth, the beauty, and the fashion of Bombay." 52

The American periodical Humphrey's Journal in December 1856 features a review of the exhibition of photographs held at Bombay in February 1856. Humphrey's mentions the work of many members of the Photographic Society of Bombay, and the list of notable and prizewinning photographers reads like a list of future contributors to the IAPA. William Johnson in particular is singled out for his mastery of the collodion process and for his "full plate portraits of groups [which] were full of life and vigor-the positions artistic, the focusing and tone excellent." ${ }^{53}$ The work of William Henderson, Henry Hinton, Dr. G. R. Ballingall and Hurrichind Chintamon also received praise.

\section{The Birth of the IAPA}

At the general meeting of the Photographic Society of Bombay held on Tuesday, April 8th, 1856 a letter is read from Messrs. Merwanjee Bomonjee \& Co., local merchants of photographic material. The letter contained a proposal to publish a photographic album, to be called The Indian Amateur's Photographic Album, and requested permission to be allowed to do so under the patronage of the Society. The request was approved, and as an indication of goodwill a copy of the Album was "subscribed for in the name of the Society," a decision that "met with general approval." Among the members of the Photographic Society of Bombay present at the meeting were William Johnson, William

${ }^{51}$ JPSB no. 6 (July, 1855): 89.

52 “Address," JPSB no. 2 (February 15, 1855): 17.

53 "Exhibition of Photographs at Bombay," Humphrey's Journal of the Daguerreotype and Photographic Arts, and the Sciences Pertaining to Heliography 8 no. 15 (Dec. 1, 1856): 233-235.

54 "General Meeting," JPSB no. 13-18 (February-June, 1856): 25. 
Henderson, Henry Hinton, Dr. G. R. Ballingall, and Archibald Robertson. The first issue of The Indian Amateur's Photographic Album appeared in November of the same year, and these men would come to be the IAPA's major contributors.

The request for patronage by the Bombay Photographic Society may be the only time the IAPA is mentioned in the JPSB, but it is not the first time a project of this nature had been proposed. At an early meeting of the Bombay Photographic Society, member Dr. George Buist proposed a similar concept as a possible fundraising effort for the society.

It would I think greatly tend to promote the Art of Photography and improve the funds of the Society and bring its name before the world, so as to conduce to its prosperity, were we to set about preparing or collecting first rate Photographic Pictures for sale, such as would be deemed desirable in England, and likely to be purchased by persons leaving India for Europe. The most accessible of these would be the Portraits of forest trees such as are to be found in Bombay on the nearest points of Salsette-the banian, peepul, the monkey bread fruit, the various palms and plantain trees, as well as of the numerous costumes to be met with in the Bazar [sic].

A much more important class of subjects is supplied by the numberless ancient buildings around us - the extraordinary leaning Monuments in Surat churchyardthe magnificent temple near Callian - the ruined churches of Bassein and Goa, all within very easy reach of us, and each affording six or eight photographs at least. Fixed sizes and a tariff of prices might be fixed upon, the terms being so liberal as to tempt our best photographers in the field. ${ }^{55}$

Buist's idea of selling society member's work to evoke ideas of India back in England is very similar to the model that eventually became the IAPA. The subject matter he proposed all found its way into various issues of the IAPA: costumes and characters, antiquities and temples, the ruins at Surat and Bassein, even trees. This mirrors earlier sentiments by Capt. Barr in his introductory address, "with the inexhaustible variety of subjects at hand, Caves, Temples, Ruins, Scenery, Costumes, and Characters-an enterprising practitioner might in

55 “General Meeting, Nov. 7, 1854," JPSB no. 1 (January 15, 1855): 10. 
a short time realize a collection of Photographs that would be considered invaluable in England." ${ }^{56}$ Neither Buist nor Barr apparently felt that the city of Bombay was an adequate source of imagery for the English market, although photographs of the British settlements would eventually form the backbone of the IAPA.

\section{Connection to the Amateur's Photographic Album}

The IAPA, much like the exchange clubs in England, was intended to disseminate the work of the society members. Unlike the exchange club albums, which were pure amateur efforts that came out infrequently, the IAPA was a monthly publication sold by subscription, each issue of three photographs costing Rs. 7 1/2 (approx. 15 shillings). Although the IAPA was published under the patronage of the Bombay Photographic Society, it was a for-profit venture by Johnson and Henderson that does not appear to have benefitted the Society financially. The monthly subscription model reflects a more commercially minded venture, one that may have been based on a similar project by Louis-Désiré Blanquart-Evrard (1802-1872) and Thomas Sutton (1819-1875) that was operating in the Channel Islands, between England and France, in 1856.

Blanquart-Evrard is known for contributing significantly to the advancement of albumen printing, which dominated photography from the early 1850s. Interested in "propagat[ing]

photography on paper by an abundant reproduction of prints," ${ }^{57}$ he operated a pioneering printing factory in Lille producing salted paper prints from 1851 to 1855 that he envisaged as "a major instrument for the progress of [the] dissemination of photographs, making possible the publication of photographically illustrated albums, books and magazines." ${ }^{58}$ At Lille Blanquart-Evrard produced numerous albums of photographs, beginning with Album Photographique de l'Artiste et de l'Amateur (The Artist and Amateur's Photographic Album) in July $1851 .{ }^{59}$ Blanquart-Evrard's venture eventually failed, but over the course of five years

\footnotetext{
56 "Introductory Address," JPSB no. 1 (January 15, 1855): iii.

${ }^{57}$ From a letter in La Lumière (September 28, 1851) cited in Isabelle Jammes, Blanquart-Evrard et les Origines de L'édition Photographique Française: Catalogue Raisonné des Albums Photographique Édités 1851-1855 (Genève: Librairie Droz SA, 1981), 41.

58 John Hannavy, ed. Encyclopedia of Nineteenth-Century Photography (New York: Routledge, 2008), 167.

59 Jammes, Blanquart-Evrard, 42.
} 
he published twenty-four compilations of original photographs in addition to printing the work of Maxime Du Camp, Auguste Salzmann and John Beasley Greene. ${ }^{60}$

In 1855 Blanquart-Evrard moved to the Bailiwick of Jersey and opened The Establishment for Permanent Printing in collaboration with Thomas Sutton. This company only lasted about two years, but in that time they published the first issue of The Amateur's Photographic Album, which was published monthly for several years. ${ }^{61}$ Each issue contained three or four photographs and the publishers appealed to "Amateurs and Professional photographers" to contribute content and "to assist in this publication by the loan of their negatives." 22 An editorial in Photographic Notes (which Sutton founded and edited) announcing the publication of The Amateur's Photographic Album offered "either two numbers of the Album, or ten mounted copies of the subject lent"63 in exchange for photographers loaning their negatives to the publication. Subsequent advertisements for The Amateur's Photographic Album published in Photographic Notes continued to appeal for photographers to submit their work for publication while simultaneously announcing the upcoming content. These advertisements promised that "this album is the cheapest photographic work ever yet offered to the public," with monthly parts available for 6 shillings and yearly subscriptions for $£ 3,3 .^{64}$

Although there is no evidence to demonstrate that Johnson and Henderson were consciously replicating Sutton and Blanquart-Evrard's model, the similarities are striking. A notice on each sleeve by the publishers of the IAPA invited submissions "from local and upcountry amateurs, the loan of negatives, whether glass or paper, contributors being entitled

\footnotetext{
${ }^{60}$ For the complete contents of the albums published by Blanquart-Evrard see Jammes, BlanquartEvrard.

${ }^{61}$ Gernsheim, Incunabula, 23.
}

See also Helmut Gernsheim, "Cuthbert Bede (The Rev. Edward Bradley, 1827-1889), Robert Hunter F.R.S. (1807-1887), and Thomas Sutton (1819-1875)," in One Hundred Years of Photographic History: Essays in Honor of Beaumont Newhall, ed. Van Deren Coke (Albuquerque: University of New Mexico Press, 1975), 65.

62 Photographic Notes 1, no. 4 (March 25, 1856): 26.

63 Thomas Sutton, "The Amateur's Photographic Album," Photographic Notes 1, no. 1 (January 1, 1856): 12.

${ }^{64}$ Advertisement in Photographic Notes 1, no. 4 (March 25, 1856): 26. 
to a copy of the album gratis for each negative acquired for publication." Bombay Photographic Society courted the attention of the European photographic societies and avidly consumed their journals, occasionally reading from them at society meetings. ${ }^{66}$ The Amateur's Photographic Album was advertised widely in Photographic Notes, which acted as the journal of the Photographic Society of Scotland and The Manchester Photographic Society. A letter published in the JPSB (edited by William Johnson) dated December 24, 1855 enthusiastically announces "the first Number of Photographic Notes edited by Thomas Sutton... also the first Number of the 'Amateur's Photographic Album,' conducted by the same gentleman."67

\footnotetext{
${ }^{65}$ The GEH album does not contain any examples of the original wrappers from the IAPA, but several are bound up into the back of the British Library's Photo 140: Views in Western India Album, described in Christopher Pinney, The Coming of Photography to India (London: The British Library, 2008), 14.

${ }^{66}$ See for example "General Meeting, June 13, 1855," JPSB no. 6 (July, 1855): 98.

67 "Letters," JPSB no. 13-18 (February-June, 1856): 35.
} 


\section{Description of the IAPA \\ The GEH Album as a Physical Object}

Subscribers to the IAPA received a paper sleeve containing the printed letterpress along with the three unmounted albumen photographs featured for the month (figure 1). The letterpress sheet for each issue is dated, identifies the issue by number, and provides the title and photographer for each of the three prints. In most cases there is a description of the image, although these descriptions vary considerably. Some descriptions only mention the title of the photograph; many provide brief single sentence explanations, while others are lengthy and extensive (figure 2). Of the three photographs included in each issue, generally there was a large portrait from a regular feature called Costumes and Characters of Western India, and two smaller architectural, urban, or landscape views. Appendix B provides a list of which photographs were included in each issue of the IAPA.

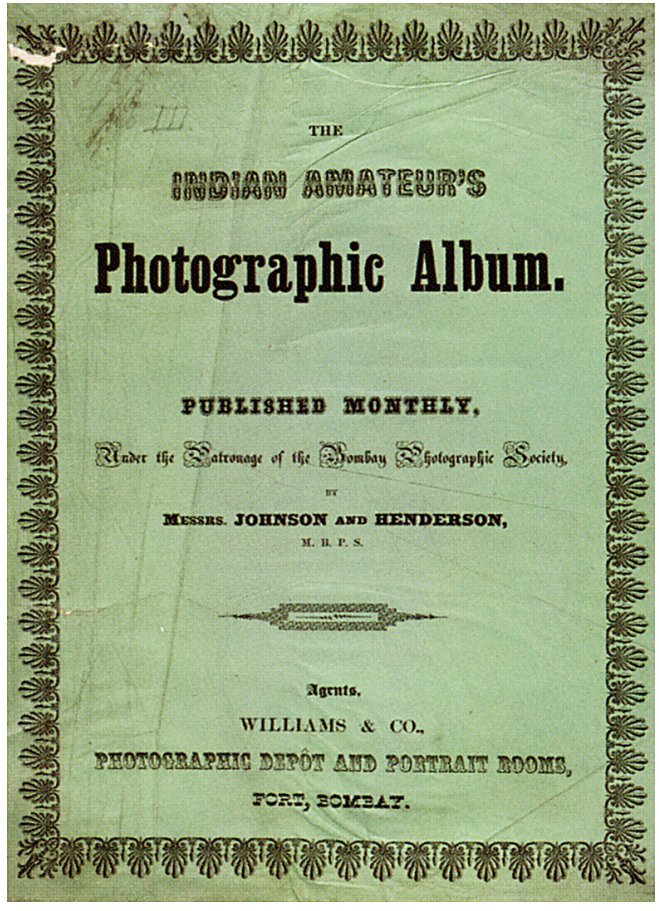

Fig. 1| An example of the paper sleeve used to contain the IAPA, from the British Library collection. Page 15 in Christopher Pinney, The Coming of Photography in India (London: The British Library, 2008).

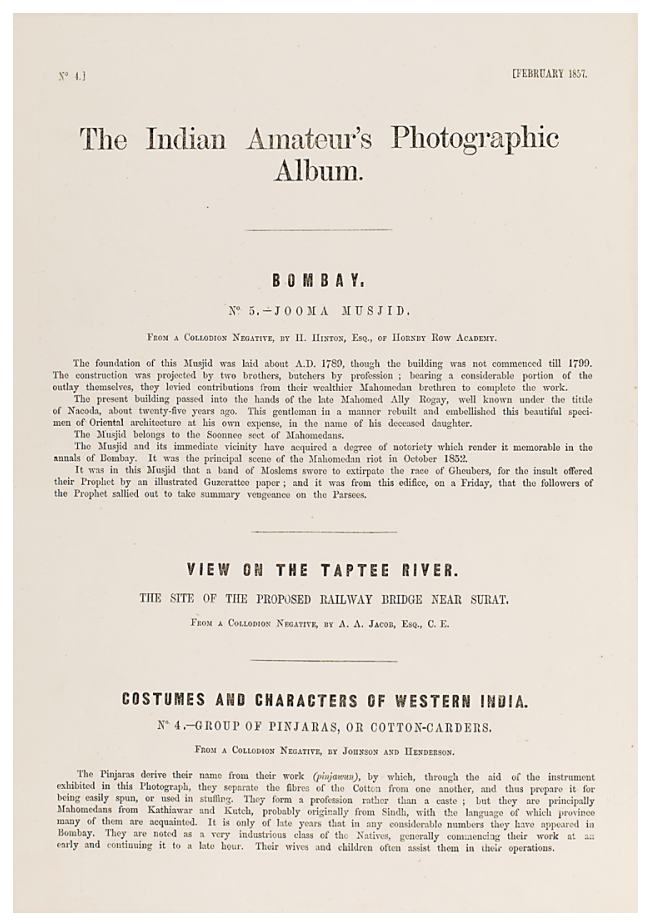

Fig. 2| The descriptive letterpress sheet for The Indian Amateur's Photographic Album no. 4 (February 1857). 
The GEH album, containing the first twenty-four issues of the IAPA, is a large (54 x $38 \mathrm{X}$ $7 \mathrm{~cm}$ approximately) green leather volume that appears to have been created specifically to house the IAPA compilation. The pages are of thick stock and have gilt edges, and the heavy board pages are hinged into the binding. The end papers of the album are decoratively marbled. The spine bears a gilded blind stamp with the words "THE INDIAN / AMATEUR'S / PHOTOGRAPHIC / ALBUM." The seventy-two albumen silver photographs and twenty-four letterpress sheets it contains are pasted directly onto the album pages. The small photographs are arranged two to a sheet, one above the other, facing the letterpress descriptions, and the large ones are mounted separately on the following page (figure 3). Other than the letterpress, there are no annotations or inscriptions in the album, and there are no printer's marks or any indication as to where or when it was bound.

This album once belonged to the prominent photographic collector Albert E. Marshall from Rhode Island. It is not known where Marshall acquired this album, but he purchased the majority of his collection from book dealers in Britain and America, with British dealers providing him with more than three-quarters of his material. ${ }^{68}$ Following Marshall's death in 1951 his extensive collection of photographically illustrated books and albums was sold by Swann Galleries in New York in 1952, a sale generally regarded to be the first auction ever devoted exclusively to photographic literature. ${ }^{69}$ Beaumont Newhall acquired the album for GEH at the Swann auction for $\$ 32.50$.

\footnotetext{
${ }^{68}$ Denise Bethel, "At Auction and in the Book Trade: Sources for the Photography Historian," History of Photography 21, no. 2 (Summer 1997): 121.

${ }^{69}$ Swann Auction Galleries, Photography: A Panoramic history of the Art of Photography as Applied to Book Illustration, from its Inception to Date; The Important Collection of the Late Albert E. Marshall of Providence, R. I. Sold by the Executors, the Estate of Albert E. Marshall (New York: Swann Auction Galleries, 1952), 19.
}

The following is the complete auction record for the item:

[Lot] 193 The Indian Amateur's Photographic Album. Parts 1-25, complete. Each part comprises three photographs (two large and one small), with sheet of printed text; all mounted on heavy boards, hinged into binding. Tall folio, full green morocco handsomely gilt; all edges gilt.

Np. November 1856 to November 1858

Considered the first book with photographs to be published in India-rare. One print is lacking - the first print of the $25^{\text {th }}$ number. 


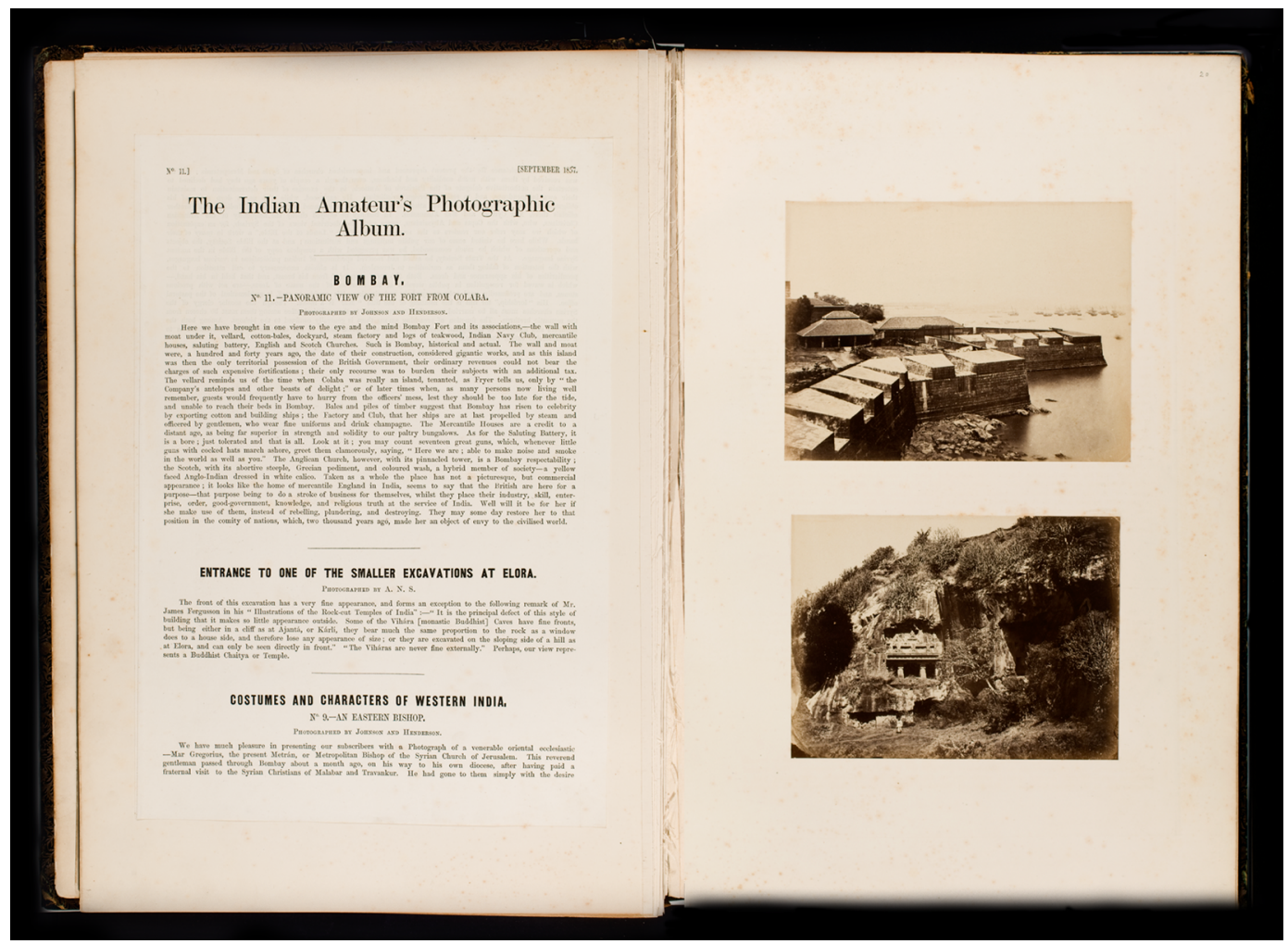

Fig. 3| Page spread for IAPA no. 11, indicating the placement of the photographs and letterpress sheet on the pages in the GEH album. The two smaller photographs are pasted in one above the other on the page facing the letterpress. Turning the page would reveal the third photograph on the right hand page, facing a blank page.

Compiling the first twenty-four issues of the IAPA into one volume, this album represents a very rare collection. Although loose prints appear at auction occasionally, compiled sets are scarce. The Victoria and Albert Museum in London has all thirty-six issues, representing one of the only known complete sets. A nearly complete set, containing 92 prints in three volumes from the first thirty-one issues, was offered for sale by a private collector at Bonhams auction house in 2006, but did not sell. ${ }^{70}$ The India Office and Records at the British Library has several issues included in various personal albums of Indian photographs and memorabilia, but they do not form a complete set. In the United States, the Newberry Library in Chicago has the first twenty-four issues compiled into two volumes.

The small photographs are arranged two to a sheet, the large ones are mounted separately. Mainly views of India, though a number of the large photographs show natives in costume.

${ }^{70}$ Bonhams, India in Books, Photographs, Maps and Manuscripts (London: Bonhams, 2006), Lot 336. 


\section{Identification of the Photographs}

The GEH album was compiled and bound at some indeterminable date after publication to form a single volume. After careful inspection of the album it became clear that many of the photographs were misidentified and the corresponding titles in the GEH database were not accurate. When the photographs were bound into the album many of them were mixed up, either by the collector or by the bookbinder, and the photographs were placed opposite the incorrect letterpress. Some of the incorrectly identified photographs depict prominent and well-known Bombay landmarks, and the misidentification of these images suggests that the album belonged to someone who was not familiar with the city. Before the photographs could be properly described and analyzed, they had to be properly identified.

The iconography in some of the photographs is clearly identifiable, and was used to determine the correct subject and hence the proper titles. In addition, a number of the photographs have been reproduced in various later books on Bombay, and this was used as a basis for their identification. ${ }^{71}$ In order to properly identify the remaining photographs, the GEH album was compared with the IAPA collection at the Newberry Library in Chicago, which also contains the first twenty-four issues. Appendix A contains an annotated catalogue of every photograph appearing in the GEH album in the order that they appear, and lists the correct title and date of publication for each photograph.

The Newberry set of the IAPA is bound as two volumes, each $41 \times 33 \times 5 \mathrm{~cm}$ volume containing twelve issues. Unlike the GEH album, which is oversized and has the letterpress sheets pasted to the album boards, the Newberry album has the letterpress sheets hinged directly into the binding. The photographs are larger than those in the GEH album, and appear to be made from copy negatives. ${ }^{72}$ The covers of the two volumes are decoratively marbled, and the spines of each volume are marked with gilded blind stamps bearing the name "INDIAN / AMATEUR'S / PHOTOGRAPHIC / ALBUM." Although of a different format

\footnotetext{
${ }^{71}$ Bombay to Mumbai: Changing Perspectives, edited by Pratapaditya Pal, was particularly helpful. In addition to containing Janet Dewan's article "Sun Pictures in the City of Gold," which provides a history of early photography in Bombay, the book utilizes photographs from the IAPA throughout the book to illustrate the geography of the city as it appeared in the $1850 \mathrm{~s}$.

${ }^{72}$ These copy negatives would have been produced by re-photographing the original prints using glass plates of a size larger than the originals.
} 
from the GEH album, the Newberry album also reflects the care taken by its owner to protect and care for the photographs.

The comparison of the GEH album with the Newberry Library album was helpful in identifying a number of the photographs, but presented a few surprises as well. The two compilations, although they both contain the first twenty-four issues of the IAPA, are not identical. There are similar inconsistencies between both albums. A description for the photograph A Scene on the Bombay and Baroda Line of Railway appears in the letterpress for IAPA no. 8 in both albums, but the actual photograph does not appear.

The photograph that I have identified as The Tomb of Mubarak Sayyid, near Mahmudabad (catalogue 49) [figures 4 and 5] appears in both the GEH album and the Newberry set, but there is no descriptive letterpress for this image in either album, and it is unclear which issue, if any, it was associated with. The fact that the GEH and Newberry Library compilations of the IAPA contain similar discrepancies may reflect problems in the production and distribution of the work at the time of publication. Discrepancies between the GEH and Newberry albums are noted in Appendix B.

Another anomaly is The Temple of Amarnath by Archibald Robertson (Catalogue 43). The descriptive letterpress for this image in IAPA no. 15 states "we present our subscribers with two photographs of the Temple of Amarnath," but both the GEH and the Newberry

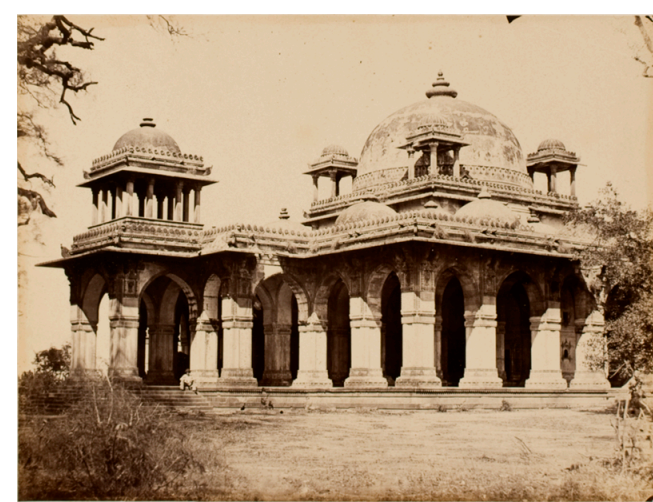

Fig. 4| Unidentified Photographer, Tomb of Mubarak Sayyid, near Mahmudabad (catalogue 49).

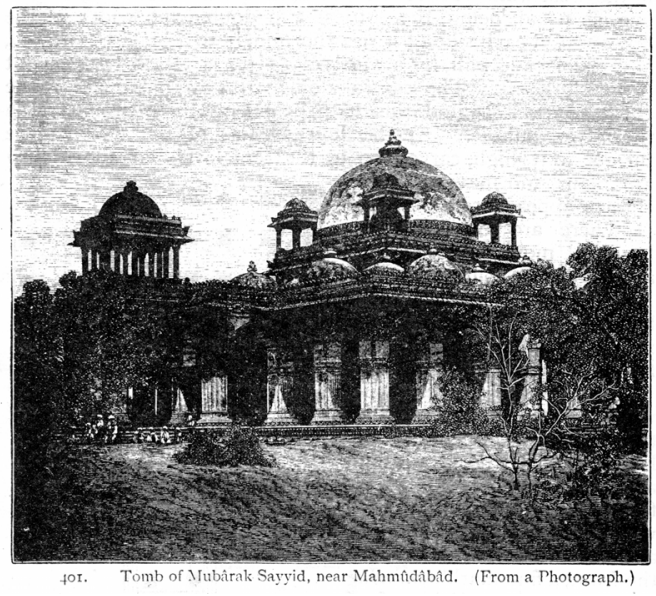

Fig. 5| Unknown engraver. Tomb of Mubarak Sayyid, near Mahmudabad (From a Photograph). Page 244 in James Fergusson, History of Indian and Eastern Architecture 2ed. (London: John Murray, 1910). University of Toronto. 
albums contain only a single print. Interestingly, the photographs are not the same. Although nearly identical, they are variant compositions. The differences in the framing of the temple itself varies only slightly, but the Newberry copy has several human figures posed in front of the temple for staffage, while the GEH copy is devoid of people. It seems possible that each subscriber received only one of the promised two photographs. The letterpress describing the Temple of Amarnath in the Newberry album contains annotations in ink that seem to indicate that the owner only received a single print.

In addition to the twenty-four complete issues of the IAPA, the GEH album contains two photographs (catalogues 71 and 72) that are bound up separately as loose prints, and do not appear to be part of any of the twenty-four issues. Both of these photographs have a letterpress description, which is pasted onto the same page as the print, but does not have any identifying information to suggest what issue they were published in. Unlike the rest of the letterpress in the IAPA, which describes three photographs on a single sheet, these letterpress sheets only identify the single photographs. Both photographs also appear in the Newberry albums. Catalogue 71 appears in the Newberry album near the photographs from IAPA no. 15, but lacks any descriptive information. Due to its placement, it seems plausible that catalogue 71 may have been offered as a substitute for the missing photograph from IAPA no. 15 mentioned previously.

The letterpress sheet for IAPA no. 6 differs between the GEH and Newberry albums. The GEH album's letterpress for IAPA no. 6 describes the photographs Falls of Mutlagherry, Near Ellichpoor (catalogue 16), Costumes and Characters of Western India no. 6-Comfortable Gosavis (catalogue 18), and Ruins in the Citadel of Bijapur (this photograph does not appear in either the GEH or the Newberry collection). In the Newberry album's letterpress for IAPA no. 6 the description for The Banyan Tree (catalogue 72) replaces the description for Ruins in the Citadel of Bijapur. Once again, due to its placement, it seems plausible that catalogue 72 was offered as a substitute for a photograph missing from IAPA no. 6.

\section{A Note on The Photographs}

The seventy-two photographs in the GEH album are of two basic types: studio and environmental portraits of an ethnographic nature, and architectural and landscape views taken in the city and throughout the Presidency of Bombay. The smaller component, 
consisting of twenty portraits, form the series Costumes and Characters of Western India. The remaining fifty-two photographs are landscape and architectural views. Although the name The Indian Amateur's Photographic Album implies photography from across the subcontinent, the majority of the architectural photographs and views are from the city of Bombay or its immediate vicinity, and although some are depictions of places far from the city, all of the locations, with one exception, are within the Bombay Presidency. ${ }^{73}$ Intended to be a vehicle for the dissemination of the work of Bombay Photographic Society associates, the photographs featured in the IAPA actually represent work by only a handful of these members, with Johnson and Henderson providing the bulk of the material.

The landscape views and architectural photographs are mostly divided into several discrete series, based on the locations depicted. These series are: Bombay, Surat, Ellichpoor, Elephanta, Elora, Poona, Bassein, Tanna, and Ahmadabad. Generally each photograph in a series is numbered, and most of the series contain the work of a single photographer. Appendix C lists the contents of each series. These series run sequentially through several issues, and in general no issue of the IAPA contains two photographs from a single series.

\section{A Note on the Letterpress}

The letterpress descriptions appear to have been written by the contributing photographers - they are not written in a single coherent voice, and range in length: some provide the title only, while others are lengthy and descriptive. In the first few issues of the IAPA the letterpress is very minimal, and often consists of only the title or a brief, twosentence description of the subject. In later issues the publishers appear to have taken an increased interest in the text and the descriptions often become longer and more detailed. In some cases the authors of the letterpress have elected to include extensive quotations from Orientalist and antiquarian scholarly works of the period to accompany the photograph. $^{74}$

\footnotetext{
${ }^{73}$ The exception is Acbar's Tomb (catalogue 1), which is in Agra.

${ }^{74}$ The lectures and writings of Scottish missionary and Orientalist scholar Rev. John Wilson (18041875) are referred to repeatedly throughout the IAPA; Wilson was a contributor to William Johnson's The Oriental Races and Tribes, Residents and Visitors to Bombay, and Wilson and Johnson collaborated on Wilson's The Caves of Karla Illustrated: In a Series of Photographs. For his
} 
The descriptive letterpress that accompanied each issue of the IAPA enables a way of reading the photographs that goes beyond what would have been provided by the image alone. At the time the IAPA was published, these texts would have served as descriptions, rather than interpretations of the culture its authors were exploring. As an additional form of representation, the letterpress now allows us to transcend the surface of the image and expand the realm of photographic interpretation. Whether utilized as a purely descriptive device or as a means of creative self-expression on the part of the author, the letterpress texts reflect British colonial sensibilities, and when considered collectively, function as important historical and cultural documents. In the following analysis sections the role of the letterpress as a form of representation will be considered more completely, using specific examples drawn from the text.

photographs of architecture in Gujarat (catalogues 59, 63, 66, and 69), H. D. Rae relies heavily on Henry George Briggs, The Cities of Gujarashtra: Their Topography and History Illustrated in the Journal of a Recent Tour (Bombay: Times Press, 1849), and Philip Anderson, The English in Western India: Being the Early History of the Factory at Surat, of Bombay, and the Subordinate Factories in the Western Coast, from the Earliest Period until the Commencement of the Eighteenth Century (Bombay: Smith, Taylor, and Co., 1854). 


\section{Analysis I: Introduction \\ The IAPA as a Record of the Colonial Experience}

Any number of reasons could bring an Englishman to India in the 1800s: the thirst for adventure, the desire to acquire a fortune, the need to escape from a chequered past at home, or the desire for career advancement through the military or civil service. Whether by choice or by necessity, the photographers whose work is featured in the IAPA found themselves in a country that was foreign to them. The colonial viewpoint is determined by the attempt to make sense of an unfamiliar land and culture while simultaneously maintaining the cultural and moral certainties of home. New arrivals from England would have their own preconceptions about their adopted homeland, continually informed by "a diet of broadly disseminated ethnographic and anthropological portraits, geographical theories, and biological and psychological profiles." ${ }^{" 75}$

The photographs produced by the members of the Photographic Society of Bombay and reproduced in the IAPA inevitably reflect the politics and economic views of what is now understood as the imperial project, a modern term used to refer to the activities of European colonialism and imperial expansion. As historian Mia Carter argues, "the complexities of colonialism are numerous, and the voices, discourses, and debates...cannot be reduced to a single perspective or simple linear narrative. It might be most useful to understand the history... as a series of continental shifts that took place over an extended period of time in which Western peoples attempted to negotiate or balance the mythical and genuine values of the Enlightenment (knowledge, discovery, science, rationalism) with the gross and often brutal realities of commercial competition and material desire."76

The colonial point of view is reflected in both the choice of subject matter and the manner in which these subjects are depicted and described. Using representational conventions that would have been familiar to them from both the existing visual culture of

\footnotetext{
${ }^{75}$ Mia Carter, "Volume Introduction: From the Company to the Canal," in Archives of Empire Volume 1: From the East India Company to the Suez Canal, ed. Mia Carter and Barbara Harlow (Durham NC: Duke University Press, 2003), 4.

${ }^{76}$ Mia Carter, "Volume Introduction," in Archives of Empire, ed. Carter and Harlow, 7.
} 
the East India Company and the emerging conventions of the amateur photographic societies, these photographers created photographs that were simultaneously of India and about the British experience there.

The creation of a British idea of India through the various forms of photographic and written representation in the IAPA can be considered within the parameters of what Christopher Pinney has described as the "colonial schemata," an attempt to "position people and objects deep within chronotopic certainties as they sought stable identities in places from which they could not escape." ${ }^{77}$ The small number of photographs included in the IAPA can be considered part of the larger accumulation of images that contributed to the representation of India in the nineteenth century. By creating photographs of the people they encountered and the physical world around them, the IAPA photographers were engaging in the creation of a colonial visual record through photographic mapping, collection, and accumulation.

This is not to suggest that the amateur photographers in Bombay were systematically defining and organizing their environment through their work, but they were creating touchstones of familiarity through the identification and placement of landmarks and cultural stereotypes. The use of recognizable visual conventions consistent with the colonial point of view made this possible. Although at the time Victorian photography utilized the medium as a means of experimentation and exploration, the resulting photographs appear to us as valuable documents resulting from the cultural process of sorting and mapping exotic people, sights, and locations. As a collection of colonial representations of India created and compiled in 1850s Bombay, the IAPA photographs participated in the formation of this visual record.

The photographs in the GEH album are described and analyzed in two separate sections, one for each of the two main types of subject matter. In considering both the ethnographic portraits and the architectural views, the letterpress is discussed as an

\footnotetext{
${ }^{77}$ Christopher Pinney, "Notes from the Surface of the Image: Photography, Postcolonialism, and Vernacular Momentum," in Photography's Other Histories, ed. Christopher Pinney and Nicholas Peterson (Durham NC: Duke University Press, 2003), 203.
} 
additional form of representation that can at times inform and alter interpretations of the photographs, but is also integral to the 'reading process.'

\section{Analysis of a 'Typical' Issue of the IAPA}

Considering the twenty-four issues of the IAPA as a single and complete entity is convenient for the purposes of analysis, and this approach is made possible by the publication of several discrete yet overlapping series that contain recurring themes and motifs. This approach will be used in the following two sections to describe and analyze the content of the IAPA as a whole, but before doing this, it is essential to consider how the publication was produced and received, as a series of discrete groups of three photographs.

The various monthly installments almost always consist of a portrait and two views, but the relationships between the three photographs that appear together are not always apparent. It seems possible that there is not always a clear rationale on the part of the publishers to group specific images together, and the choice of sequencing may simply reflect the material that was available to them that month. However, examining a typical issue as it would have been received by the subscriber provides a useful way to understand the IAPA as a part of the British visual record and experience of India, and to understand how it is inseparable from the colonial mode of thinking that resulted in the widespread accumulation of photographic documents.

A typical issue would generally contain an installment from the Costumes and Characters of Western India series. The two remaining photographs might illustrate some aspect of the urban topography of Bombay, a photograph of a temple or antiquity from somewhere in the Bombay Presidency, and/or a photograph documenting the expanding British infrastructure.

The Indian Amateur's Photographic Album no. 4 (February 1857) contains the photographs Bombay no. 5-Jooma Musjid by Henry H. Hinton (catalogue 10) [figure 6], View on the Taptee River, The Site of the Proposed Railway Bridge Near Surat by A. A. Jacob (catalogue 11) [figure 7], and Costumes and Characters of Western India no. 4Group of Pinjaras, or Cotton-Carders by Johnson and Henderson (catalogue 12) [figure 21, page 55]. 


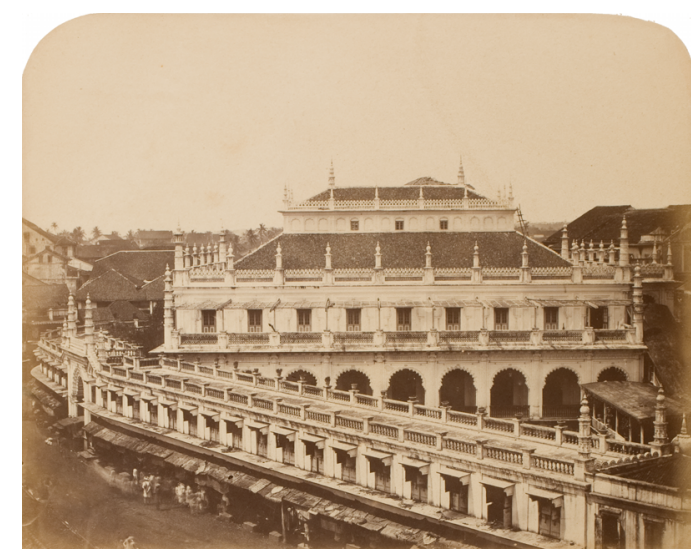

Fig. 6| Henry H. Hinton, Bombay no. 5-Jooma Musjid (Catalogue 10).

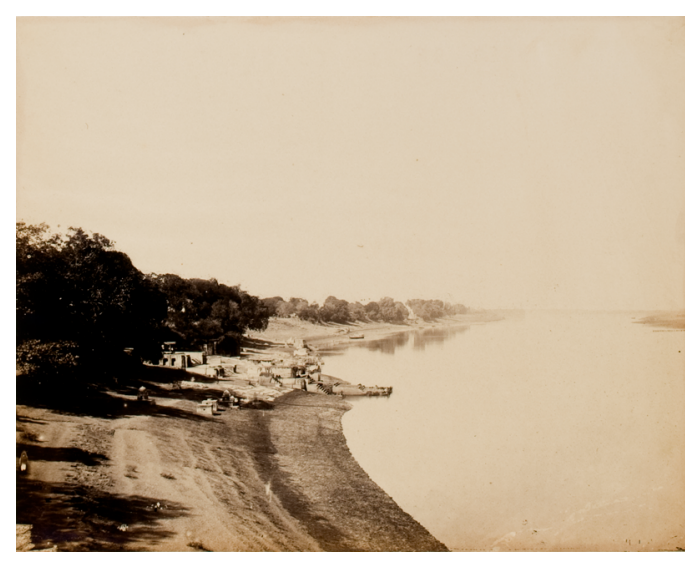

Fig. 7| Arthur A. Jacob, View on the Taptee River, The Site of the Proposed Railway Bridge Near Surat (Catalogue 11).

The portrait (catalogue 12) presents four men posing in a plain studio with the tools of their trade, which they used to separate cotton fibres in preparation for spinning. In keeping with the general style of the IAPA, these men are not named, and are meant to be representative 'types' of their occupation. The author points out that these men "form a profession rather than a caste," and that such tradesmen are generally "Mahomedians from Kathiawar and Kutch, probably originally from Sind."78

The urban view documenting the mosque (catalogue 10) is typical of the views of Bombay depicting Indian architecture in the city, which are entirely devoted to religious buildings. The accompanying letterpress provides a brief history of the structure, described as a "beautiful specimen of Oriental architecture." ${ }^{39}$ Unlike the majority of architectural photographs of Indian buildings in the IAPA there is some inclusion of real-life activity, in this case the busy market stalls that line the mosque's walls, visible at the bottom edge of the photograph. This seems peripheral, however, as the subject of the photograph is clearly the building itself.

Jacob's photograph (catalogue 11) lacks any description beyond the title of the photograph. As a representative of the small but important group of IAPA photographs

\footnotetext{
${ }^{78}$ IAPA no.4 (February 1857): n.p.

${ }^{79}$ IAPA no.4 (February 1857): n.p.
} 
documenting the expansion of colonial infrastructure into the Indian countryside, this photograph of the future site of a railway bridge is emblematic of British imperial ambitions.

Taken collectively, the three photographs of IAPA no. 4 are indicative of the British colonial attitudes that permeate the publication. The portraiture documents local people performing manual work in the commercial cotton trade, and the subjects are reduced to the status of occupational 'types.' One of the landscape views documents the growing British Empire in the form of the site of a future railway line, a contemporary project and source of pride to the English residents of India, encapsulating a spirit of progress. The architectural view of a religious building however presents the local culture as belonging to the past, worthy of appreciation and study perhaps, but belonging to a previous era. These are common themes in the photographs of the IAPA, and the threads of commercial and imperial ambition run through the entire body of work. 


\section{Analysis II: Ethnographic Portraiture Introduction}

Of the seventy-two photographs in the GEH album, twenty are ethnographic portraits from a series entitled Costumes and Characters of Western India. Published serially from the very first issue of the IAPA and included in nearly every issue thereafter, this series depicts the non-European people of Bombay. (For a complete listing of the series contents, refer to Appendix C.) Emphasizing the various castes, occupations, and races likely to be encountered by Europeans, the series highlights outward appearances and manners of dress. A significant feature of this series is the consistency of its authorship: twelve of the photographs are credited to the publishers Johnson and Henderson, and five are credited to William Johnson alone. Although three photographs are not attributed, they bear the hallmarks of the distinctive style of portraiture seen in the rest of the series and it seems likely that they are also the work of either Johnson and Henderson or Johnson alone. As a coherent and unified body of work, Costumes and Characters of Western India displays a distinctive and consistent visual style. Demonstrating a sophisticated mastery of the wet-collodion portrait, these photographs are elegant examples of colonial genre photography and indicate an early application of the ethnographic and cultural 'type. ${ }^{80}$

The series includes photographs of various castes and occupations, as well as holy men, visiting dignitaries, and prominent local religious figures. As an ethnographic text, defined by Mary Louise Pratt in a 1991 article as one in which "European metropolitan subjects represent to themselves their others (usually their conquered others)," Costumes and Characters of Western India presents a series of portraits embodying Victorian cultural stereotypes. Similar to countless other photographs from the nineteenth century depicting local 'types' and 'native life,' the photographs reveal as much about the photographer's British colonial values as they do about the subjects. The text and descriptions that accompany the photographs imply an assumed racial

\footnotetext{
${ }^{80}$ Although the term 'type' when applied to photography can often refer to racial type specifically, I am using the word more loosely, to include the generic representation of a social class, caste, or profession.

${ }^{81}$ Mary Louise Pratt, "Arts of the Contact Zone," Profession 91 (1991): 35.
} 
and cultural superiority, and reveal that the photographers view their subjects as objects of fascination to be studied, examined, and classified.

Representing numerous races, ethnicities, castes, tribes, and trades from across India and beyond its borders, the people of Bombay presented an overwhelming array of difference to the English. Photography provided a convenient means for them to sort through the unfamiliar appearances, religions, and styles of dress, and to capture this diversity by producing portraits that simplified the complexities of otherness and presented individuals as representative of a group. Christopher Pinney likens this process of European sorting to "a kaleidoscope which eventually dissolved into meaningful order...in which the initial bewilderment created by the variety of social groups in India gave way to a reassuring certainty that they were all identifiably distinct elements which could be arranged legibly and clearly in the 'living museum of mankind.'”82

Johnson's and Henderson's technical skills and knowledge of the conventions of portrait making enabled them to present the various groups they encountered to a Western audience using pre-existing and familiar visual tropes and conventions. The multitude of classes, races, castes, and professions in Costumes and Characters of Western India are depicted photographically as individuals, but are often reduced to the status of objects through the use of generic titling and the descriptions in the accompanying letterpress in the IAPA.

\section{Pre-existing Visual Conventions}

The illustrated depiction of urban life by British artists predates photography and was not unique to India. C. A. Bayly argues that the British used photography to create images of a familiar nature, as a means to map and order India "for political and financial purposes, but also to organize their own experiences in the categories of

${ }^{82}$ Christopher Pinney, "Colonial Anthropology in the 'Laboratory of Mankind,'” in C. A. Bayly, The Raj: India and the British, 1600-1947 (London: National Portrait Gallery Publications, 1990), 253. 
genre painting which were now common in Britain." 83 Books such as Picturesque Representations of the Dress and Manners of the English ${ }^{84}$ and Costumes of the Lower Orders of London ${ }^{85}$ contained hand-coloured engravings of various professions and 'types' drawn from all classes, accompanied by explanatory letterpress, and were gaining in popularity with British audiences.

Within India the use of photography to represent various 'types' emerged from an established tradition of genre paintings that fed the expanding interest in Indian

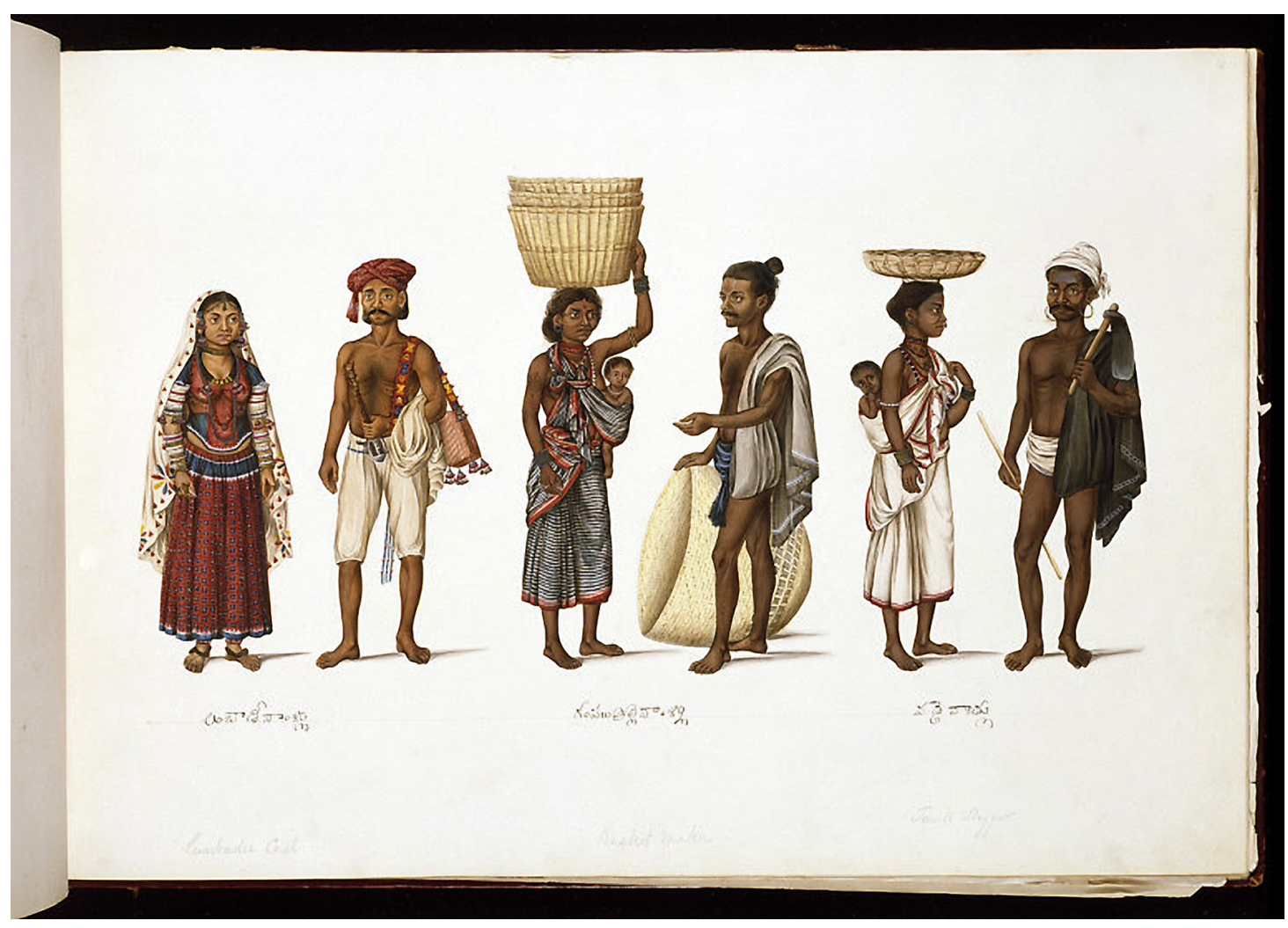

Fig. 8| Unidentified artist, Left $A$ couple of the Lambadi caste, Centre $A$ basket-maker and his wife, Right $A$ tankdigger and his wife; Company painting from a volume containing thirty folios depicting castes, occupations, methods of cultivation, and procession scenes. Tanjore, ca. 1830. Gouache and watercolour, 39.5 X $58.5 \mathrm{~cm}$. Inscribed in ink with identifications in Tamil, Telegu and Modi (Tanjore Marathi) and with faint penciled inscriptions in English. Victoria and Albert Museum, London.

${ }^{83}$ C. A. Bayly, "From Company to Crown. Nineteenth-Century India and its Visual Representation," in C. A. Bayly, The Raj: India and the British 1600-1947 (London: national Portrait Gallery Publications, 1990), 134.

${ }^{84}$ William Alexander, Picturesque Representations of the Dress and Manners of the English (London: W. Bulmer and Co. for John Murray, 1814).

${ }^{85}$ Thomas Lord Busby, Costumes of the Lower Orders of London: Painted and Engraved From Nature (London: Baldwin \& Co., 1820). 
memorabilia. Produced by Indian artists working in a mixed Indo-European style, these 'Company paintings' (see figure 8 as an example of this genre, dating from around 1830) were meant to appeal to the European employees of the various East-India Companies. Consisting of landscapes and architectural studies, but mainly of genre portraits, these paintings attempted to "objectively observe the Indian scene in all its aspects, including natural history and human society," and were popular among the European population in India both as souvenirs and as collectable art objects. ${ }^{86}$ Similar to the Costumes and Characters of Western India, many of these earlier Company paintings illustrated various occupations and castes, presenting the subjects as a series of 'types.' Bayly argues that the classification and portrayal of the local people in Company paintings helped to shape the Western perception of India, and the reliance on picturesque and exotic representations had the effect of presenting "an unchanging view of traditional society." ${ }^{87}$ Visual depictions of Indian life and society as unchanging were consistent with British imperial ideology, in which it was generally felt that British governance was bringing progress to an aging and stagnant culture. Mia Carter suggests that among the British there was a "fundamental assumption that India was out of 'civilized,' orderly time, hopelessly stuck in the static time of ancients or heathens." 88

The IAPA portraits are not the earliest example of British photographers in India producing ethnographic documents. East India Company surgeon John McCosh had been photographing native people as early as 1843, producing a series of salted-paper portraits of Indian and Burmese natives. ${ }^{89}$ In his 1856 book Advice to Officers in India, McCosh advocated photography as a hobby and a means by which officers could accumulate a collection of Indian images, notably portraits of the local people:

I would strongly recommend every assistant-surgeon to make himself a master of photography in all its branches.... During the course of his service in India, he

\footnotetext{
${ }^{86}$ Mildred Archer, Company Paintings: Indian Paintings of the British Period (London: Victoria and Albert Museum with Mapin, Ahmedabad, 1992), 11.

${ }^{87}$ Bayly, "From Company to Crown," 134.

${ }^{88}$ Carter, "Volume Introduction," 3.

89 Taylor, Impressed by Light, 121.
} 
may make such a faithful collection of representations of man and animals, of architecture and landscape, that would be a welcome contribution to any museum. ${ }^{90}$

In an 1857 address to the Bengal Photographic Society, Reverend Joseph Mullens noted that although "we have all practiced upon our servants, and taken advantage of an auspicious moment to focus the bullock cart employed in carrying goods from next door," the organized and methodical use of photography to document the people of India was absent from current photographic practice. Noting the "deep and growing interest now felt in Europe in everything Indian," Mullen proposed a "more complete and systematic" photographic endeavour to document "the perfect specimen of all the minute varieties of Oriental Life; of Oriental Scenery, Oriental nations and Oriental manners." He proposed:

The population itself will supply those who have portrait cases with abundance of illustrations. One set may give an entire set of house servants; another, specimens of the different nations and races of India in particular, and of Asia in general. No city in the world gives such facilities for this as Calcutta, unless it be Bombay. Another could give us a clear and complete view of the different costumes, showing the mode in which they are worn and in which they are fastened. On this point our English artists are dreadfully at fault. ${ }^{91}$

The inclusion of a regular series of portraits in the IAPA appears to be an attempt to provide the beginnings of such a "complete and thorough" study of the "different nations of India," and to present it the public. By using photographs to classify and order the local population based on visible differences and outward appearance Johnson and Henderson anticipate the more rigorous and systematic approach to documenting native people later utilized by visual anthropologists, and inaugurate many

\footnotetext{
90 John McCosh, Advice to Officers in India, 1856, cited in Ray McKenzie, "The Laboratory of Mankind': John McCosh and the Beginnings of Photography in British India," History of Photography 11, no. 2 (April-June 1987): 109.

${ }^{91}$ Rev. Joseph Mullens, "On the Applications of Photography in India," Journal of the Bengal Photographic Society 2, no. 21(January 1857):33, cited in John Falconer, "Ethnographic Photography in India 1850-1900," The Photographic Collector 5, no. 1 (1984): 16.
} 
of the conventions by which India would be photographically represented to and for Europeans.

\section{The Johnson and Henderson Style}

The distinctive visual style found in Costumes and Characters of Western India stems from Johnson's and Henderson's experiences as portrait photographers, a background that provided them with the ability to represent people and costumes in an attractive and elegant manner. Photographic reproduction enabled the dissemination of these images in a way that the Company paintings did not, and Johnson and Henderson used their publication as a vehicle to distribute their work to a wider audience.

Both men were employed in the Bombay civil service as their primary occupation, but they maintained commercial photographic practices as well. Johnson operated a daguerreotype studio in Grant Road as early as 1852. ${ }^{92}$ The Bombay Calendar and Almanac for 1856 indicates that Johnson had at that time a studio in Colaba, ${ }^{93}$ while Henderson is listed in the Bombay Almanac and Directory as a photographer starting in 1857. ${ }^{94}$ The two were briefly studio partners starting in $1858 .{ }^{95}$ Little is known about the nature of their studio practices, the extent of their business, their clients, or the dynamics of their partnership. Presumably though, their studios existed to produce photographic portraits of the local European population. Both Johnson and Henderson independently exhibited portraits at the Bombay exhibition of 1856. Henderson presented "collodion positives" (ambrotypes), while Johnson was commended for his "full plate portraits and groups...full of life and vigour," photographed with collodion negatives. A reviewer writing about the 1856 exhibition stated that Johnson had "devoted his energies chiefly to this process," and "the positions [were] artistic, the focusing and tone excellent." was singled out for praise.

\footnotetext{
92 Falconer, India: Pioneering Photographers, 139.

${ }^{93}$ Bombay Calendar and Almanac, 381.

${ }^{94}$ Cited in Dewan, "Sun Pictures," 113.

${ }^{95}$ Falconer, India: Pioneering Photographers, 139.

96 "Exhibition of Photographs at Bombay," 234.
} 
Their experience with portraiture is apparent upon the examination of the series. A distinctive and consistent aesthetic strikes in its elegance and simplicity, and reflects the technical skill of the photographers. Overall these portraits share a distinctive 'Johnson and Henderson style,' combining the graceful use of even lighting, balanced and centred composition of the subjects, and a relaxed and confident appearance to the subjects that allows them to appear 'naturalistic.' While 'relaxed' and 'naturalistic' are of course relative terms that are difficult to quantify, it seems likely that by treating these photographic portrait sessions as studio visits rather than the aggressive collection of specimens they enabled the sitters to manifest self-confidence. Unlike the systematic anthropological photographs of racial 'types' prevalent in the latter half of the nineteenth century, where photographers sought to convey the scientific and objective validity of their pursuit through rigid and standardized posing conventions and by using a background grid to quantify their measurements, the subjects in Johnson and Henderson's portraits appear more comfortable and less self-conscious.

\section{Inside the Studio/Out in the Street}

Of the twenty portraits included in the GEH album, approximately half were photographed in the studio (catalogues 6, 9, 12, 15, 18, 32, 42, 46, and 52). The portraits are all full-length, although some subjects are seated either in chairs or on the ground. The subjects are almost always in pairs, or arranged into small, visually pleasing groups. Throughout the work there is great consistency to the studio lighting, which is soft, even, and from above. The set décor, either completely bare or sparsely decorated, is consistent with many of the stylistic conventions of Victorian studio portraiture both in India, ${ }^{97}$ and in England. Parsee Lady and Child (catalogue 15) [figure 9] and Comfortable Gosavis (catalogue 18) [figure 10] illustrate the consistency of the studio portraits. The same Doric column, patterned carpet, and ornate wooden chair

\footnotetext{
${ }^{97}$ Compare for example with the portraiture in Falconer, India: Pioneering Photographers, $102-$ 105, or the portraits by Linnaeus Tripe in Janet Dewan, The Photographs of Linnaeus Tripe: A Catalogue Raisonné (Toronto: Art Gallery of Ontario, 2001), 337-343.
} 
can be seen in both photographs, and the people are composed in such a way that the image overall has symmetry and balance..$^{98}$

Although both of these photographs have the appearance of being studio portraits of individuals, and the photographers may have responded to their subjects that way, in the culture of the letterpress the subjects remain unnamed, and are described as typical representatives of their social groups. The accompanying text to catalogue 15 provides a lengthy historical account of the migration of the Parsis from Persia to India and a comment about their commercial success in Bombay. A description of typical Parsi dress follows: "The lady stands forth in modest dignity, and with no superfluity of self-confidence, arrayed in her silken sárí with its embroidered border."99

Likewise, the description for catalogue 18 is impersonal, and generalizes about the Gosavis, a type of Hindu devotee previously known for their austerity and penance, but now generally embracing a material lifestyle: "Witness the figures of the Giribárthi Purí

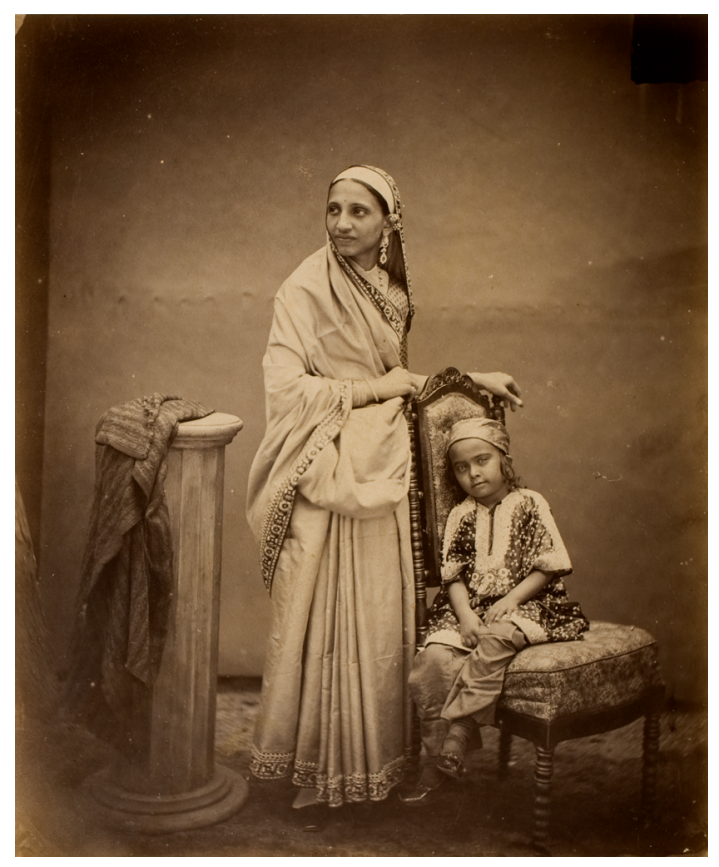

Fig. 9| Johnson and Henderson, Costumes and Characters of Western India no. 5-Parsee Lady and Child (Catalogue 15).

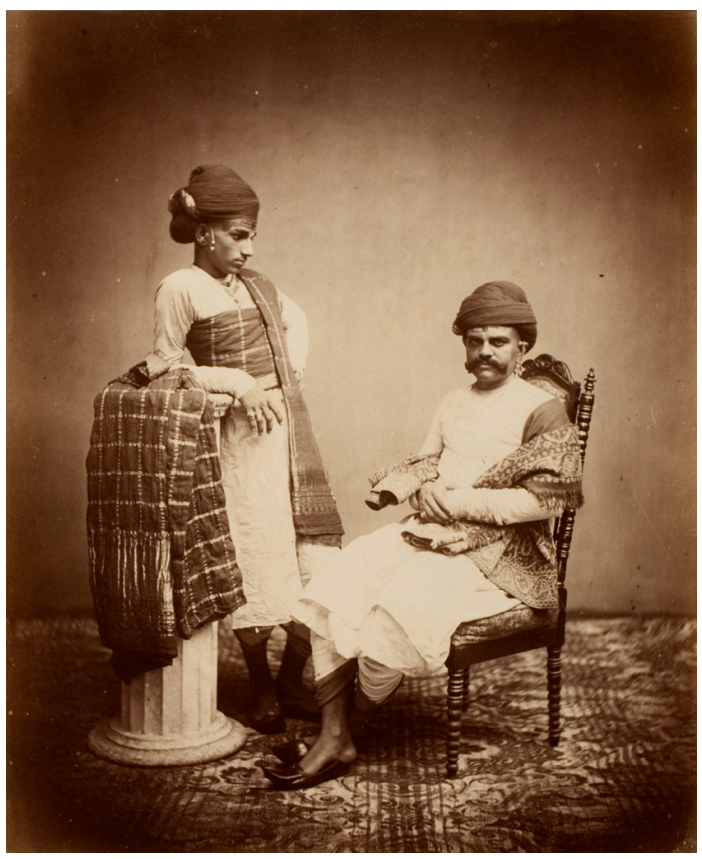

Fig. 10 0 Johnson and Henderson, Costumes and Characters of Western India no. 6-Comfortable Gosavis (Catalogue 18).

${ }^{98}$ Although these are the only portraits to feature the column, the chair and/or the carpet are present in catalogues $6,15,18,32,42,46$, and 61.

${ }^{99}$ IAPA no. 5 (March 1857): n.p. 
Gosavis, now presented to the public! Food and clothes of the finest quality are not despised by them, but worn with conscious satisfaction, if not with pride. They make money, and they lend money; and though they neither give nor get in marriage, they don't despise in its fruits, but adopt children of promise as their disciples and heirs."

The photographs that were made outside (catalogues 3, 25, 29, 35, 38, 41, 47, 55, $61,67,70)$ demonstrate a similar mastery of even lighting and careful composition. Although many of the photographs have the appearance of being made in the street, they are controlled and organized to appear almost as if they were studio productions: the backdrops are simple and uncluttered and make careful use the physical environment to create a pleasing arrangement. The subjects are often posed with wellchosen props to indicate their occupation or profession, and the camera appears to have caught them in an unguarded (but elegantly composed) moment of their daily lives.

The Mehtas, or Native Writers of catalogue 67 seem actively engaged in their task

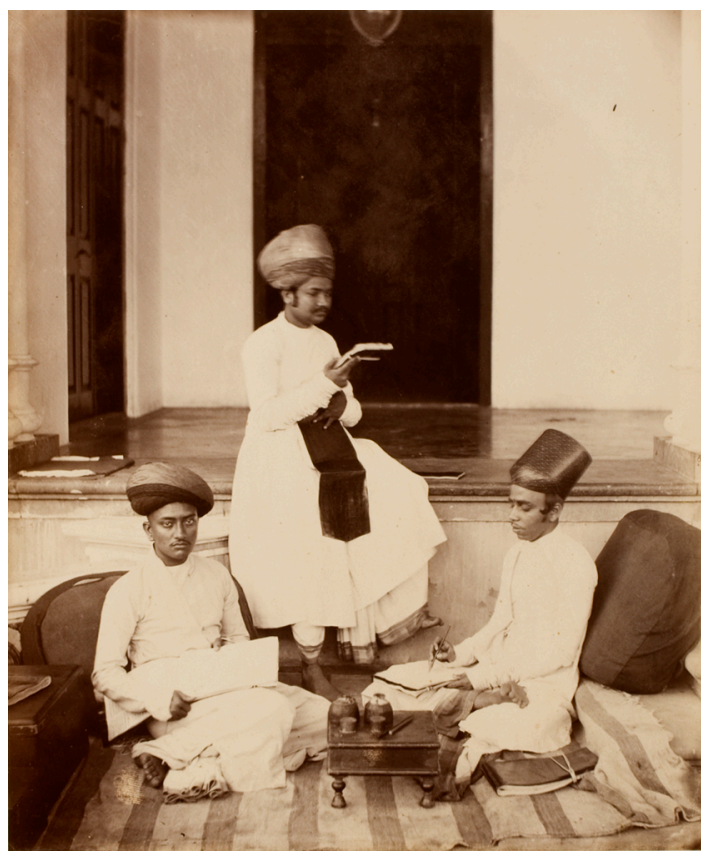

Fig. 11| Unidentified Photographer, Costumes and Characters of Western India no. 19-Mehtas, or Native Writers (Catalogue 67).

${ }^{100}$ IAPA no. 6 (April 1857): n.p.

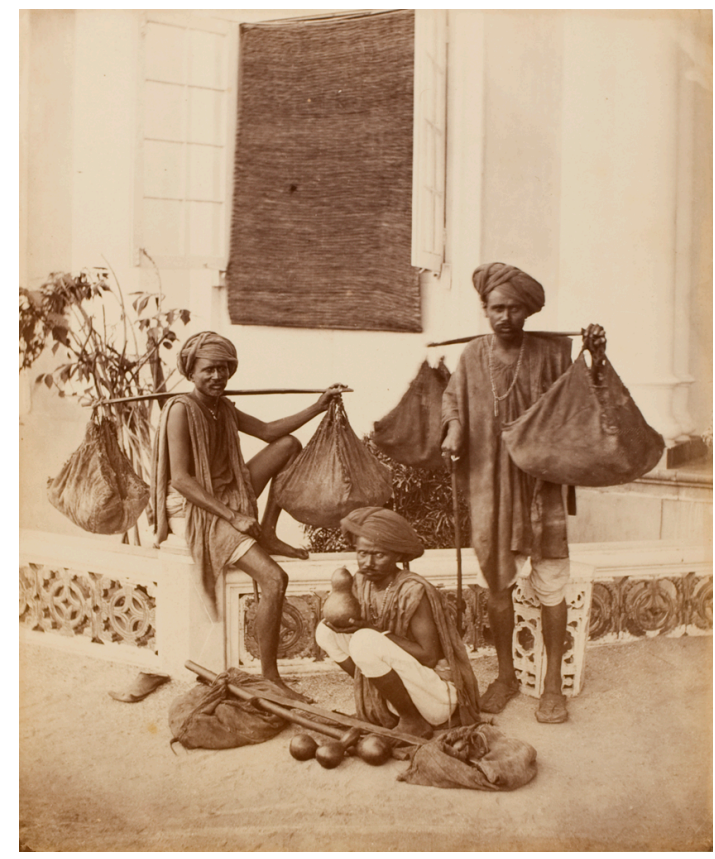

Fig. 12| Unidentified Photographer, Costumes and Characters of Western India no. 20-Naka-Dole Waidyas (Catalogue 70). 
of accounting, yet are posed in a triangular arrangement that combines with the strong vertical lines of the porch [figure 11]. All three are involved in some slight variation of the same chore, presumably to illustrate their trade accurately. The Naka-Dole Waidyas (described as "Medicasters of the first grade") ${ }^{101}$ in catalogue 70 [figure 12] are posed in a different triangular arrangement, and while two of the men stand at ease with their bundles of medicines over their shoulders, the third man is squatting before them with his pouches and gourds laid out on the ground. In both photographs the studied casualness of the composition almost draws attention to itself through its striking order and symmetry.

\section{Costumes and Characters of Western India}

The name of the series itself is both revealing and culturally important, and may originate with Bombay Photographic Society president Capt. Harry Barr, who uses the phrase in his introductory address to the Society. ${ }^{102}$ 'Costumes' and 'characters' are both complex words, and when combined, present a range of possible meanings. The use of the word 'costumes' implies an emphasis on outward appearance and modes of dress, and suggests that the people depicted can be defined by visual inspection. 'Characters' alludes to the array of ethnicities, races, nationalities, professions and castes to be found in Bombay; although the word could apply to the nature of an individual's personality, its use here suggests foreignness and exoticism. The combination of 'costumes and characters' also seems to imply the existence of an ongoing stage play, the complex kaleidoscopic view of life in India recently described by Pinney as ripe for de-mystification and ordering through the use of discrete photographic representations. The photographs in the series Costumes and Characters of Western India present the varied physiognomies and styles of dress of the diverse cultural makeup of Bombay, highlighting the array of racial and ethnographic differences between the white English residents and the non-European races, castes, and professions.

\footnotetext{
${ }^{101}$ IAPA no. 24 (October 1858): n.p.

102 “Introductory Address," JPSB no. 1 (January 15, 1855): 2.
} 
Although each photograph in the series Costumes and Characters of Western India is accompanied by a descriptive letterpress providing some information about the caste, profession, or type being presented, the series overall lacks a statement of intention. The absence of a clear declaration by the publishers as to the purpose of the series and the photographers' overarching attitudes towards the subjects is unfortunate, but can be assumed to be similar to that provided in the preface to The Oriental Races and Tribes, Residents and Visitors of Bombay, an 1863 work by Johnson that represents a more serious foray into ethnography, and which re-uses many of the same images in an altered context:

Of Bombay more than of London in the eye of the poet Cowper, it may be truthfully said-

$$
\begin{aligned}
& \text { "Oh, thou resort and mart of all the earth, } \\
& \text { Chequered with all complexions of mankind." }
\end{aligned}
$$

In that great and wealthy city, supposed to be now the most populous in India, faces are to be seen of every variety of hue, from that of the fair northern European to that of the tropical African, nearly as black as ebony. It contains numerous representatives of almost all the races and tribes of the Indian Continent and Islands. It has, every season, numerous visitors from the countries of Central Asia, and from even remoter lands....

Photographic delineations of the numerous Peoples and Tribes frequenting -

"(This) Bombay's wealthy isle and harbour fam'd;

Supine beneath the shade of cocoa groves"-

have long been desiderata both among the students of Geography and Ethnography, and the lovers of Art, notwithstanding partial attempts to supply them made by various local amateurs.... The Collection of Negatives procured for the present work was made with great labour, and in many instances with no little persuasion addressed to the scrupulous personages, whose effigies have been successfully delineated by the solar ray. ${ }^{103}$

\footnotetext{
${ }^{103}$ William Johnson, The Oriental Races and Tribes, Residents and Visitors of Bombay, vol. I (London: W. J. Johnson, Bolton and Barnitt, 1863), 9.
} 
As an important hub for global trade, Bombay was an economic centre for cotton, opium, and spices, and the population of the city was made up of British, Portuguese, Arabs, Persians, and Indians from all parts of the country and all social classes. When the British began to solidify Bombay's position as a valuable trading post in the 1700s, the islands were sparsely populated, so the English encouraged migration from other parts of India, offering religious freedoms that had been unheard of under the previous Portuguese rulers. The result was a steadily increasing population in which numerous religions, castes, and ethnic groups were represented. The series Costumes and Characters of Western India can be seen as an attempt to address the diversity that defined Bombay in the 1850s. However, often the subjects appear to have been selected primarily for their picturesque appearance, highlighting exotic visuality, typified by such accessories as elaborate hats and flowing robes. The result presents a striking cast of characters, as reflected in the series' title.

The photograph The Gosayins (catalogue 3) [figure 13], for example, presents exotic subject matter with a pronounced emphasis on unusual outward appearance. These Hindu 'fakirs' had long fascinated foreign travellers and residents of India, and

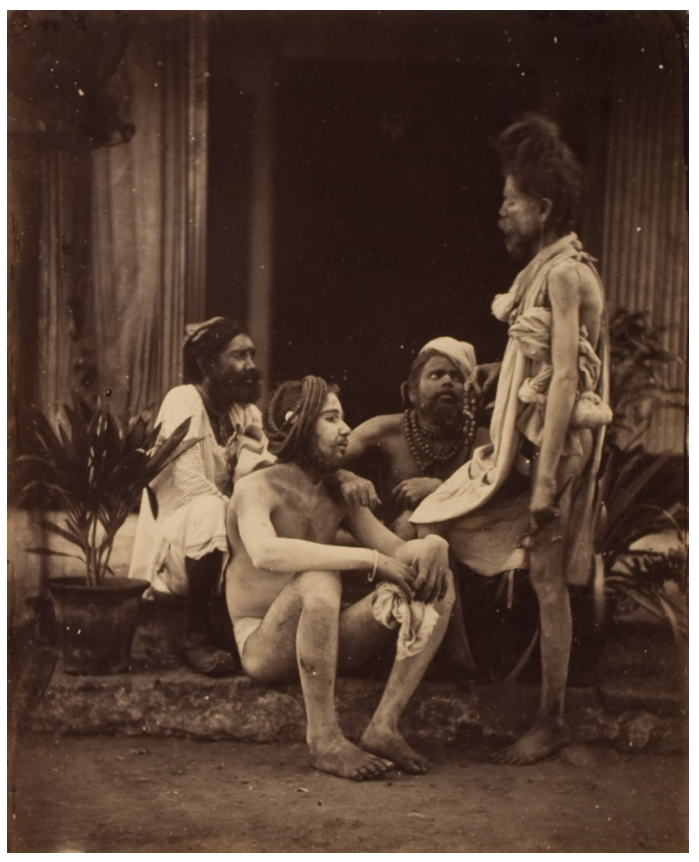

Fig. 13| William Johnson, Costumes and Characters of Western India no. 1-The Gosayins (Catalogue 3).

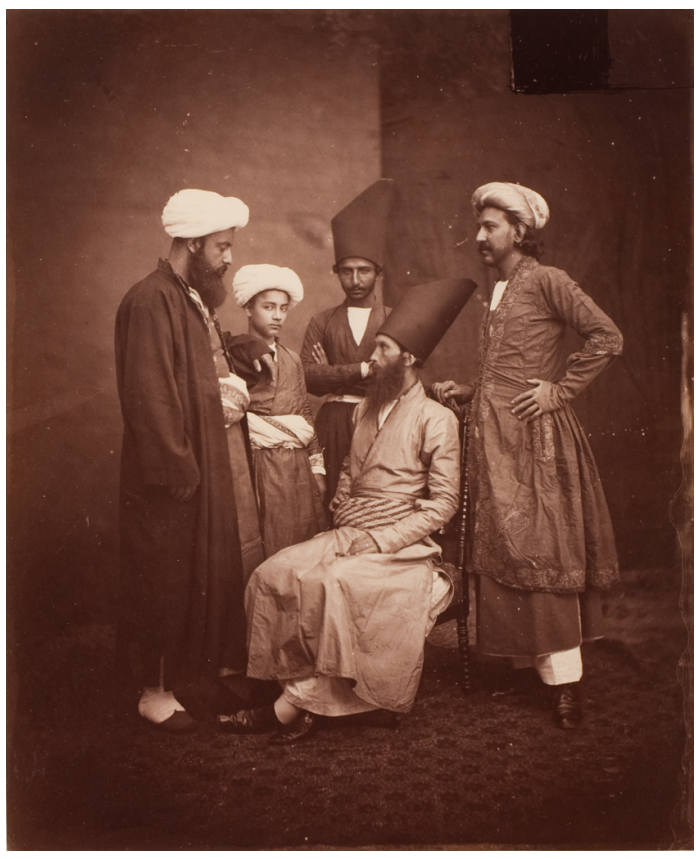

Fig. 14| Johnson and Henderson, Costumes and Characters of Western India no. 2-A Group of Persians (Catalogue 6). 
had often been the subject of Company paintings. Nearly naked, "besmeared with yellow ochre, chalk, or ashes, with hair which has been allowed to grow to an inconceivable length, matted and twisted into most fantastic shapes," ${ }^{104}$ these wandering Hindu ascetics defined an extreme instance of otherness to the English inhabitants of India. Although they now do not constitute more than a half a per cent of the total population, ${ }^{105}$ these mystics, with their pronounced outward displays of spirituality were ideal subjects for the foreigner's camera: their visually spectacular and overwhelming foreign appearances, described as "very picturesque or very disgusting." 106

Another photograph in which the subjects were seemingly chosen for the striking foreignness of their appearance is A Group of Persians (catalogue 6) [figure 14]. This group of five individuals, with their tall felt hats, long blouses and pointed shoes, has been posed in the studio. They are symmetrically arranged around a man with a long and prominent beard, and some are gazing at the camera while the rest look at each other. Although the title of the photograph identifies the men only as "A Group of Persians," the text informs us that they are actually foreign dignitaries, and that the group "consists of the leading men and Merchants of the Persian Community at this Presidency; the "Gentleman in the chair" being no less a personage than the Persian Consul." 107 Despite their prominent local standing, they are labelled in the IAPA with a generic title that addresses what they are rather than who they are, which seems to imply that the exotic dress and outward appearance of these men is more important than their social position.

\section{Castes}

The diversity of peoples and cultures in India seemed confusing and overwhelming to its European residents and visitors. This would have been particularly true in a concentrated microcosm such as Bombay, where people had migrated from all over

\footnotetext{
${ }^{104}$ IAPA no. 1 (November 1856): n.p.

${ }^{105}$ Dolf Hartsuiker, Sadhus: Holy Men of India (London: Thames and Hudson, 1993$), 7$.

106 IAPA no. 1 (November 1856): n.p.

${ }^{107}$ IAPA no. 2 (December 1856): n.p.
} 
the country, and even from beyond India's borders. Complex and hierarchical, the Hindu caste system was poorly understood by the British residents of India, and contributed to their confusion about the local culture. Although the caste system was intricate, to the British it provided a convenient way to sort the people they encountered, and enabled people to be identified, sorted and organized.

Govind Narayan's (1814?-1865) 1863 Urban Biography, translated from Marathi, was the first book on Mumbai written in that language, and provides impressions of the city from the point of view of an observant and well-read Indian, rather than through European eyes. Narayan's work describes the cosmopolitan array of religions, ethnicities, languages, classes, castes and communities encountered in Bombay: "Among the Hindus there are over a hundred castes... there is no end to the differences and variations within these castes." Then there are "other castes-Parsi, Mussalman, Moghul, Yahudi, Israeli, Bohra, Khoja, Memon, Arab, Kandhari" which are "identified by

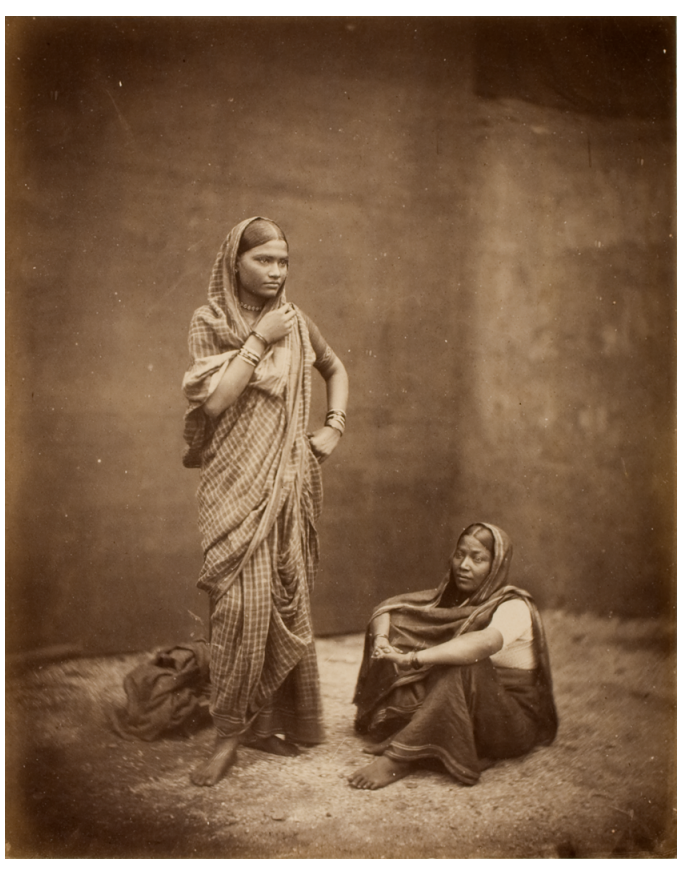

Fig. 15| Johnson and Henderson, Costumes and Characters of Western India no. 3-Parwari Women (Catalogue 9). the eighteen different head-dresses. And then come the hatted races, including the English, Portuguese, French, Greek, Dutch, Turkish, German, Armenian and Chinese. Not only is one entertained by the variety of strange costumes worn by these tribes, but the sight of them inspires yet other thoughts in the mind." 108 As Narayan's description reveals, the diverse nature of the city was not only of interest to the English, nor were they alone in using visual cues in their identifications and classifications.

On its most basic level the caste

\footnotetext{
${ }^{108}$ Murali Ranganathan, ed. and trans. Govind Narayans's Mumbai: An Urban Biography from 1863 (London: Anthem Press, 2008), 52.
} 


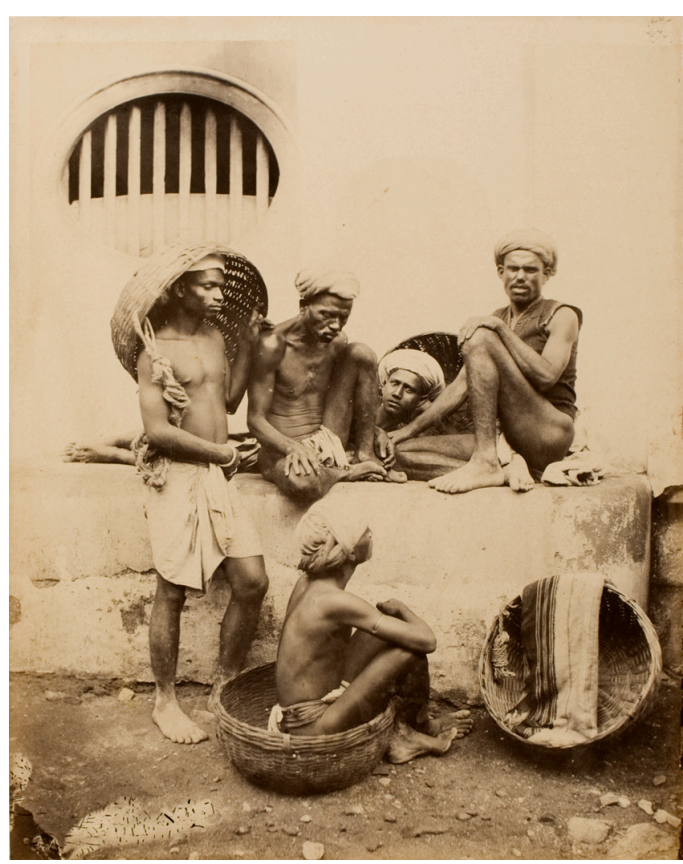

Fig. 16| Johnson and Henderson, Costumes and Characters of Western India no. 7-Group of Maratha Ghatis (Catalogue 25).

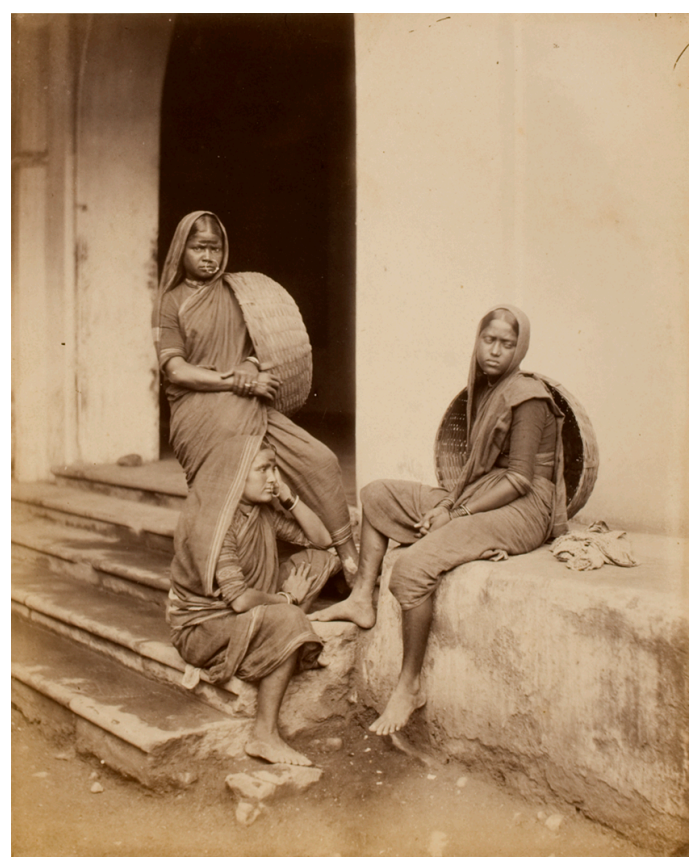

Fig. 17| Johnson and Henderson, Costumes and Characters of Western India no. 8-Maratha Women of the Labouring Class (Catalogue 29).

system divides all Hindus into one of four broad, hierarchical categories, where Brahmins form the highest caste. In practice however, these four main caste distinctions are subdivided into numerous sub-castes and categories, with strict and complex rules of commensality and ritual purification determining the interactions and relations between castes on a social and practical level.

Johnson and Henderson's process of selecting subjects is consistent with the evolving colonial typology of the time that divided the local population into clear caste divisions. Although caste hierarchy in India is very real, the British fascination with representing their own class-consciousness may have been influential in rigidifying the existing system. According to Bayly, "the policies of the East India Company emphasized and made more rigid some aspects of caste... people became more aware of caste identity and made attempts to become more 'orthodox' in their social lives."109

The use of a few unnamed individuals to represent all members of a caste, profession, race, or nationality elevates a simple portrait from being a mere

109 Bayly, "From Company to Crown," 134. 
reproduction of likeness into something emblematic or stereotypical, which is the very essence of the social 'type.' The depictions of Parwari Women (catalogue 9) [figure 15], the Group of Maratha Ghatis (catalogue 25) [figure 16], Maratha Women of the Labouring Class (catalogue 29) [figure 17], and Smarta Brahmans (catalogue 46) [figure 20] illustrate Johnson and Henderson's use of a few individuals to stand in for an entire caste. The people photographed are all unnamed, and there is no attempt to describe them as individuals; the letterpress describes the habits and lifestyles of the group as a whole.

The Parwaris are "the lowest caste in the Maratha country," and catalogue 9 depicts two of them, in plain cotton saris and with minimal jewelry. While one figure sits on the ground, the other stands and they are posed against a blank studio background that creates a non-descript space. Instead of addressing them as individuals, the habits and lifestyles of the group as a whole are described: "Dead cattle they claim as their property, eating them if not much affected by disease. They are found in the employ of Europeans, in several capacities, as coachmen, grooms, peons, \&c., but are avoided

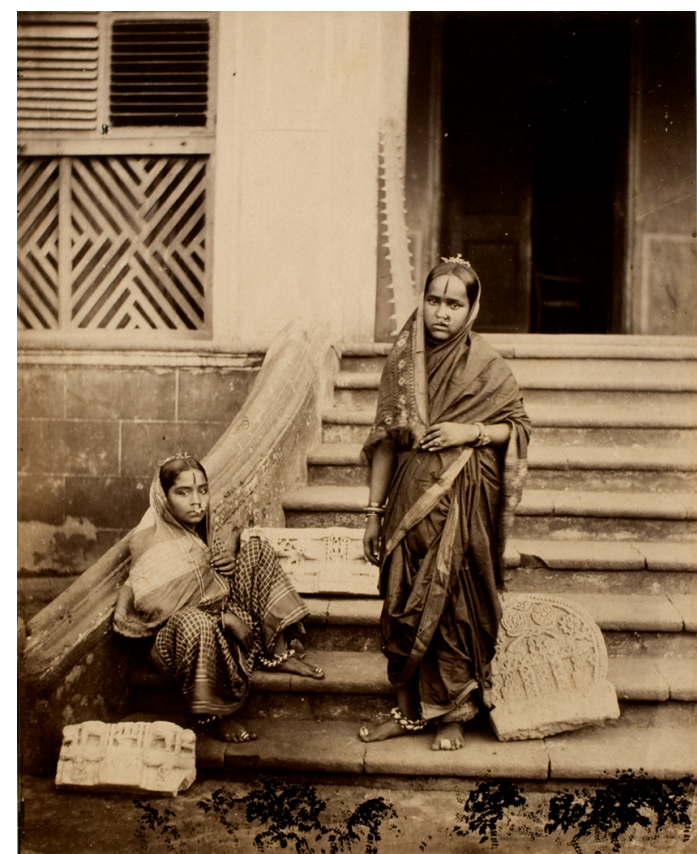

Fig. 18| Johnson and Henderson, Costumes and Characters of Western India no. 11-Brahmani Ladies (Catalogue 38).

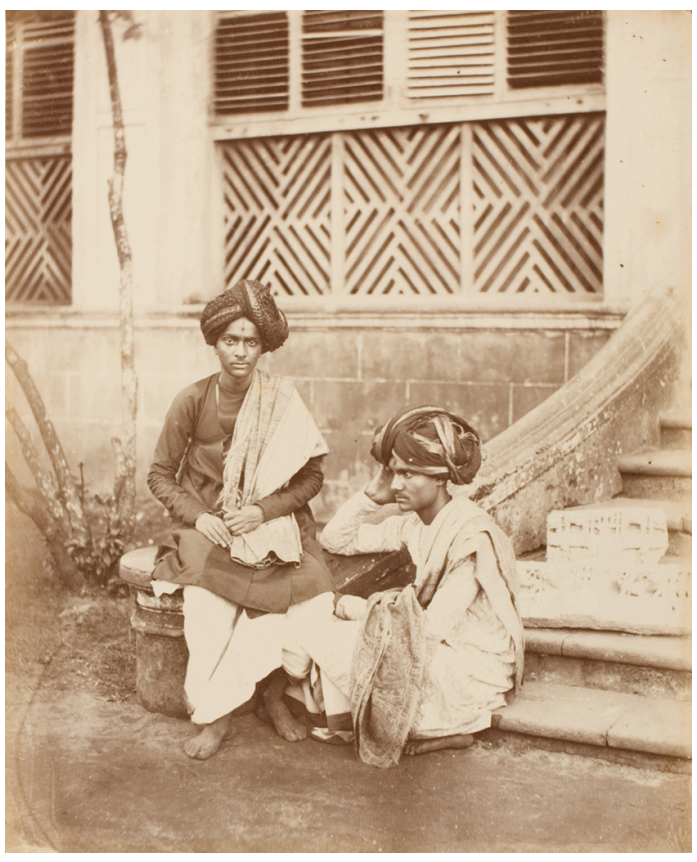

Fig. 19| Johnson and Henderson, Costumes and Characters of Western India no. 12-Brahmin Students of English Literature (Catalogue 41). 
by the natives of other castes, who think themselves polluted if touched by them." 110

Likewise, the Group of Maratha Ghatis (catalogue 25), and Maratha Women of the Labouring Class (catalogue 29), represent the men and women of the "general agricultural population of the Maráthá country," who are "generally employed as daylabourers, and are noted for their industry." Although the men and women are photographed separately, they are both depicted holding baskets, a common motif from the Company paintings. They are described as hard workers, regularly employed by the English, and "ready to put their hands and their baskets to any decent work that may be assigned to them." A note is made of the caste hierarchy and relationship with the other workers previously depicted in catalogue 9, and "they reckon themselves far superior in the social scale to the stout-bodied Parwaris, whom, in their villages, they profess to regard as their entire subordinates."

Despite being labeled as characteristic of the group they are representing, some of the subjects are identified by name in the accompanying letterpress. Brahmani Ladies (catalogue 38) [figure 18], indicates a departure from the anonymity of the majority of the portraits, and provides a personal reference to the women in the photograph:

We have great pleasure in submitting to our friends a Photograph of two very interesting female representatives of the Bráhman tribe. The elder of these two intelligent young ladies, [is] Aralá Báí...and the younger, Lakshmí Báí... They are both at present in Bombay, under the care of their venerable grandmother, enjoying instruction, principally through the medium of our noble English tongue, -for they are already proficients in their vernacular Maráthí, -at the missionhouse, Ambrolie, under the direct guidance of Dr. Wilson's family. The attention shown by their father, -who is much distinguished in the judicial service of Government, -to their training and culture, is highly exemplary, and much to be commended, especially in a country in which, even among the higher classes of the natives, it is so rare. ${ }^{111}$

\footnotetext{
110 IAPA no. 3 (January 1857): n.p.

${ }^{111}$ IAPA no. 13 (November 1857): n.p.
} 
Unusual for the IAPA in that the subjects are identified by name, these ladies appear to have been singled out for praise due to their father's decision to provide them with a Christian education in the hands of local missionaries. The addition of personal biographical information appears to interfere with the universality and objectivity implied in an ethnographic study, however the ladies are still are identified as "representative" of female Brahmins, and the behaviour of their father as "exemplary."

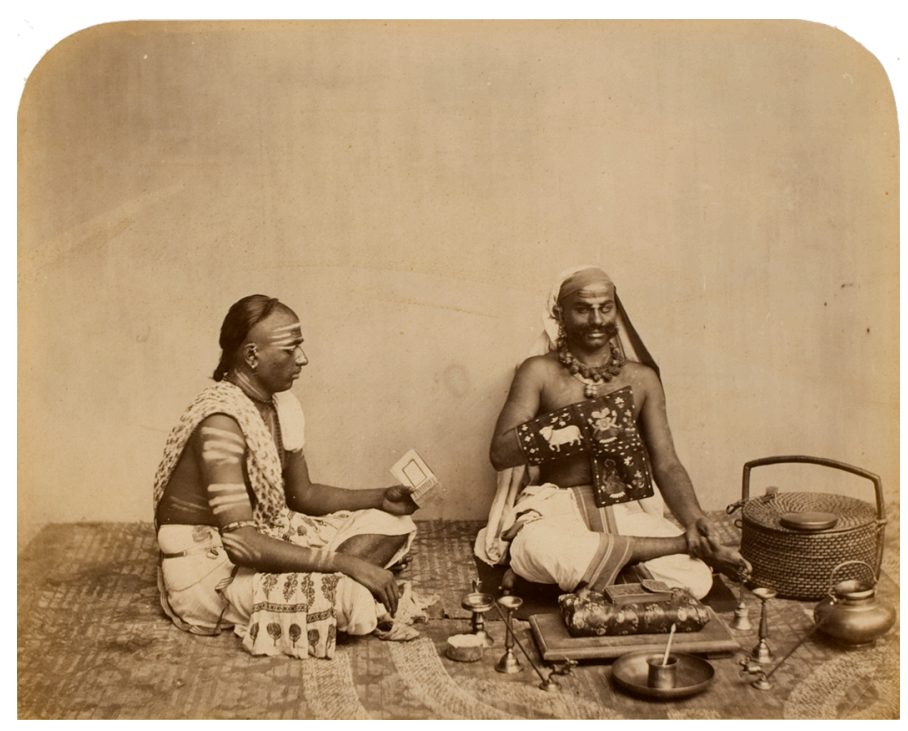

Fig. 20| Johnson and Henderson, Costumes and Characters of Western India no. 14-Smarta Brahmans (Catalogue 46).
The

photograph

Students of English

Literature (catalogue 41)

[figure 19] depicts the husbands of the young Brahmin ladies, although they are not identified by name. Catalogue 41 continues to elevate its subjects, suggesting that by renouncing the idolatry of Hindu worship and

embracing Christian morals they are somehow above the majority of the Brahmins:

Their costume is that of the higher classes of natives devoted to secular duties in the southern Maráthá Country and the Karnátik, and not that of the youths belonging to their class who are the devotees of the Vedas and Shástras or the scrubbers or anointers of the idols of stone and metal. Their form and figure, which do not much differ from the Western mould, are indicative of the Aryan race, to which the Brahmans belong. They have come to the seat of the Presidency to pursue their study of the English language in the Free General Assembly's Institution. ${ }^{112}$

${ }^{112}$ IAPA no. 14 (December 1857): n.p. 


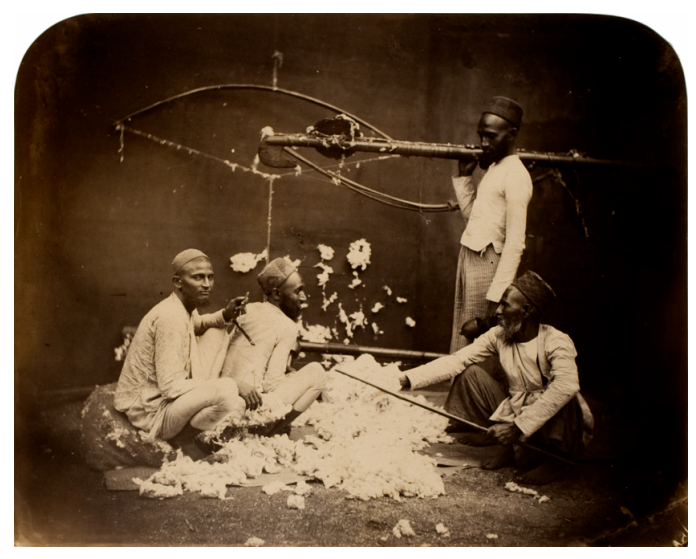

Fig. 21| Johnson and Henderson, Costumes and Characters of Western India no. 4-Group of Pinjaras, or Cotton-Carders (Catalogue 12).

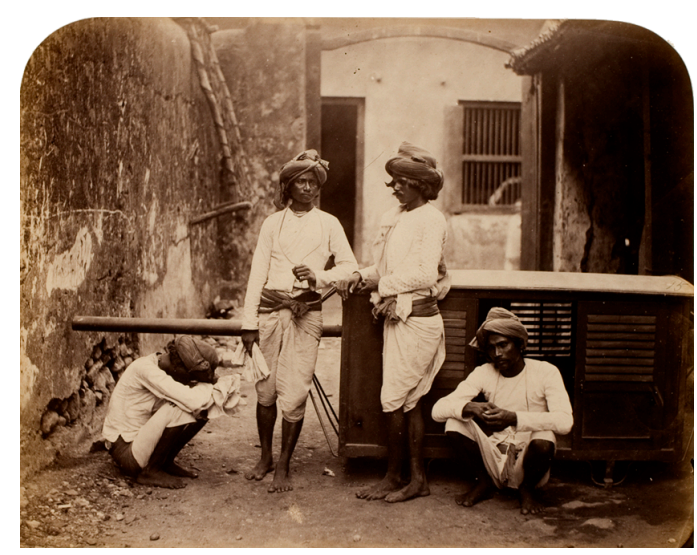

Fig. 22| William Johnson, Costumes and Characters of Western India no. 15-Bengali Hamals (Catalogue 47).

These depictions contrast with that of the Smarta Brahmans (catalogue 46) [figure 20], portrayed with the "idol-Bell, and various cups and platters of idol-service," that are the symbols of his faith, "repeating his mantras, or invocations, and turning his rosary by one of his hands covered by a bag." The letterpress provides a brief history of the sect that these men belong to, and by describing the "sectarial marks, on their brows, breasts, and arms," seems more intent on providing a means of identification of the group rather than humanizing them in any way.

The lower castes (catalogues 9, 25, and 29) are noted for their hard work ethic and their willingness and ability to serve as labourers for the English, and the distinctions that they draw between themselves seem to be looked down upon with amusement by the British authors. The higher castes (catalogues 38, 41, and 46), although viewed with less condescension, are still treated as objects of study, and a clear distinction is drawn between those who engage with their native Hindu culture, and those who embrace the English Christian ways, who are seen as having the potential to redeem the entire nation.

\section{Professions and Occupations}

Reminiscent of the genre studies popular in the Company paintings, the occupational photographs depict people at work, posing with the tools that define their profession. Generally photographed in groups and always unnamed, these professional portraits are intended to convey the typical workers one encountered in the daily life of Bombay. 
Grouped in such a way as to convey a constructed narrative of their profession, these portrait subjects were photographed with objects intended to convey a sense of their daily activity, for as Rosalind Morris points out, "the essence of the type was tied to the context and the activities of the sitter."113

The men photographed in Group of Pinjaras, or Cotton-Carders (catalogue 12) [figure 21] appear to be caught in the act of separating cotton fibres, while the Bengali Hamals (catalogue 47) [figure 22] seem to have put down the palanquin they were carrying to be photographed while taking a short break. Both groups are involved in activities that were of importance to the residents of Bombay, and in the accompanying text, they are highly praised for their work ethic. While the Pinjaras are "noted as a very industrious class of the Natives, generally commencing their work at an early and continuing it to a late hour," the Hamals "belong to a class who keep themselves remarkably clean, and are willing workmen." In both examples the apparent casualness with which the photographer has captured these scenes of working life is betrayed by the careful posing of the subjects, who have clearly been placed in such a way as to produce a symmetrical and stable composition. This casualness forms part of the images' documentary value, and provides an aspect of authenticity to the scenes by showing the subjects in their own environment, rather than being isolated in a studio setting.

The complex relationship between profession and caste further complicates the task of visual classification. While a person's caste will often determine their profession, the converse is not always true, and a profession does not have to imply a rigid caste association. Some workers form a distinct profession although its members are

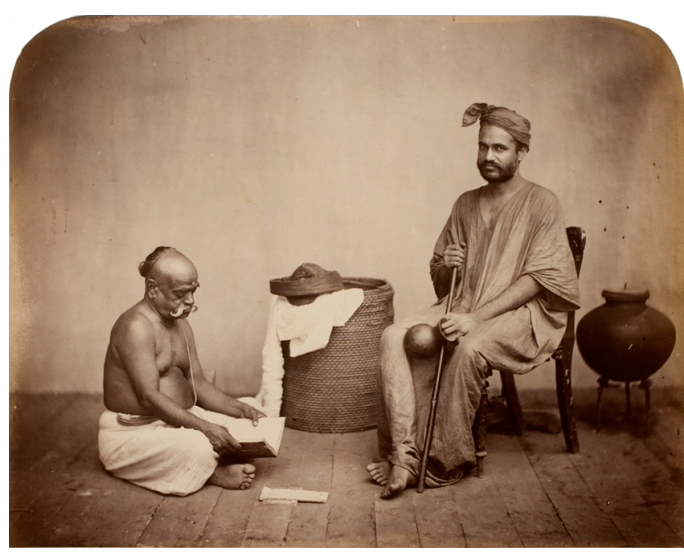

Fig. 23| Unidentified Photographer, Costumes and Characters of Western India no. 17-The Brahmachari Bawa, Vishnu Bhiku (Catalogue 52).

\footnotetext{
${ }^{113}$ Rosalind C. Morris, "Introduction," in Photographies East: The Camera and Its Histories in East and Southeast Asia, ed. Rosalind C. Morris (Durham NC: Duke University Press, 2009), 3.
} 
not drawn from any particular caste. While it would be convenient if all occupations could be identified by the tools of their trade, this is not the case, as Johnson and Henderson often take pains to point out. The Native Knife-Grinder and his Assistant (catalogue 55) represents a "profession and not a caste," (catalogue 47) or palanquin bearers of Bombay, belong to several classes of the natives." 115

\section{Physiognomy}

With the development of theories of physiognomy, beginning in the late eighteenth century, it was commonly and widely felt that bodies and faces could be read to reveal the true character of a person. A photograph of a person could, by extension, be used to determine the worth and attributes for an entire race or tribe, since to the Victorian mind, as Pinney has recently argued, "each person literally embodied his or her racial and cultural identity."116 Although Costumes and Characters of Western India makes only a few explicit mentions of this type of analysis it is clear that Johnson and Henderson were familiar with it, and it may have been a concern of the intended audience. The photograph The Brahmachari Bawa, Vishnu Bhiku (catalogue 52) [figure 23], one of the few to serve as a portrait of an individual, depicts a controversial Brahmin whose religious lectures occasionally brought him into conflict with British missionaries. The text of the letterpress is fairly neutral, but the tone suggests that the author is less than supportive of the Bawa's ideas. In a strange parting line the author states, "as he has been so kind as to sit before us for his picture we leave the public to form its own opinion of his marked physiognomy."

Although the publishers felt that a modicum of respect for their subject was only fair, the same was not necessarily true of the viewing public, who may have had their own interpretation of the photograph, and the subject's physiognomy. This is evident from an 1859 article in the English photographic journal The Photographic News

\footnotetext{
${ }^{114}$ IAPA no. 19 (May 1858): n.p.

115 IAPA no. 17 (March 1858): n.p.

116 Pinney, "Colonial Anthropology," 253.
} 
discussing catalogue 52, in which the author does not hesitate to do what the IAPA author will not:

On the part of the public thus invited to do that which delicacy prevented the photographer from doing, we have no hesitation in saying that the features and forehead of this Hindoo orator would not have been despised by Lavater and Spurzheim, ${ }^{117}$ when looking or feeling for intellectual capacity and energy. With a bright eye (which might be of great help to an eloquent tongue), a well formed mouth, and lofty os frontis, the effect of the whole countenance is grave and impressive, if not commanding. The Bawa, with all his religious austerities, may have had some little pride when he brought to the artist's studio the companion, who is squatted on the floor, for we must say that the wrinkled features, sunken eye, receding forehead, and mis-shapen person of the disciple make an admirable foil to the face and figure of his master. ${ }^{118}$

The Costumes and Characters of Western India series predates the ostensibly scientific recording methods of early physical anthropologists and physiognomists who, beginning in the 1860s and early 1870s used photography to collect data to create hierarchical categorizations of human (generally foreign) specimens. ${ }^{119}$ This early attempt in 1857-59 to map the local population predates more structured projects such as The People of India ${ }^{120}$ seeking to amass data on the local population by classifying them into physical 'types' and accumulating a comprehensive archive to assist in the administrative, strategic, commercial, and scholarly ends of the British in

\footnotetext{
117 Proponents of theories of physiognomy and phrenology, respectively.

118 "Photography in Western India," The Photographic News 1, no. 23 (February 11, 1859): 265.

${ }^{119}$ See Elizabeth Edwards, "Photographic 'Types': The Pursuit of Method," Visual Anthropology 3 (1990): 235-258.

${ }^{120} \mathrm{~J}$. Forbes Watson and Sir John William Kaye, The People of India: A Series of Photographic Illustrations, with Descriptive Letterpress, of the Races and Tribes of Hindustan, 8 vols. (London: Wm. H. Allen \& Co., 1868-1874). For a comprehensive account of the creation of this text, see John Falconer, "'A Pure Labour of Love,' A Publishing History of The People of India," in Eleanor M. Hight and Gary D. Sampson, eds. Colonialist Photography: Imag(in)ing Race and Place (London: Routledge, 2002), 51-83.
} 
India. That these photographs can be considered antecedents to later more rigorous ethnographic work has been well documented. ${ }^{121}$

\section{Conclusion}

The series Costumes and Characters of Western India attempts to capture the many ethnicities present in the dynamic and vibrant city of Bombay, a legendary cultural melting pot and a thriving centre of economic activity. The individual photographs serve as cultural touchstones and visual landmarks the photographers use to define the uncertain cultural terrain that surrounds them and their intended audiences by producing anchors of familiarity. Reducing the unfamiliar to the familiar and presenting it in a palatable way for consumption by a European audience, the selection of subjects seems to be designed to present an exotic image of India, both to function as souvenirs for local residents, and to fuel the imaginations and preconceptions of the British at home by providing images of a distant empire. As this brief examination of these portraits indicates, the selection and presentation of the subjects in Costumes and Characters of Western India reveal the biases, preconceptions, imperatives, and ideas of the colonial state at both the visual and written levels. Emerging from the British obsession with classification, order, and the definition of cultural archetypes based on clothing and physical appearance, these photographs are predecessors to later, more systematic ethnography.

${ }^{121}$ A discussion of the IAPA in the continuum of ethnographic photography and the development of visual anthropology in India is found in Falconer, "Ethnographical Photography," 16-46. 


\section{Analysis III: Architecture and Views Introduction}

Throughout the 1850s IAPA contributors and Bombay Photographic Society members were using photography to document the topography, architecture, and archeological sites of India, the accumulation of which contributed to the colonial visual record. Of the seventytwo photographs in the GEH album, fifty-two are architectural photographs and landscape views, an aspect of the IAPA that has not previously received significant scholarly attention. Twenty of these views depict the city of Bombay, in particular the areas inhabited by the English, while the majority of the remainder depict the temples, ruins, and antiquities of the Bombay Presidency. A small but significant third component documents British constructions and expanding imperial infrastructure in the form of railway construction and engineering projects in the Presidency. These photographs served many purposes to their British creators: to define the urban topography of the city they lived in, to document the architecture of the city and of the Presidency, and to produce archeological records. Serving now as valuable documents of the British presence in India in the mid-nineteenth century, some of these photographs capture urban structures that were soon to disappear while others are indicators of the British attitudes towards India's antiquities and cultural heritage.

The photographs of the IAPA function as a means to document the unfamiliar physical and cultural terrain of India by its British residents during a period of aggressive imperial growth. Documenting the landscape was a natural extension of colonial practice, as W.J.T. Mitchell has observed, since the discourse of imperialism "conceives itself precisely (and simultaneously) as an expansion of landscape understood as an inevitable, progressive development in history, an expansion of 'culture' and 'civilization' into a 'natural' space in a progress that is itself narrated as 'natural."'122

Unlike the ethnographic photographs of the IAPA, which form a single coherent series and share authorship, the majority of the architectural and landscape views are divided into

\footnotetext{
122 W. J. T. Mitchell, "Imperial Landscape," in Landscape and Power, ed. W. J. T. Mitchell (Chicago: University of Chicago Press, 1994), 17.
} 
ten series of varying lengths representing the work of at least ten photographers. ${ }^{123}$ Each series depicts a single locality, and a few individual photographs were also published that do not form part of a series. While most series represent the work of a single photographer, others contain work by two or more photographers. (For a full listing of the series, their contents, and their photographers, refer to Appendix C.) Rather than describing and treating each series individually and providing an analysis of each series in order, this essay treats the photographs by discussing the various themes and motifs that run through the work as a whole.

\section{The Picturesque Aesthetic}

As discussed in the chapter "Setting the Scene: Photography in 1850s Bombay and the Origins of the IAPA," the 'picturesque' was the dominant landscape aesthetic of European photographic societies, ${ }^{124}$ and strongly influenced Bombay amateur photographers as well. Critics and writers such as the Reverend William Gilpin (1724-1804) formulated the aesthetic conventions of the picturesque that dictated the rules governing landscape representation in the late eighteenth century. Gilpin's guidebooks and essays advised the artist how to organize representations of nature. Artists operating in India including Thomas Daniell (1749-1840) and William Daniell (1769-1837) used these formulations in producing their landscape and architectural paintings. James Ryan argues that the Daniells, and other late eighteenth century artists such as William Hodges (1744-1797) "explicitly related their work to colonial exploration." ${ }^{25}$ These influential pre-photographic representations of India helped to establish a visual tradition that was subsequently adopted by photographers.

The landscape of ancient India with its crumbling temples was ripe for photographers seeking picturesque subjects, since as Roger Taylor has recently explained, "all ruins were considered picturesque, no matter how dilapidated." 126 To the IAPA photographers, India's

\footnotetext{
${ }^{123}$ Some of the work is unattributed, and some photographers chose to use pseudonyms. There is no way of knowing, for example, if the repeated use of "An Amateur" consistently refers to the same person.

${ }^{124}$ See Taylor, Impressed by Light, 3-13.

125 James Ryan, Picturing Empire: Photography and the Visualization of the British Empire (London: Reaktion Books, 1997), 47.

${ }^{126}$ Taylor, Impressed by Light, 77.
} 
ancient temples, monuments, and antiquities substituted for the ivy-clad cottages and rustic rural bridges of the British landscape. These distinctly Indian subjects were frequently depicted in the IAPA, mixing picturesque image making with antiquarian scholarship. Ruins were particularly popular subject matter for members of the Bombay Photographic Society, because, as Anne McCauley points out in a discussion of amateurs photographing the English landscape, ruins were considered to be "texturally harmonious with the surrounding vegetation, historically rich in associations, and symbolic of the temporality of life and the moral rectitude of a previous age." ${ }^{27}$

\section{Stern Fidelity: The "Pencil of the Sun"}

Although the majority of the photographs in the IAPA are informed by the picturesque aesthetic, it would be overstating the case to say that it was the overarching concern of the work as a whole. In addition to its ability to create artistic impressions, the camera was celebrated for its ability to represent the visual world with accuracy, what Reverend Joseph Mullens described in 1857 as its "stern fidelity." 28 The British East India Company felt that the architectural heritage of India was part of the material property of the empire, and therefore worth studying, documenting, and preserving. Photographic representation was viewed as being accurate and objective, and the use of photography to document architecture and produce faithful archeological notations was seen as vastly superior to subjective and potentially inaccurate hand-produced forms of representation.

As early as 1854 the Company, aiming to save on the time and expense of hiring an artist and a draughtsman to delineate antiquities, had hired Capt. (later Col.) Thomas Biggs (1822-1905) for the purpose of "obtaining representations of the Ancient Sculptures and Inscriptions of Western India by means of Photography." ${ }^{29}$ This was the beginning of the Company's policy of employing Army officers to document temples and antiquities in an official capacity using photography, replacing the visual artists the Company had previously

\footnotetext{
${ }^{127}$ McCauley, "Evasion," 5.

${ }^{128}$ Rev. Joseph Mullens, "On the Applications of Photography in India," Journal of the Photographic Society of Bengal 2, no. 21 (January 1857): 33, cited in Falconer, India: Pioneering Photographers, 8.

${ }^{129}$ Court Despatch to Bombay, No. 42 of 1855 (25 August), marginal note, India Office Records, cited in Dewan, "Delineating Antiquities," 302.
} 
employed. This program, which would eventually involve such men as Linnaeus Tripe (1822-1902) of the Madras infantry and Dr. William H. Pigou (1818-1858) of the Bombay Medical Service, was followed with interest by the members of the emerging Bombay Photographic Society. The Society members lionized Biggs, were in regular correspondence with well-known archeological documentarian Maj. Robert Gill (18041879) of the Madras infantry, ${ }^{130}$ and inquired in letters how they could replicate Dr. Pigou's techniques in their own photographs. ${ }^{131}$

The camera's growing reputation for faithful reproduction meant that, to a nineteenth century viewer, seeing a photograph of a temple was considered tantamount to visiting it in person. An artist's representation was viewed as suspect, as this contemporary account of Captain Biggs' "endeavour to obtain Photographic Fac Similes [sic] of the Caves and Temples of Western India" makes clear:

A number of oil paintings of Caves has been transmitted home, and several more, we believe, are in course of completion; but however perfect and beautiful these paintings may be in themselves, it will still remain a question, with those especially who may not have had an opportunity of visiting the places represented, how far they are to be relied upon as accurate, and how much of their details are to be set down to that peculiar species of "license" which "Poets and Painters" are proverbially partial to.

Should Captain Biggs prove successful...photography will have accomplished a stupendous undertaking, and the Court of Directors [of the East India Company] will be placed in possession of a series of Photographic views...which shall combine the truth and faithfulness of the "PENCIL OF THE SUN" with the grace and beauty of the "PAINTER'S BRUSH." 132

The IAPA photographers do not appear to have been concerned by the apparent contradiction between the sensibilities of the picturesque with its emphasis on artist-

\footnotetext{
130 JPSB no. 6 (July 1855): 103; JPSB nos. 13-18 (February - June 1856): 39.

131 JPSB no. 5 (May - June 1855): 84.

132 “Address," JPSB no. 2 (February 15, 1855): 17.
} 
mediated arrangements of nature and the "stern fidelity" afforded by the camera. Ryan observes that this discordance between accurate architectural documentation and subjective pictorial expression was common in mid-nineteenth century British landscape photography, whose practitioners "disguised their dependence on pictorial convention in order to promote photography as an objective record of sight, in the process reinscribing imperial landscape as a natural way of seeing."133

${ }^{133}$ Ryan, Picturing Empire, 47. 


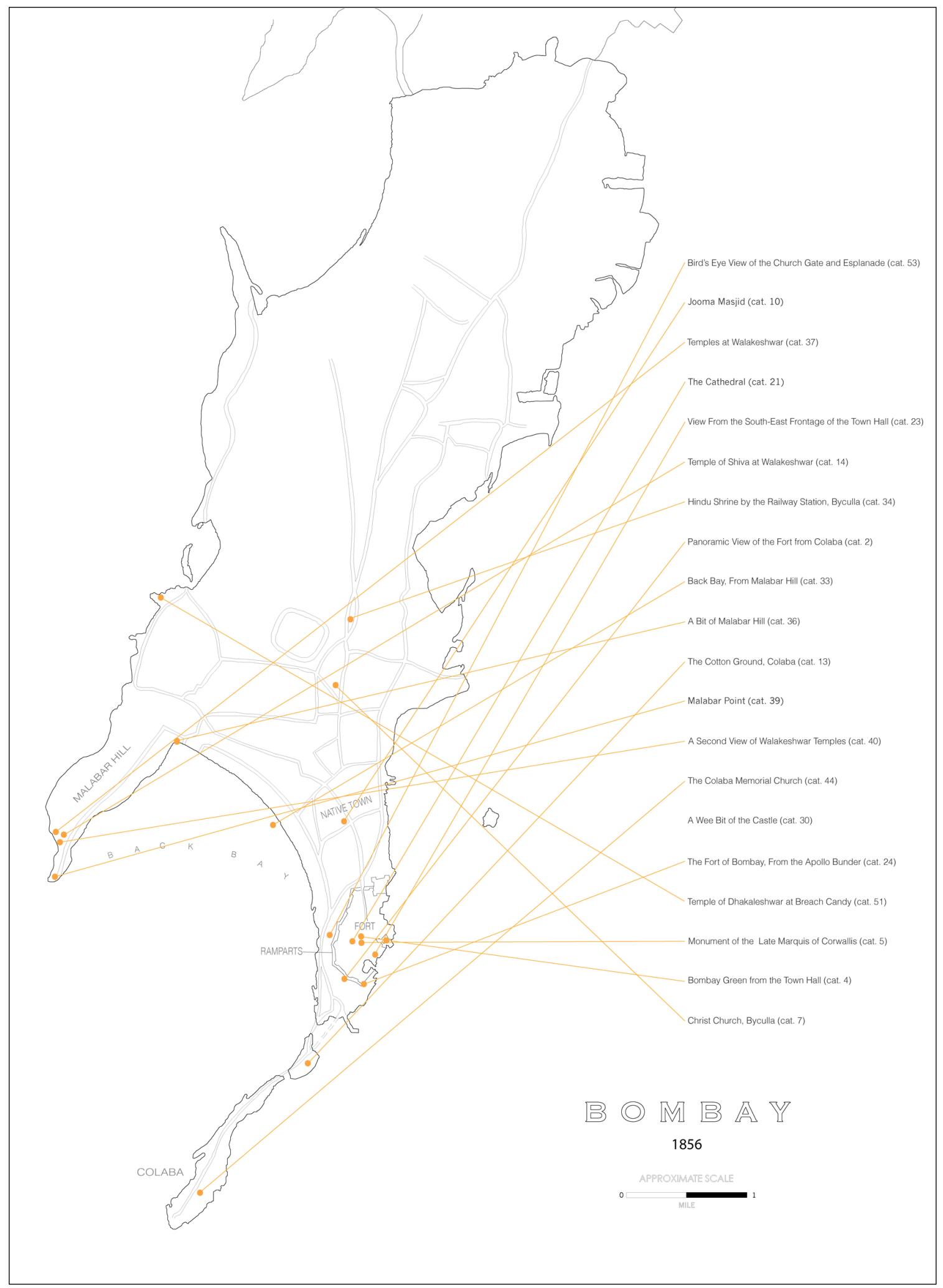

Fig. 24| Map of Bombay ca. 1856, indicating the locations of photographs in the IAPA, with the corresponding catalogue numbers. 


\section{Photographing Bombay City}

\section{British Bombay: Sites of Familiarity and Colonial Growth}

Although there are ten series depicting architectural and landscape views in and around the Presidency, the series Bombay forms the backbone of the IAPA: with twenty-one photographs by five photographers, it is the longest running and most comprehensive group of photographs. It is hardly surprising that such a large amount of the IAPA contributor's photographic efforts consist of documenting subjects that were familiar and immediately accessible. Primarily centred on the Fort Area, which was the main English settlement, the locations selected represent a distinctly colonial view of the city.

The map in figure 24 illustrates the city of Bombay in 1856, with the locations of IAPA photographs indicated. The ramparts and walls of the Fort can be clearly seen in the lower right portion of Bombay Island. This is the area of most highly concentrated photographic activity, although there are also numerous photographs documenting the area in and around Malabar Hill, and some of and around Colaba. The 'Native Town,' located to the North of the Fort area, although densely populated, is only documented peripherally, with the exception of catalogue 10, which depicts a prominent mosque there.

In the eighteenth century the entire European population lived in the Fort, and although by the 1850s some English and Europeans lived beyond the confines of its walls, most business was still conducted there. Until the ramparts and its surrounding moat were removed in 1862-63, the Fort was physically separated from the rest of the city, and its

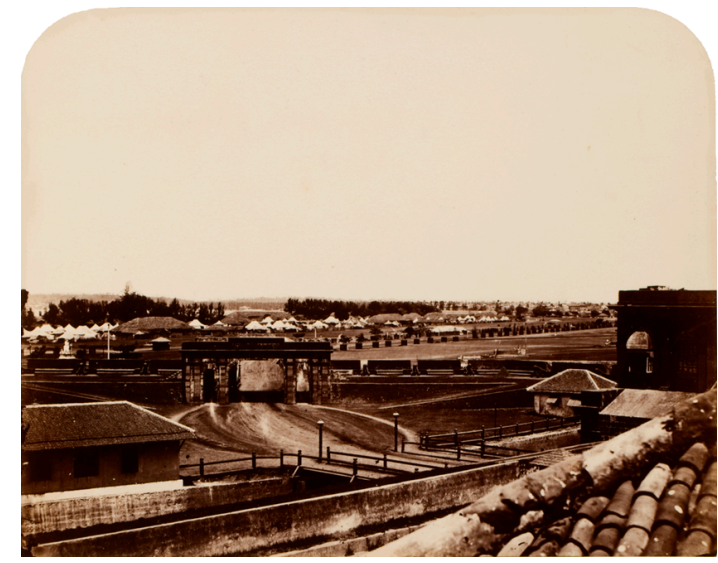

Fig. 25| Dr. G. R. Ballingall, Bombay no. 1-Bird's Eye View of the Church Gate and the Esplanade, from the Bank of Bombay (Catalogue 53).

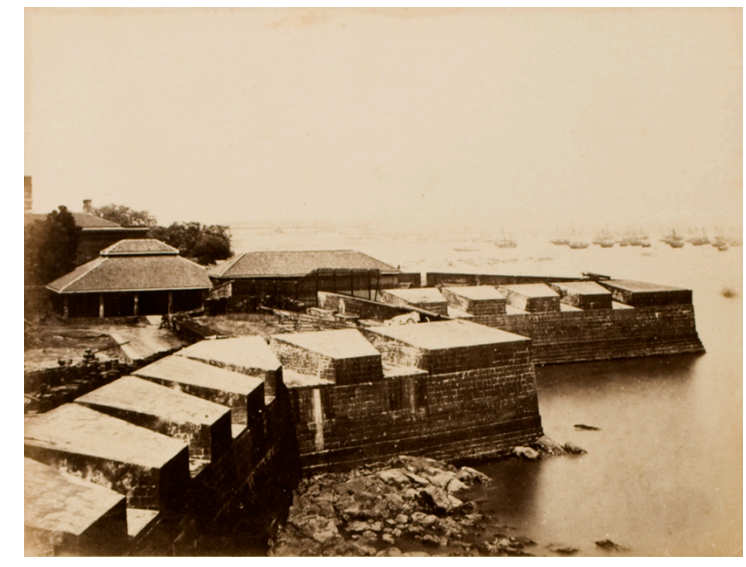

Fig. 26| An Amateur, Bombay no. 9-A Wee Bit of the Castle (Catalogue 30). 
interior was crowded with homes, businesses, and civic and government buildings. The photographs in catalogues 2, 24, 30, and 53 all document various aspects of the Fort's exterior.

Two such photographs, Bird's Eye View of the Church Gate and the Esplanade, from the Bank of Bombay (catalogue 53) [figure 25], and A Wee Bit of the Castle (catalogue 30) [figure 26] clearly emphasize the strength of the fortifications. Catalogue 53 illustrates one of the few entrances to the Fort. The Esplanade beyond it, which was kept clear of construction in order to provide a clear line of fire for the fort's cannons, is seen littered with military tents, while the native quarter is barely visible on the far right edge of the frame. Dr. G. R. Ballingall's decision to photograph the scene from above allows him to incorporate many elements of military potency into a single frame, and clearly depicts Bombay as a European construction dominated by its military, and physically divided into British and native portions. Catalogue 30 reinforces this idea of strength even further by allowing the walls of Bombay Castle, the seat of government, to occupy so much of the frame, depicting the fortified castle walls as impenetrable and imposing.

The focal point and most prominent feature of the Fort's interior was an open space known as The Green, a public space used for recreation and meetings, as well as commerce. The Town Hall, the meeting place for the Bombay Photographic Society, was located on the perimeter of the Green, and the area in and around the Green features prominently in the work of IAPA photographers, as seen in catalogues 4, 5, 21, and 23.

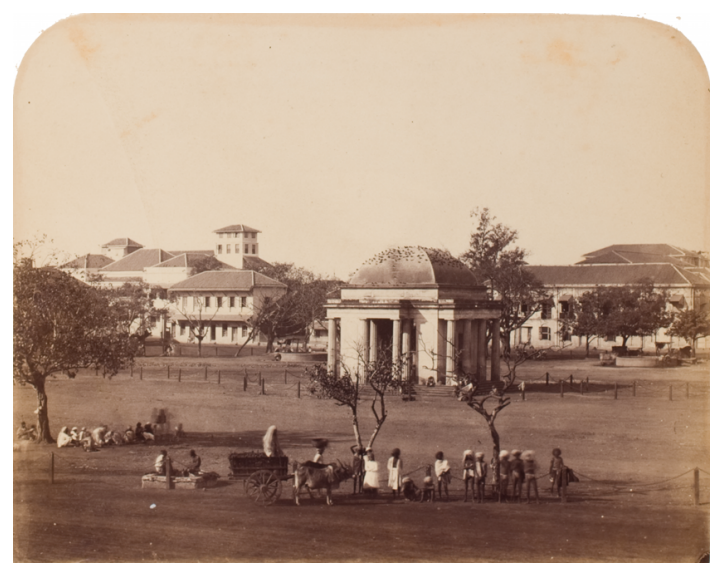

Fig. 27| A. Z. (Albert Zorn?), Bombay no. 3-Monument to the Late Marquis of Cornwallis, Governor General of India (Catalogue 5).

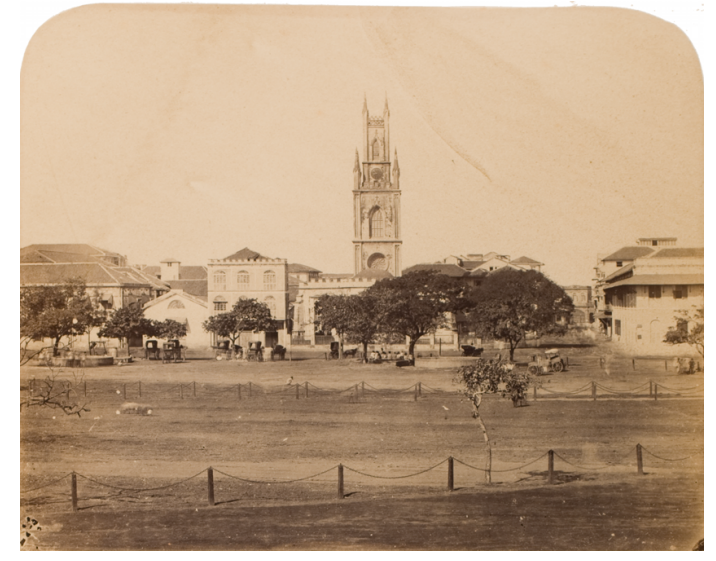

Fig. 28| Johnson and Henderson, Bombay no. 2-Bombay Green from the Town Hall (Catalogue 4). 
When viewed together, the photographs Monument of the Late Marquis of Cornwallis, Governor General of India (catalogue 5) [figure 27], and Bombay Green from the Town Hall (catalogue 4) [figure 28], provide a slightly overlapping panoramic view of the buildings surrounding the Bombay Green along the western side. Taken from the steps of the Town Hall, the two photographs clearly depict the chains that surrounded the Green's open space as well as the monument to Cornwallis (in the centre of catalogue 5), and St. Thomas' Cathedral (in the centre of catalogue 4). Groups and clusters of Indians can be seen in both photographs, huddled in the shade of the tamarind trees or standing watching the photographer. To the British inhabitants of Bombay in the 1850s this view would have defined life in the Fort, and represented the centre of social and business activity.

The 1860s brought economic prosperity and massive growth to Bombay resulting in significant changes to the city's appearance. Many of the early colonial structures vanished as the small trading outpost began its gradual transformation into the massive overpopulated metropolis that it is today. However, the utilitarian and plain building style seen in catalogues 4 and 5 was to dominate the cityscape of Bombay until later in the century, when the "dull uniformity in architecture"134 was replaced by the neo-Gothic and neo-Saracenic styles that would come to define the modern city of Bombay and still defines the historical sections of Mumbai.

\section{Imperial Economies: Sites of commerce}

Perhaps the most manifest displays of the colonial viewpoint are the photographs depicting the English sites of industry. Cotton, opium, and shipbuilding were the primary sources of income for the trading city of Bombay in the 1850s, and photographs such as catalogues $2,13,23$, and 24 depict various aspects of these activities.

The Cotton Ground, Colaba (catalogue 13) [figure 29] illustrates the extent of trade in "the principal article of exportation from Bombay." 135 Visually representing the significance of the cotton trade through sheer overwhelming, mountainous evidence, catalogue 13 portrays "the large open space in the rear of Grant Buildings... as it appears during the

\footnotetext{
134 Bayly, "From Company to Crown," 133.

${ }^{135}$ IAPA no. 5 (March 1857): n.p.
} 
season, with its piles of bales, its temporary office sheds, and other appurtenances of the traffic." ${ }^{136}$ The bales of cotton, each stuffed to overflowing, fill the courtyard defined by the surrounding buildings, while the large scales used for weighing the bales dot the landscape. The heyday of Bombay cotton, which eventually defined the city by transforming it economically, did not occur until the outbreak of the American Civil War, but catalogue 13 indicates that it was already a significant commodity in the 1850s, as "from about Christmas to the setting of the Monsoon rains, the bustle and uproar are seldom intermitted." 137

Panoramic View of the Fort from Colaba (catalogue 2) [figure 30] describes the south side of the Fort's exterior, viewed from the island of Colaba. In this one photograph, Johnson and Henderson have managed to encapsulate the very essence of Bombay as a colonial city with its associated industries, defences and fortifications, symbols of Christianity, and trappings of power, succinctly displaying the iconography of the British presence in Bombay. The accompanying letterpress reads:

Here we have brought in one view to the eye and the mind Bombay Fort and its associations-the wall with moat under it, vellard, cotton-bales, dockyard, steam factory and logs of teakwood, Indian Navy club, mercantile houses, saluting battery, English and Scotch churches. Such is Bombay, historical and actual.... Bales and

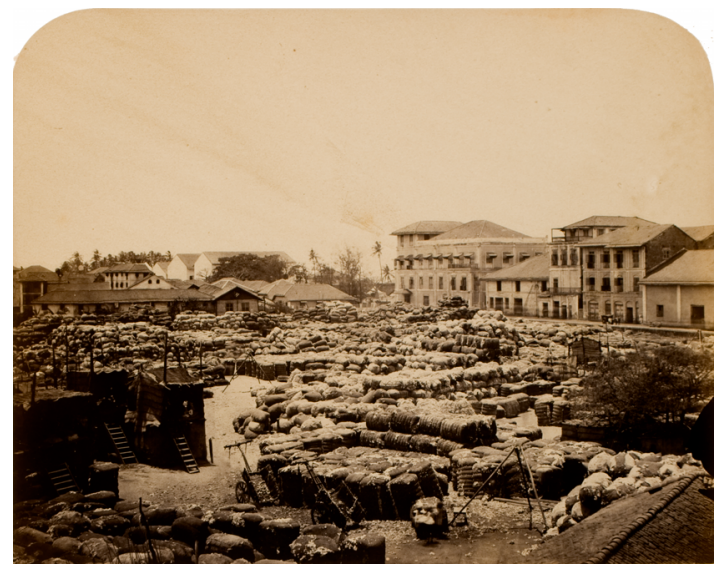

Fig. 29| Johnson and Henderson, Bombay no. 6-The Cotton Ground, Colaba (Catalogue 13).

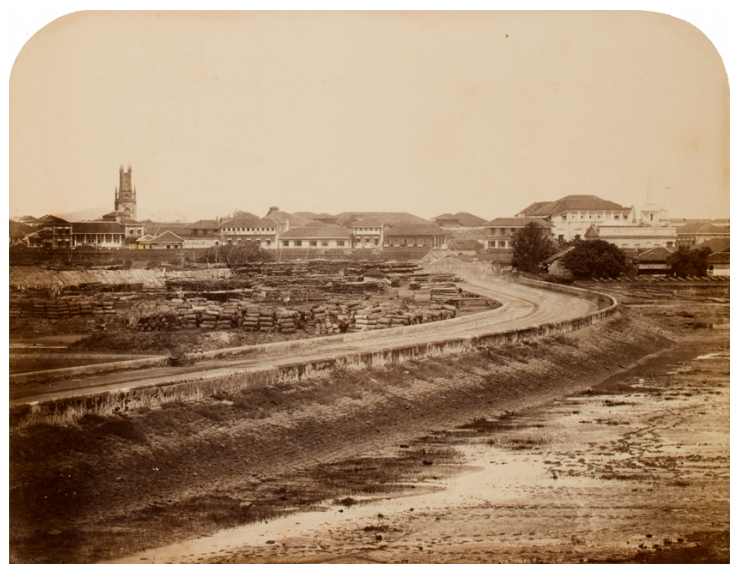

Fig. 30| Johnson and Henderson, Bombay no. 11Panoramic View of the Fort from Colaba (Catalogue 2).

\footnotetext{
${ }^{136}$ IAPA no. 5 (March 1857): n.p.

${ }^{137}$ IAPA no. 5 (March 1857): n.p.
} 
piles of timber suggest that Bombay has risen to celebrity by exporting cotton and building ships; the Factory and Club, that her ships are at last propelled by steam and officered by gentlemen, who wear fine uniforms and drink champagne.... Taken as a whole the place has not a picturesque, but commercial appearance; it looks like the home of mercantile England in India, seems to say that the British are here for a purpose-that purpose being to do a stroke of business for themselves, whilst they placed their industry, skill, enterprise, order, good-government, knowledge, and religious truth at the service of India. Well will it be for her if she make use of them, instead of rebelling, plundering, and destroying. They may some day restore her to that position in the comity of nations, which, two thousand years ago, made her an object of envy to the civilized world. ${ }^{138}$

The photographs provide confirmation of great colonial prospects, and suggest that under British rule the previous glory of past empires could be restored. The positive contributions of the British involvement in India is a recurring theme in the texts of the IAPA, which imply the right and duty of the British to rule and to profit, while simultaneously improving the Indian subcontinent. Such blatant boosterism functioned as selfaggrandisement to the British, and provided post-mutiny validation of their colonial presence.

\section{Picturesque city}

The city of Bombay, despite its growing stature, was far from being as densely built up and urban as the current city of Mumbai, and afforded possibilities to the photographer seeking picturesque landscape views. Three views in and around Malabar Hill, Back Bay, from Malabar Hill (catalogue 33) [figure 31], A Bit of Malabar Hill (catalogue 36), and Malabar Point (catalogue 39) [figure 32] apply this aesthetic. The view shown in catalogue 33 depicts a Bombay in which nature has not yet been overtaken by the city, employing nuanced layers of light and dark between the hills and the sky to produce contrast. The hills recede into the distance, and the irregular shapes of fishermen's traps form a pronounced foreground element, both deliberate hallmarks of the picturesque. Extensive coconut groves encroach on the few English bungalows that can be seen. The houses of the Native

\footnotetext{
${ }^{138}$ IAPA no. 11 (September 1857): n.p.
} 
Town are barely visible in the background and seem to form part of the landscape, while the mountains of the Western Ghats rise beyond that. The description in IAPA no. 11 implies that while the beauties of nature are worth contemplating, they exist in harmony with the contributions of British colonial infrastructure:

It is a beautiful part of a beautiful island; one of the fairest scenes in this land of the sun. The charms are those of Nature condescending to put on ornaments that man has presented her with. The sun, the sea, the mountains, are hers; the roads and scattered habitations owe their origin to the fostering beneficence of British rule. ${ }^{139}$

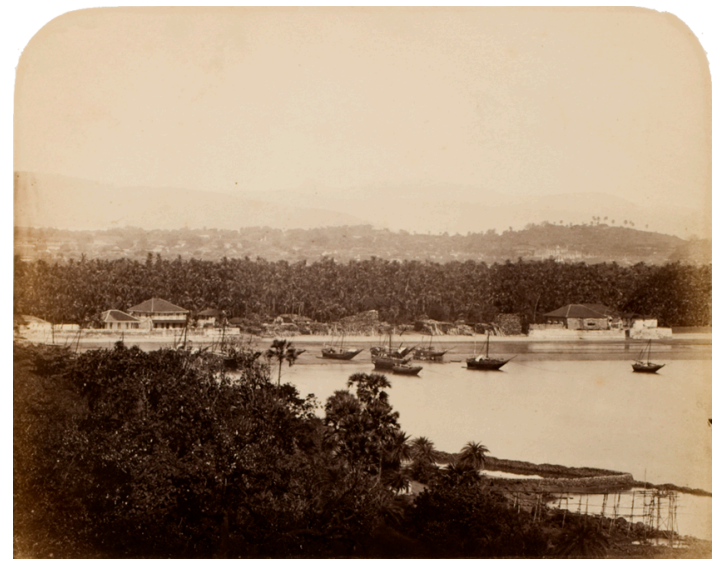

Fig. 31| Johnson and Henderson, Bombay no. 12-Back Bay, from Malabar Hill (Catalogue 33).

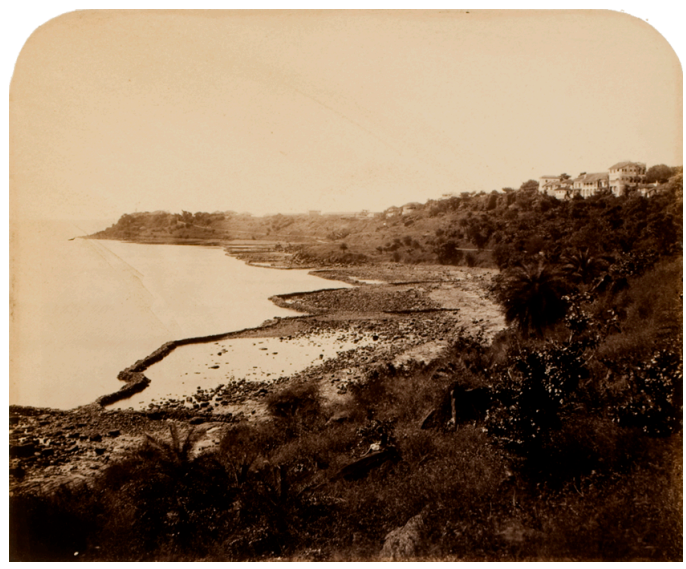

Fig. 32| Johnson and Henderson, Bombay no. 15Malabar Point (Catalogue 39).

The description of catalogue 36 also alludes to the picturesque beauty of Malabar Hill:

Few spots in the world are more picturesque than this during the rainy season. Here is observed a natural scarp, there are massive boulders; all varied with direct and climbing shrubs, and as festooned with the most elegant creepers. The prospect at such a time, when the sun and cloud struggle each to make its own lights and shades, and the distant shower sweeps across the ruffled sea, to scatter its last gems over the heads of the everlasting hills, is surpassingly magnificent. ${ }^{140}$

\footnotetext{
139 IAPA no. 12 (October 1857): n.p.

${ }^{140}$ IAPA no. 13 (November 1857): n.p.
} 


\section{Native Bombay}

Although the photographs of British Bombay portray the constructions produced by the English as progressive and industrious, depictions of Indian buildings are restricted to places of worship, usually selected for their picturesque and exotic qualities. Although they are respectfully portrayed, they are often less than favourably described. There are no depictions of the Native Town, and few attempts to represent Indian life or to represent a thriving local culture. Although the ethnographic work discussed previously suggests a British fascination with the people of India, its reliance on stereotyped visual representations depicts them as belonging to a culture stuck in the past. There is little in the architectural photographs to depict India as a living culture, or to connect its people with the spaces they occupy in the city. Of the twenty-one photographs depicting Bombay, there is one photograph of a mosque (catalogue 10), and four photographs of temples (catalogues 14, $34,37$, and 40,51$)$.

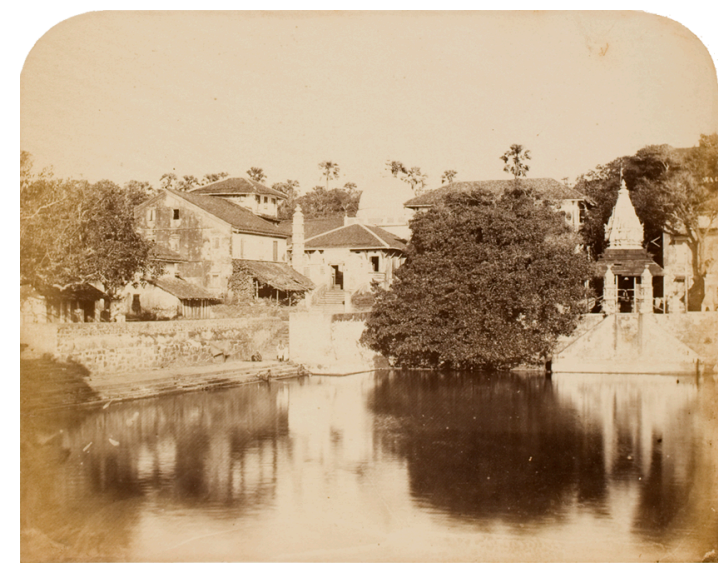

Fig. 33| Johnson and Henderson, Bombay no. 14Temples at Walakeshwar (Catalogue 37).
Catalogues 14, 37, and 40 describe the temple complex of Walkeshwar at Malabar Point, clustered around the Banganga bathing tank depicted in catalogue 37 [figure 33]. It was, and still is, used by Hindus for ritual washing, causing Johnson and Henderson to note in the accompanying letterpress, "the locality, though somewhat picturesque, is not salubrious, especially to parties using the dirty and stagnant water of the 'holy' tank,

in which bodily ablutions are constantly practiced."141 In catalogue 37 the reflection in the still water of the tank forms the most significant compositional device, and the temples are reduced to a picturesque view more concerned with an aesthetic response than a religious one.

${ }^{141}$ IAPA no. 14 (December 1857): n.p. 


\section{Protestant Architecture}

India is a land filled with temples and mosques, representing the multiple faiths of Hinduism, Islam, Jainism, Buddhism, Sikhism, Judaism and Zoroastrianism. The multiple depictions of Protestant churches in the IAPA in catalogues 4, 7, 21, 44, and 54, photographed in a frontal and direct manner, form a stark contrast with the picturesque views of the Walkeshwar temples [figure 33]. These icons of Protestant belief would have been powerful symbols to the English, representing oases of civilization among what was perceived of as the heathen natives. The Colaba Memorial Church (catalogue 44) [figure 34]

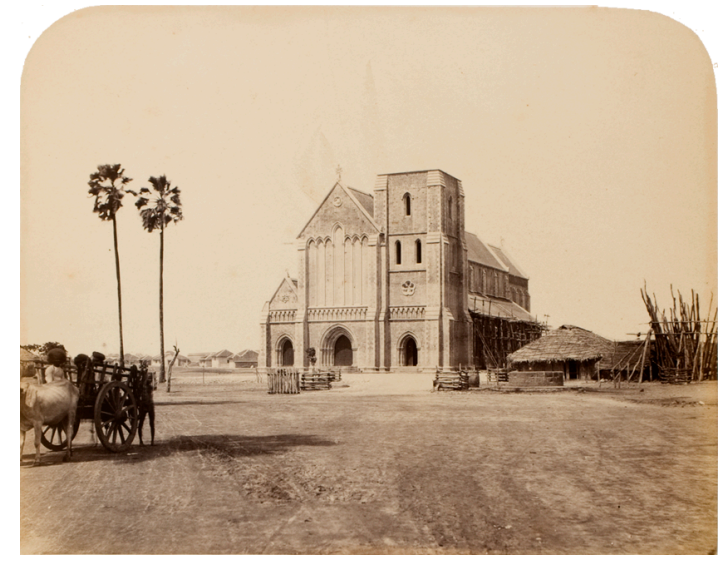

Fig. 34|William Johnson, Bombay no. 17-The Colaba Memorial Church (Catalogue 44).

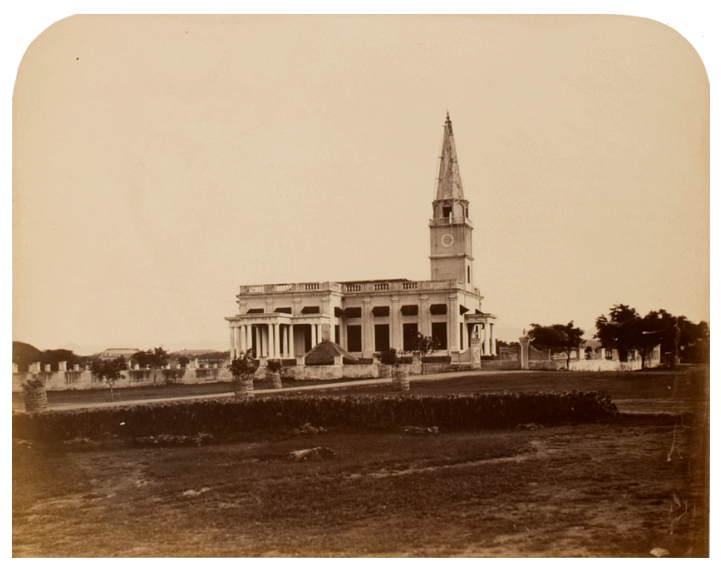

Fig. 35| Henry H. Hinton, St. Mary's Church, Poona, (Catalogue 54).

appears to be emerging directly from the ground. Otherwise known as the Afghan Church, it was built to commemorate the British soldiers based in the Presidency who had died in the disastrous First Anglo-Afghan War of 1839-1841. As a physical reminder of the losses suffered at the hands of the Afghans while attempting to exert strategic gains over the Russians, it serves as both a memorial of past defeat and a solid reminder of emerging British supremacy in India. Similarly, St. Mary's Church, Poona (catalogue 54) [figure 35], erected shortly after the British victory in Poona and intended to serve the military garrisons stationed there, functions as a symbol of the expansion of British military power into the Bombay Presidency. It is built on a hill, providing it with "a full view of the Lines of the European Regiments of Foot and Artillery." ${ }^{142}$

\footnotetext{
${ }^{142}$ IAPA no. 19 (May 1858): n.p.
} 


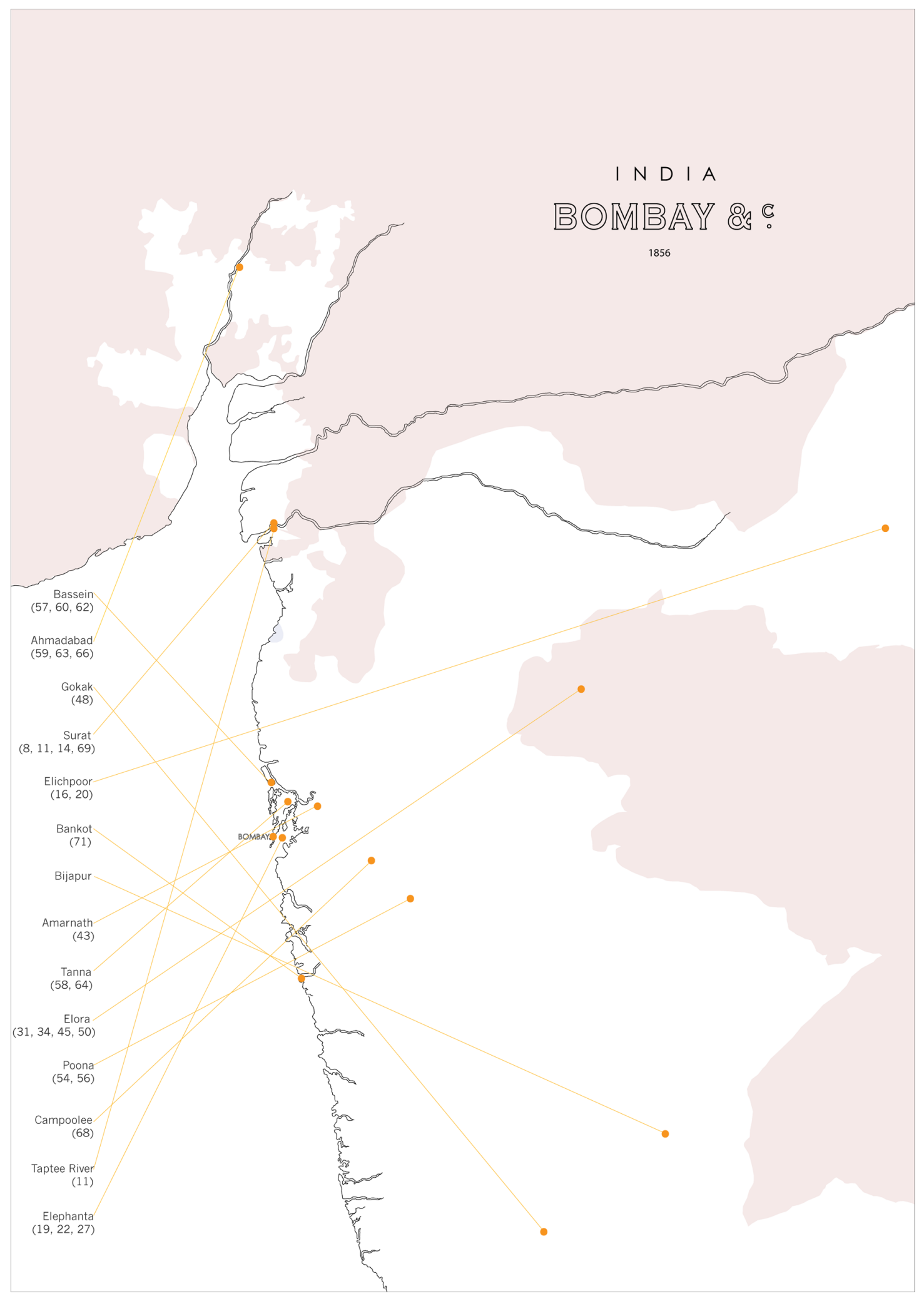

Fig. 36| Map of Bombay Presidency ca. 1856, indicating locations of photographs published in the IAPA. Areas under British control are marked in white. Numbers in brackets refer to the catalogue. 


\section{Photographing Bombay Presidency Mapping Traces of Empire and Sites of Decay}

By the mid-nineteenth century the British presence in India represented near-complete domination and control. In the preceding centuries though, there were multiple competing commercial and colonial interests including the French, Dutch, and Portuguese, as well as the Mughal and Maratha Empires, and countless feudal states. By documenting the cumulative marks left by previous imperial powers, each with the same objective of territorial domination, the IAPA photographers appear to affirm the more recent authority of the British occupation of India. The recurring motif of presenting ancient and past glories hidden beneath subsequent decay is seen in the many representations of Portuguese cathedrals, neglected Hindu temples, and Dutch and English tombs from the early days of the East India Companies.

The map in figure 36 illustrates the Bombay Presidency in 1856, with the locations of IAPA photographs indicated. Elephanta, Poona, Campoolee, Tanna, and Amarnath are relatively close to the city, while Elora, Ellichpoor, Surat, and Ahmadabad are located significantly further away from the city of Bombay.

\section{Amarnath and Gokak: Picturesque Indian Antiquities}

Whether motivated by a preservationist instinct, an interest in local history and antiquarianism, or simply to produce a series of picturesque views, photographs of the ancient temples of India were popular among the members of the Bombay Photographic Society, and several examples appear in the IAPA. Among these are the photographs The Temples of Amarnath by Archibald Robertson (catalogue 43) [figure 37] and Ancient Temple at Gokak by A.Z. ${ }^{143}$ (catalogue 48) [figure 38]. Dilapidated and picturesque, these temples bear the marks of time, and were ideal locations for amateur photographers to practice their art.

The temple of Ambernath, which had only recently been "particularly noticed by Europeans," but which now "deservedly attracts much attention," has "suffered much both from the hand of violence, and the no less destructive hand of time" and functions in a dual

\footnotetext{
143 Janet Dewan speculates that the acronym A.Z. stands for Albert Zorn, based on a record in the Bombay Almanac bearing the same combination of initials. Dewan, "Sun Pictures," 121.
} 
capacity "to gratify the curiosity of both the artist and the antiquary." 144 Robertson's depictions of the temple appeared in IAPA no. 15, which promised two photographs, although both the GEH and Newberry collections contain only one, each slightly different. ${ }^{145}$ The two images differ by a slight shift in composition and vantage point, and the use of Indian figures for staffage, which appears in only the Newberry version. The large tree to the left of the temple is a prominent part of the composition and both it and the small figures in the landscape draw the viewer's gaze into the photograph and provide a balanced and 'natural' composition, which along with the inclusion of an ancient monument fulfills the requirements of the picturesque aesthetic.

Part of the appeal of photographing locations such as Ambernath and Gokak is that they were not easy to get to. Photography became as much an exploration as an art, and dedicated expeditions to difficult to reach parts of the Presidency were required to produce work. Photographs of Ambernath were noted at the time not only for their technical qualities and their pictorial elegance, but also for the travails of the photographer who produced them. In an article reviewing the 1856 exhibition at the Bombay Photographic Society, a photograph of the temple by Society member Dr. G. R. Ballingall was praised for all of these reasons:

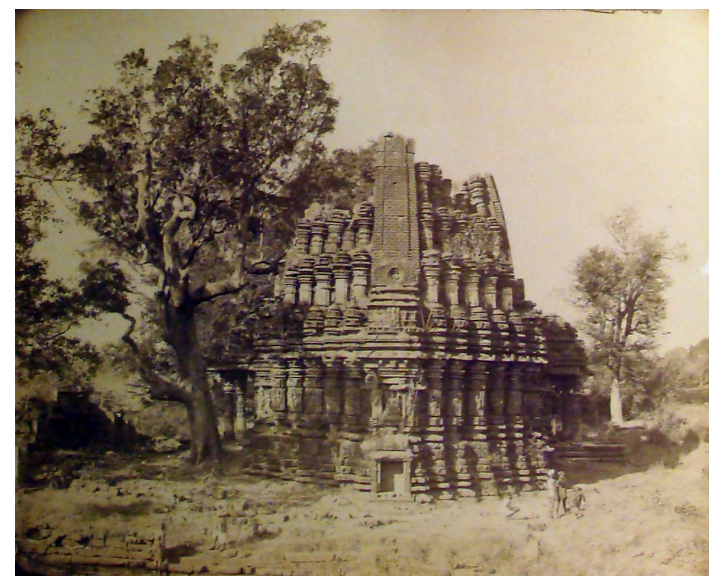

Fig. 37| Archibald Robertson, The Temple of Amarnath. Newberry Library Collection.

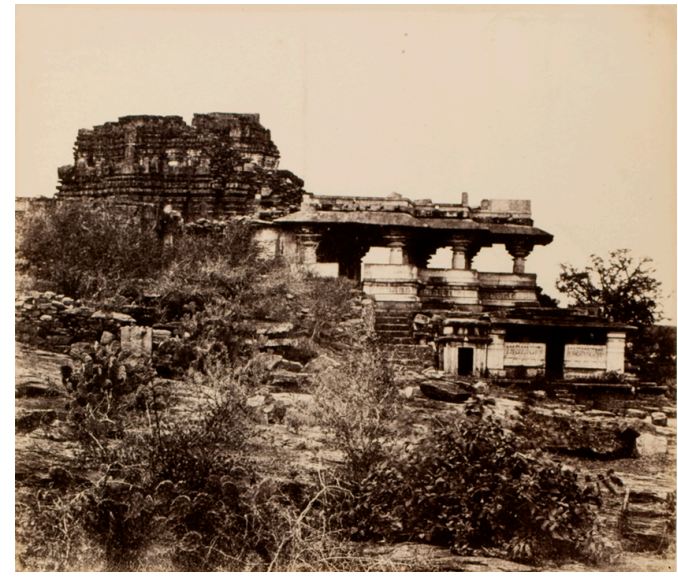

Fig. 38| A. Z. (Albert Zorn?), Ancient Temple at Gokak (Catalogue 48).

${ }^{144}$ IAPA no. 15 (January 1858): n.p.

${ }^{145}$ Although the Newberry and GEH versions (catalogue 43) of this image are different, it is unclear if these are the two photographs described in the letterpress, or if they are these simply variants of one the views. Comparison with another collection of IAPA photographs would bear this out. 
Those who know the difficulties of approach to Umbernath, and the many difficulties in working there, will readily understand that no one but one well skilled in the art could have produced so favourable a specimen of that celebrated but now fast decaying monument of Hindoo worship. ${ }^{146}$

\section{Bassein: Picturesque Ruins, Faded Colonial Splendour}

Catalogues 57, 60, and 62 form part of a series depicting the former Portuguese settlement of Bassein. Located only fifty kilometers north from Bombay, the sixteenth and seventeenth century ruins of Bassein are treated as decrepit ruins rather than evidence of a former power, and "afford many inviting scenes for the photographic art." ${ }^{147}$ Although Bassein had been an important Portuguese colony and trading centre for over 200 years, the IAPA's letterpress suggests that the photographers are more interested in the visual qualities of the city's "fortifications, ...numerous Churches, Convents, Seminaries, and other public buildings, for the picturesque ruins of which, clasped in the arms of the banyan-tree and festooned by creeping plants, it is now so remarkable."148

Catalogue 60 [figure 39] represents the ruins of an old Portuguese church whose roof has collapsed from neglect. Despite stating, "it is not for us, as artists, to pronounce a

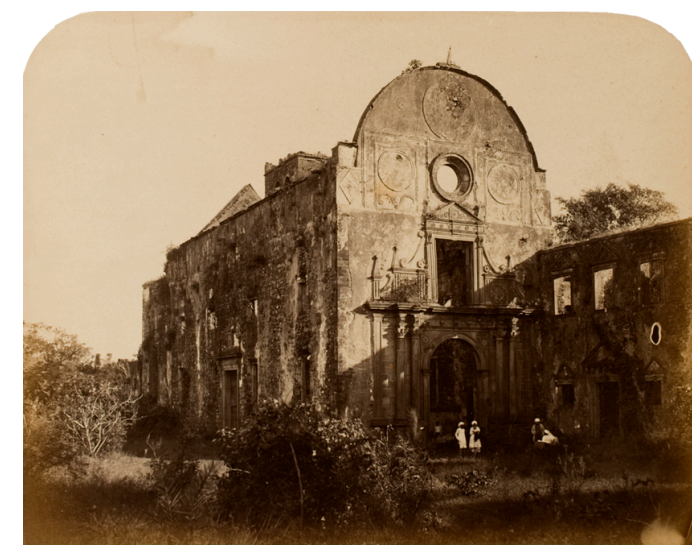

Fig. 39| William Johnson Bassein no. 2-The Church of St. Paul (Catalogue 60).

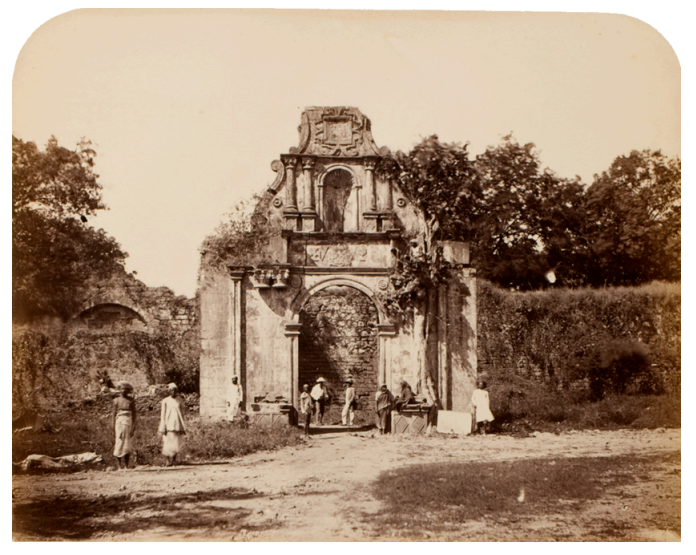

Fig. 40| William Johnson, Bassein no. 3-The Main Entrance into the Inner Fort (Catalogue 62).

\footnotetext{
146 "Cursory Notes Taken at the Exhibition of Photographs, Bombay, February 1856," JPSB 13-17 (February - June 1856): 26.

147 IAPA no. 20 (July 1858): n.p.

${ }^{148}$ IAPA no. 20 (July 1858): n.p.
} 
judgement on the question of principle and practice" of the Catholic former rulers, the author of the descriptive text cannot help but assert his Protestant moral superiority. He clearly does not approve of Catholicism, and denigrates the religious practice of the Portuguese "who were not, like the Protestant English, contented in the first instance with places of meeting for the spiritual worship of God... but who sought for sacred edifices for sacred images and sacred masses and oblations from the very beginning." ${ }^{49}$

The inclusion of native people as staffage in colonial photography was a common practice, but is not frequently employed in the IAPA, making the photographs of Bassein particularly notable. The two English men in catalogue 62 [figure 40] appear confidently in the centre of the arch, while the half dozen or so Indians are scattered throughout the frame, posed stiffly and directly facing the camera. The use of the figure in these three photographs demonstrates the photographer's ability and willingness to manipulate the Indians to stand where they wanted them in the interests of better picture making and photographic composition.

\section{The Colonial Occupier as Photographer}

Under the British East India Company's administration India became increasingly connected as the railway was developed and expanded, and the telegraph and postal systems were introduced. Landscape photography in the IAPA can be tied in with imperial expansion, and in some cases can be associated with military power, topographical surveying, and the construction of the railroad. Three photographers in particular, Capt. Allan N. Scott, H.D. Rae, and Arthur A. Jacob, are emblematic of this aspect of colonialism. Capt. Scott was a soldier in the Madras infantry, Rae was an Assistant Superintendant with the Guzerat Revenue Survey, and Jacob worked as a civil engineer for the Bombay, Baroda, and Central India Railway Company. Their positions would have provided them with the opportunities to access landscapes and monuments that were beyond the easy reach of the Bombay Photographic Society members confined to the city. Collectively they contributed a large amount of the work from Surat, Ahmadabad, Elora, and Ellichpoor - the furthest reaches of the Bombay Presidency (catalogues 11, 16, 17, 20, 31, 45, 50, 59, 60, $63,65,66$, and 69).

${ }^{149}$ IAPA no. 21 (July 1858): n.p. 
Rae's task was surveying the land in Guzerat State for the East India Company, establishing boundaries, registering the state's occupants, and fixing taxes based on local soil and water conditions. This position enabled him to document the abundant remnants of the Mughal Empire that are found in that state (catalogue 59,63, 66), as well as previous English settlements at Surat built in a characteristically Muslim style (catalogue 69). The buildings and monuments of the Mughal Empire are not only distinctive, in some ways they had come to define Indian architectural style by the mid nineteenth century to many westerners. Depicted as isolated, desolate, and abandoned, there is no evidence of the thriving population that Rae was there to survey. Rae's documentation of Mughal architecture in and around Ahmadabad [figures 41 and 42] is reminiscent of the style practiced by Col. Biggs, and he largely forgoes the picturesque in favour of the literal and the descriptive, producing frontal, readily comprehensible views.

Scott's involvement with the military placed him in various locations around India, many of which were remote and would have been difficult to access for the average amateur photographer from Bombay. His numerous contributions ${ }^{150}$ of photographs of cave temple architecture and the details of antiquities and monuments from locations such as Ellichpoor (catalogue 16 and 20) and Elora (catalogue 17, 31, 45, and possibly 50) ${ }^{151}$ provide a

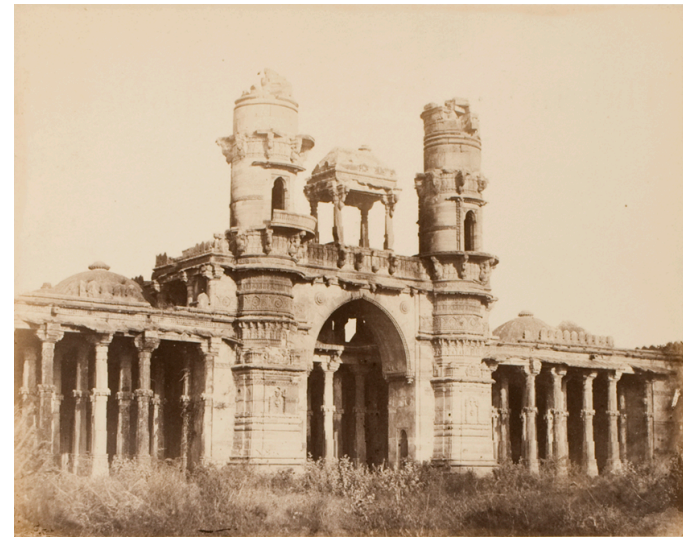

Fig. 41|H. D. Rae, Ahmadabad no. 1-The Masjid of Alimpura (Catalogue 59).

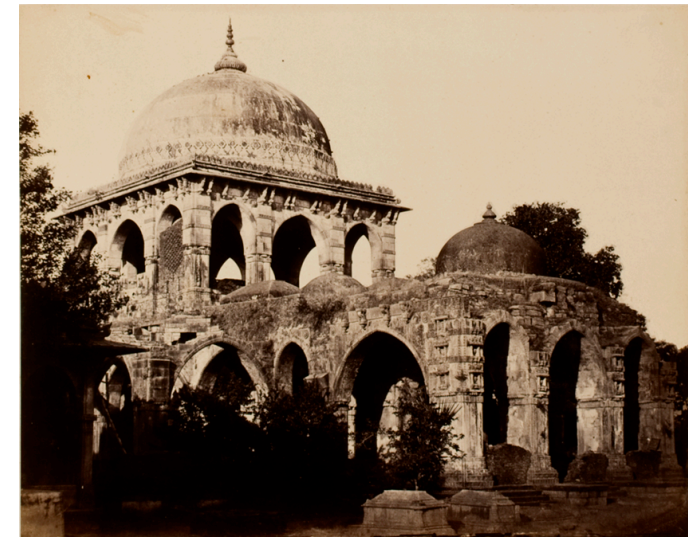

Fig. 42| H. D. Rae, Ahmadabad no. 2-The Gambaj of Ganj Bakshi (Catalogue 63).

\footnotetext{
${ }^{150}$ Scott is referred to as "a zealous contributor" by the publishers in IAPA no. 12.

${ }^{151}$ Catalogue 17, Entrance to the Monumental Temple of Kailas at Elora, is attributed to 'J. N. S.' in the IAPA. Since this is the only time that J. N. S. appears, and since the photograph forms part of the series of the Kailas temple at Elora by A. N. S. (Allan Newton Scott), it seems likely that these photographs are all by Scott.
} 
glimpse into India's past glory that would have been nearly impossible for most to view in person, due their remoteness. In a review of IAPA photographs in The Photographic News of 1859 , Scott's work is singled out as "a good example of what can be done by this art to rescue from "the tooth of time and the razure of oblivion" the monuments which abound in India of past greatness, and a zealous though deluded and misdirected piety." ${ }^{152}$ Figures 43 and 44, depicting various components of the vast complex of cave temples at Elora, typify the colonial photographic practice of capturing the archaeological remains of ancient civilizations, in which the monuments are part of an empty and desolate space, both spatially and temporally beyond the realm of modern civilization.

\section{Documenting the Emergence of the New Empire}

In addition to photographs documenting the traces of former English and European empires, the IAPA features three photographs that form a small but significant component depicting the newly constructed infrastructure of the ever-expanding East India Company's consolidation of portions of India. These photographs are significant as documents reflecting the enthusiasm India's British residents had about the colonial progress of the nineteenth century, as well as the pride they felt in the strength of English technical ingenuity and knowhow.

Jacob was involved in the design and construction of an important north-south railway line running between Bombay and Baroda, connecting the city with the rest of Western India and providing an artery essential for the transportation of troops, supplies, and trade

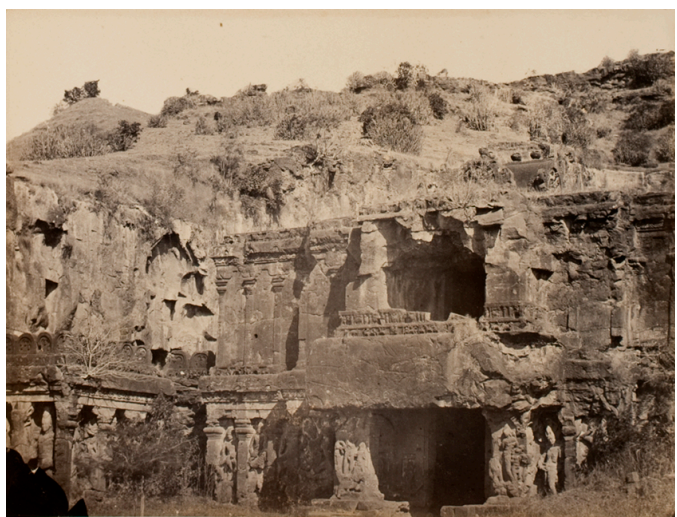

Fig. 43| J. N. S. (Capt. Allan N. Scott?), Entrance to the Monolithic Temple of Kailas at Elora (Catalogue 17).

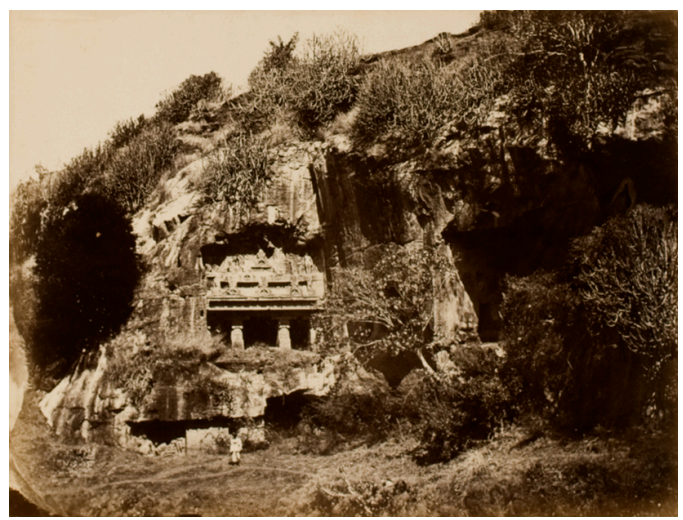

Fig. 44| Capt. Allan N. Scott, Entrance to One of the Smaller Excavations at Elora (Catalogue 31).

152 "Photography in Western India," The Photographic News 1, no. 23 (February 11, 1859): 265. 


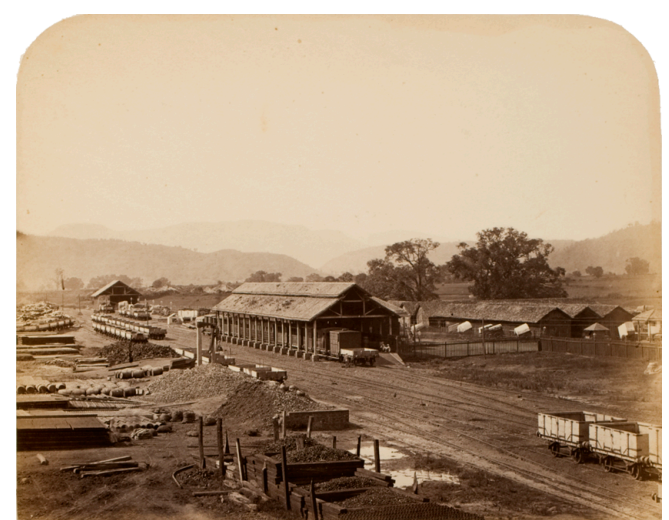

Fig. 45| Unidentified Photographer, Campoolee (Catalogue 68).

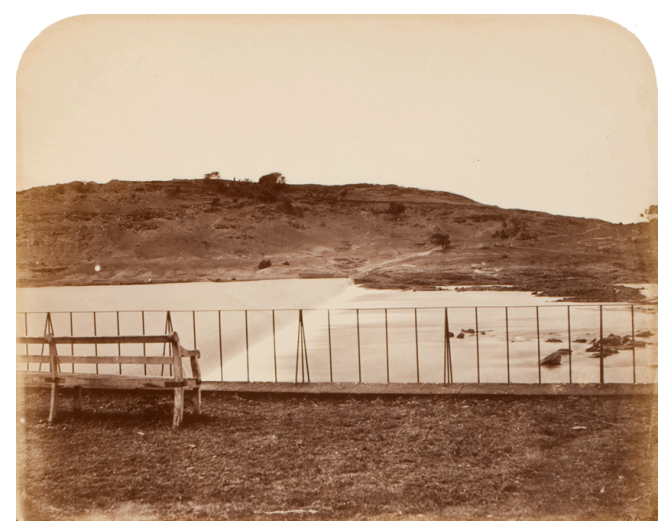

Fig. 46| Henry H. Hinton, Poona no. 2-The Jamsetjee Bund (Catalogue 56).

goods. This construction greatly expanded the reach of colonial authority while simultaneously strengthening Bombay's trading position by connecting it to the rest of the subcontinent. The railroad was seen both as a symbol of British cultural superiority and an indicator of colonial progress, and while overseeing its completion, Jacob was able to capture this spirit of progress in his photography. In the letterpress accompanying the photograph A Scene on the Bombay and Baroda Line of Railway Jacob describes a stretch of the railway currently under construction: "When the extensions of the Bombay and Baroda Railway are finished, an English Army will be able to leave London and reach the Bolan Pass in six weeks." 153

Jacob was not the only photographer providing imagery of colonial infrastructure to the IAPA. Catalogue 56 [figure 45] depicts a sluice gate near Poona constructed at great expense by the Bombay Engineers after several previous attempts had failed. Catalogue 68 [figure 44] illustrates the railway station at Campoolee, at the base of the Bhore Ghaut incline. The construction project on the incline, a tremendous engineering feat intended to "surpass in magnitude every undertaking of the same nature in the world," was essential to building the railway line connecting Bombay with Poona. The photograph's description captures the enthusiasm for the colonial project, reflecting the certainty that the British expansion into the country was sure to be a success, and in the process the town of

${ }^{153}$ IAPA no. 8 (June 1857): n.p. 
Campoolee was bound to "rise into a place of considerable importance," following the "completion of the railway works above the Ghaut."154

\section{Conclusion}

Architectural photographs and views describing the urban and rural landscape, including Indian temples and antiquities, faded empires of the past, and expanding and developing colonial infrastructure form the bulk of the IAPA. Unlike the ethnographic portraits discussed previously, which form a tight and conceptually united series by the same photographers, the diversity of architectural and landscape imagery by multiple photographers suggests a less programmatic and more open-ended body of work. The vast number of architectural and landscape views published in the IAPA, reflecting the output of many photographers working in different styles and to divergent ends, is indicative of the importance such imagery held for both the photographers and their intended audience.

The British imperial project resulted in the expansion of their empire, which the IAPA photographers explored, mapped, and recorded through the use of photography by documenting both the city and the Presidency of Bombay. Whether capturing familiar locations of English urban life and representing India as a culturally thriving and modern imperial place, or documenting the remote temples of an ancient civilization and depicting a picturesque and monumental space belonging to the past, colonial attitudes can be seen in the photographs of the IAPA both in the choice of subjects and the manner in which those subjects are depicted and described. As products of India's colonial residents, they present a fascinating look at what the British felt to be worthy of documentation and display.

Through their inclusion and publication in the IAPA, these scenes were captured for sale to an audience in Bombay and presumably the wider colonial world beyond. As photographs produced of India during the nineteenth century, they today serve as valuable cultural documents, and form a portion of the overall colonial visual record.

${ }^{154}$ IAPA no. 24 (October 1858): n.p. 


\section{After the IAPA: Professional Aspirations and Nineteenth Century Visual Culture}

\section{Introduction}

Little is known about the extent of the IAPA's distribution. The albumen prints contained in it would have been produced by hand, and in small quantities, limiting the audience of subscribers and the number of copies produced. Although the intention of the publication was clearly to appeal to audiences in England, it is uncertain how many copies were distributed beyond Bombay's and India's borders. However, despite the limited, three-year run of the IAPA, the imagery contained within it was circulated in reproductions well into the nineteenth century. After the IAPA ceased to be a vehicle for the dissemination of their photographs, many of the IAPA photographers continued to produce work and created their own outlets for presenting it.

The following discussion of the role the IAPA played in nineteenth century visual culture is not intended to be exhaustive, and merely aims to demonstrate that the photographic forms of representation initially published in Bombay during the 1850 s circulated beyond the time and place that created them. By reaching beyond the borders of India and transcending the period in which it was created, the IAPA's exposure was perhaps greater than what its publishers intended. The role the IAPA played in the visual culture of the nineteenth century is worthy of further study.

Even in the 1850s the work presented in the IAPA went beyond Bombay and garnered notice in the other Presidencies and in England. At an exhibition held at the Madras Photography Society in 1859 the lack of work by Bombay photographers was noted, as it was "well know[n] from the Bombay Amateur Photographic Album [sic], that that Presidency is far from being deficient in zealous and successful prosecutors of the Art."155 In Bengal as well there was some notice, and the IAPA attracted some attention in The Calcutta Review. ${ }^{156}$ An article in London's The Photographic News in 1859, reprinted from

\footnotetext{
155 "At a Meeting of the Photographic Society, held at the School of Arts on the $7^{\text {th }}$ April 1859," Madras Journal of Literature and Science 21(1859-60): 177.

156 "List of Works on India and the East Published During the Quarter," The Calcutta Review 33 (JulyDec. 1859): xxxviii. The article lists the contents for IAPA nos. 26 and 27.
} 
the Bombay Gazette, reviews photographs from IAPA nos. 18 and 19. The amateur photographers of Bombay are lauded for their "steady progress," and the author praises the IAPA as a "spirited and well-conducted undertaking." 157

\section{Professional Aspirations}

Despite its name, The Indian Amateur's Photographic Album also contains work by commercial photographers, and many of its contributors appeared to have had aspirations that transcended those of the amateur. William Johnson produced a three-volume portfolio of character studies and views, Photographs of Western India, ${ }^{158}$ containing 287 prints, many originally published in the IAPA. ${ }^{159}$ The first volume of eighty-six photographs contains ethnographic portraits and is entitled Costumes and Characters. The second and third volumes, Scenery, Public Buildings, Churches, Temples, etc. contain 100 and 101 photographs respectively. ${ }^{160}$ Photographs of Western India is an extensive compilation of work that includes alternate views of many photographs from the IAPA, ${ }^{161}$ suggesting that the views in the IAPA were often selected from a larger body of work indicative of a systematic approach to documenting a given subject.

Although complete sets of this portfolio are extremely rare, much like full sets of the IAPA, it does demonstrate that Johnson intended to disseminate his photographs to a wider audience, and to provide photographs that could be collected as souvenir objects to serve as reminders of time spent in India. The library at Southern Methodist University in Dallas Texas has a copy of this portfolio originally owned by Sir Henry Bartle Edward Frere, the Governor of Bombay from 1862-1867, perhaps a memento of his time spent in Bombay.

157 "Photography in Western India," 255-266.

${ }^{158}$ William Johnson, Photographs of Western India, 3 vols, Bombay, 1860 or later.

159 Hugh Rayner, personal communication, January 17, 2011.

${ }^{160}$ For information regarding the contents of each volume, see Christies, $19^{\text {th }}$ Century Indian Photographs from the Kanwardip Gujral Collection (London: Christies, Sept. 27 2001), lot 91.

${ }^{161} \mathrm{Vol}$. II of the portfolio contains twenty-two prints from the IAPA: catalogues 2, 5, 7, 10, 13, 14, $19,21,22,23,24,26,27,33,36,37,40,43,51,53,60,62$, as well as alternate views of six others: catalogues $7,13,34,39,43,51$. This information was provided by Hugh Rayner, personal communication, January 17, 2011. 


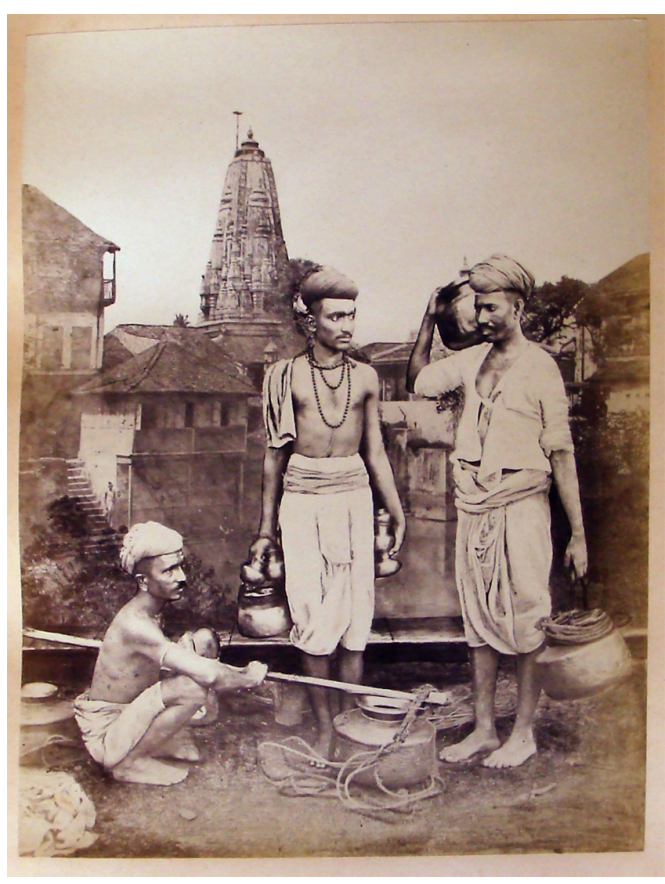

Fig. 47| William Johnson, Owdich Brahmins. Page 171 in William Johnson, The Oriental Races and Tribes, Residents and Visitors of Bombay vol. 1 (London: W. J. Johnson, Bolton and Barnitt 1863).

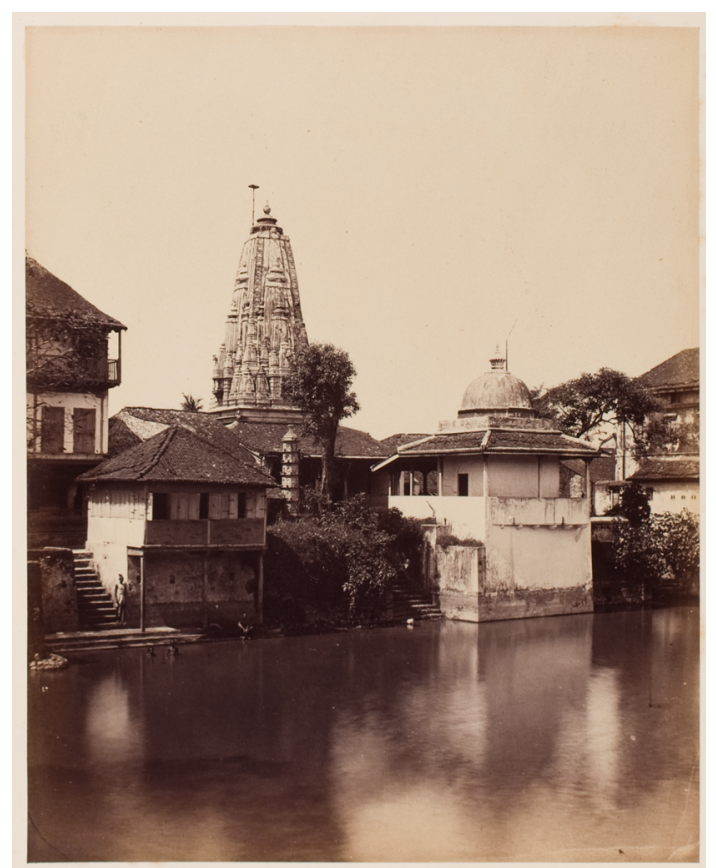

Fig. 48| William Johnson, Bombay no. 18-Temple of Shiva at Walakeshwar, from IAPA no. 3 (Catalogue 14).

A few years after the IAPA ceased publication, a number of photographs from it reappeared in William Johnson's two-volume publication The Oriental Races and Tribes, Residents and Visitors of Bombay (1863 and 1866). ${ }^{162}$ This publication is particularly significant for the transformation the IAPA work undergoes: Johnson creates layered images through combination printing, using a portion of a landscape negative for the background and a different negative for the portraits for the foreground [figures 47 and 48). By combining studio photographs and landscape views, many originally published in the $I A P A$, the ethnographic types are made to appear as though they are in a more natural environment.

Although Francis Frith (1822-1898) never traveled to India, the Frith Co. did sell Indian photographs, and John Falconer suggests that Frith obtained most of the negatives used to produce Frith Series India vol. 1 from William Johnson in the late 1860s. There are 150 photographs in the series, consisting of landscape views and portraits of Indian types and

162 William Johnson, The Oriental Races and Tribes, Residents and Visitors of Bombay, 2 vols (London: W.J. Johnson, Bolton and Barnitt, 1863, 1866). 
several of the prints have had their backgrounds painted out on the negatives, presumably in preparation for the photomontage process seen in The Oriental Races and Tribes, Residents and Visitors of Bombay. Although Falconer attributes the work to Johnson and Henderson, he speculates that the majority of the work is that of Johnson's alone. ${ }^{163}$

Other IAPA contributors also went on to publish photographically illustrated books of their own in the 1860s. Henry Hinton published a series of views documenting the antiquities of Bijapur, The Ruins of Beejapoor, in a Series of Nineteen Views from Collodion Negatives. ${ }^{164}$ Hinton occasionally contributed photographs to act as source material for the engravings accompanying news stories in The Illustrated London News. ${ }^{165}$

Captain Allan Newton Scott published Sketches in India: Taken at Hyderabad and Secunderbad, in the Madras Presidency in 1862, featuring 101 half-stereo photographs of military and native life in India as well as several architectural views of temples and antiquities. $^{166}$ Brief letterpress descriptions accompany the images and provide accounts of life as a military officer in India in the nineteenth century. Several of the photographs appear to have been made around the time that Scott produced the photographs of Elora and Ellichpoor that appear in the IAPA. One of the photographs in this book is nearly identical to catalogue 20 , and was used as the

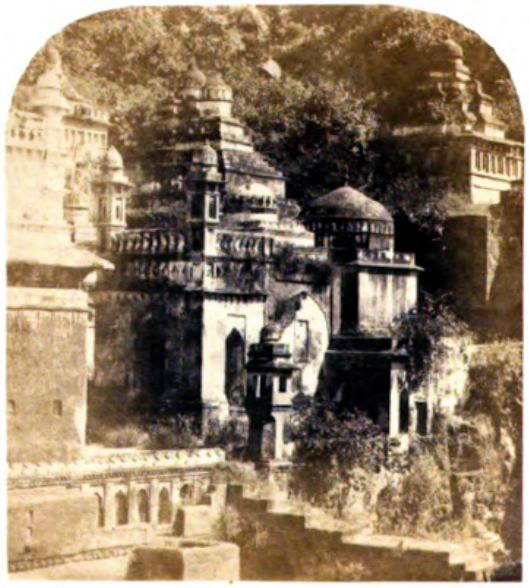

Fig. 49| Capt. Allan N. Scott, Very Ancient Jain Temple at Mucktagherry, Near Ellichpoor, plate 13 in Sketches in India: Taken at Hyderabad and Secunderbund, in the Madras Presidency, 1862. basis for the attribution of Scott's work in the IAPA, where his photographs appears under the acronym

\footnotetext{
${ }^{163}$ Falconer, "The Photograph Collection of the RCS," 38

${ }^{164}$ Henry Hinton, The Ruins of Beejapoor, in a Series of Nineteen Views from Collodion Negatives (Bombay, 1860). This work is discussed briefly in Dewan, "Delineating Antiquities," 308, 310.

165 For example, see "Proclamation of the Queen's Rule in India," The Illustrated London News, January 1, 1859, 17, and "The Hindoo Money Changer," The Illustrated London News, October 8, 1859, 342.

${ }^{166}$ Capt. Allan N. Scott, Sketches in India: Taken at Hyderabad and Secunderbad, in the Madras Presidency, ed. Charles Richard Weld (London: Lovell Reeve, 1862).
} 
A.N.S. [fig. 41].

\section{The IAPA in Nineteenth Century Visual Culture}

Photography and photographic reproductions played an important part in forming the visual culture through which the West viewed India. The Indian Mutiny and Uprising of 1857 led to an increased interest in India by the British public, and illustrated news magazines such as The Illustrated London News and The Graphic often used photographs from the IAPA as the source for their illustrations and images of India. The photograph Costumes and Characters of Western India no. 12-Brahmin Students of English Literature (catalogue 41) was reproduced as an engraving with the caption "Brahmin Students," in The Illustrated London News in August 1858 [figures 50 and 51], in a section called "Sketches in India." The brief text accompanying the image is nearly identical to the letterpress description that accompanied the photograph in IAPA no. 14 in December 1857. Indicative of the British anxiety to avoid another mutiny in India, the text takes great pains to point out that these men are not associated with their own native culture, but rather have embraced the ways of the British:

BRAHMIN STUDENTS OF ENGLISH LITERATURE. We are indebted to the "Photographic Album" of Bombay for the characteristic Sketch of two Brahmin Students of English Literature which we this week present to our readers. These two youths are members of the higher class of natives devoted to secular duties in the Southern Maratta country and the Carnatic, and are not of the class who devote themselves to the study of the Vedas, or the devotees of Shastras, or the scrubbers or anointers of the idols of stone and metal. Their form and figure, which do not differ much from the Western mould, are indicative of the Aryan race, to which the Brahmin belongs. They have come to the seat of the Presidency to pursue their study of the English language.

Although the expansion of photography beginning in the 1860 s produced many commercial studios specializing in pictures of India, such as Bourne and Shepherd, the IAPA continued to be mined as an image source for illustrated texts well into the nineteenth century. 


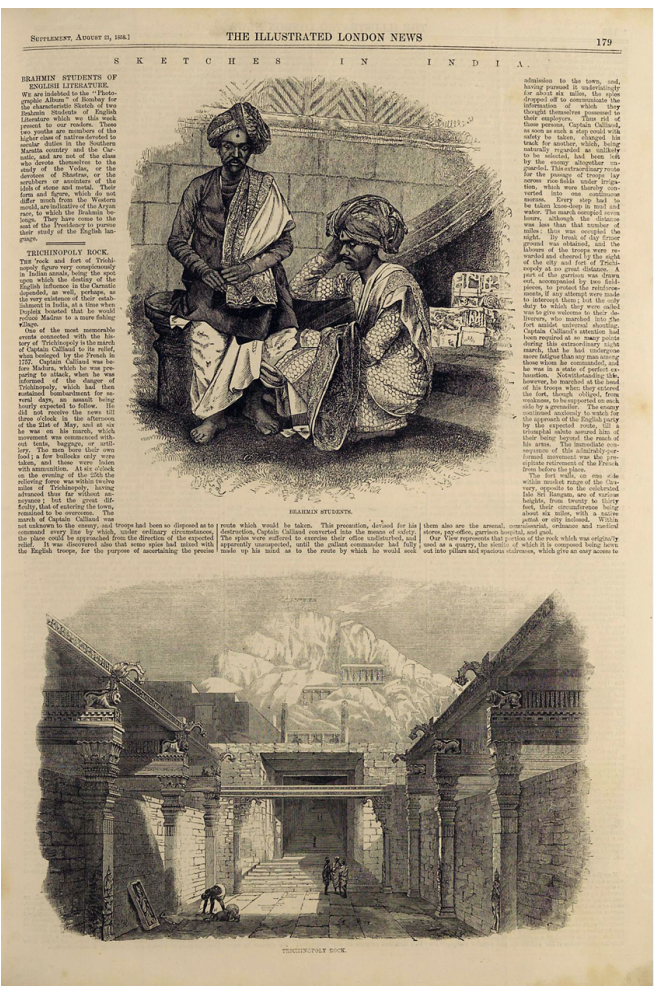

Fig. 50| Unidentified engraver, Brahmin Students. Wood engraving and letterpress. Page 179 in The Illustrated London News (August 21, 1858).

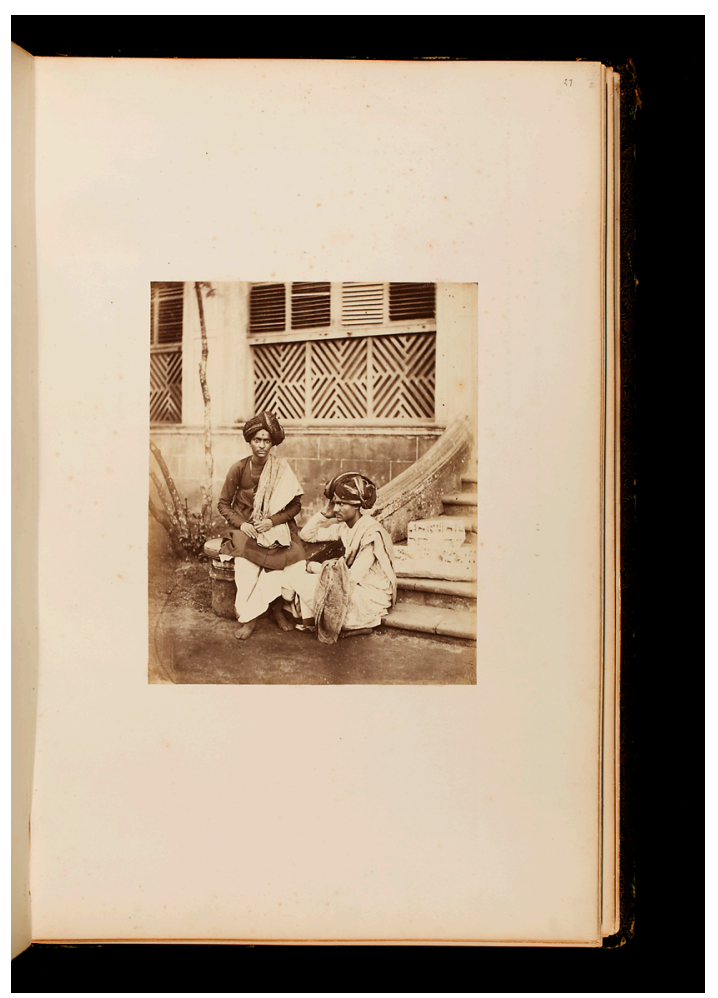

Fig. 51 | Johnson and Henderson, Costumes and Characters of Western India no. 12-Brahmin Students of English Literature (Catalogue 41).

The Prince of Wales enjoyed a privileged place in the emerging celebrity culture of the late nineteenth century, and his 1875 visit to India was well documented by the English press, with both the Graphic and The Illustrated London News providing extensive coverage. The Prince's tour was, in the recent words of post-colonial historian Hazel Hahn a "unique convergence of royal spectacle, the theatre of the colonies, and the theatre of exotic tourism" and had the effect of "affirm[ing] imperial authority."167 The event was conveyed to the British public primarily through images, and the illustrated weekly newspapers published extensive special issues that featured reproductions of several photographs from the IAPA as engravings, although it was by then 20 years old. The Graphic Indian Number, an issue commemorating the Prince's visit utilizes The Religious

\footnotetext{
${ }^{167}$ Hazel H. Hahn, "Indian Princes, Dancing Girls, and Tigers: The Prince of Wales' Tour of India and Ceylon, 1875-1876," Postcolonial Studies 12, no. 2 (2009): 175.
} 


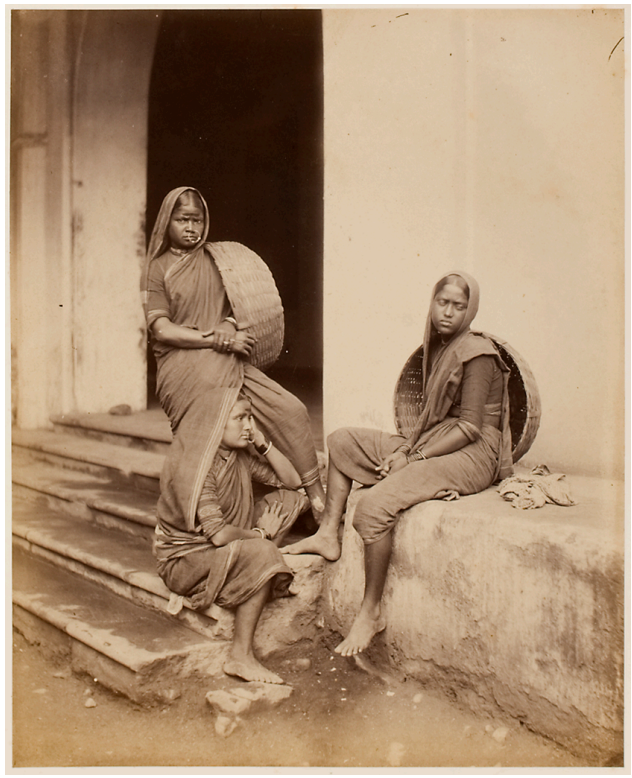

Fig. 52| Johnson and Henderson, Costumes and Characters of Western India no. 8-Maratha Women of the Labouring Class (Catalogue 29).

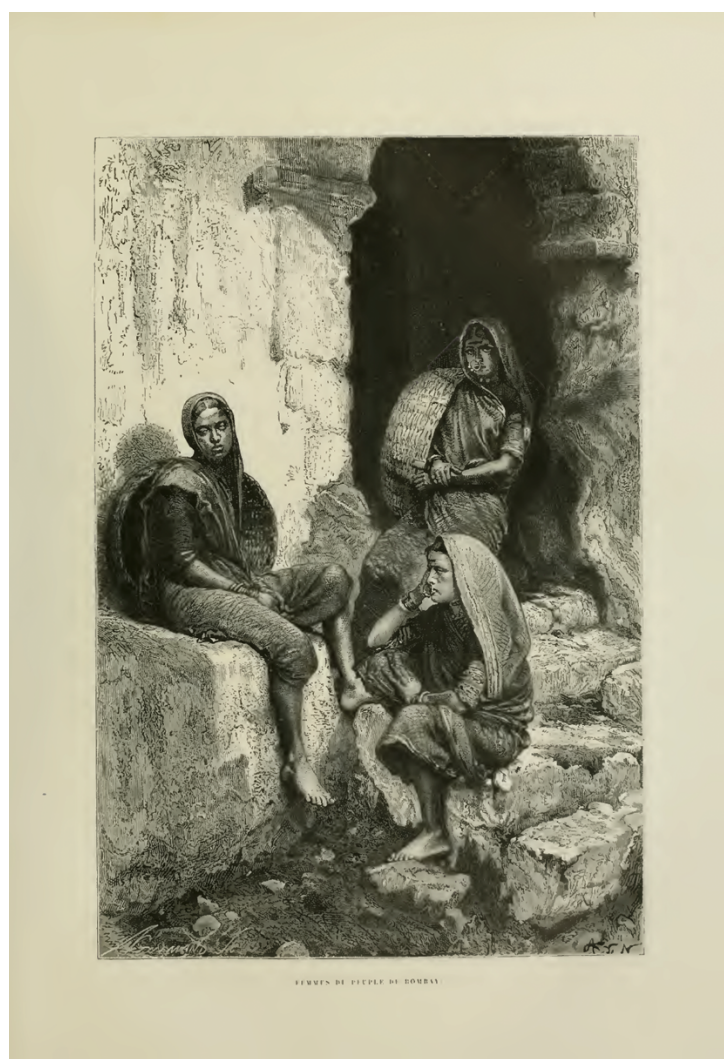

Fig. 53| Unidentified engraver, Femmes du Peuple. Page 11 in Louis Rousselet, L'Inde des Rajahs: Voyage dans L'Inde Central et dans Les Présidences de Bombay et du Bengal (Paris: Librairie Hachette et Co., 1877).

Service of the Jainas (catalogue 61), and The Cotton Green, Colaba (catalogue 13) to provide illustrations of Bombay. ${ }^{168}$

There are scattered appearances of work derived from or based on the IAPA throughout the remaining years of the nineteenth century and into the twentieth, primarily as illustrations or as source material for wood-cuts and engravings appearing in articles or books about India or Bombay. Two of the best known India travelogues from the nineteenth century, Louis Rousselet's L'Inde des Rajahs ${ }^{169}$ and Rev. Urwick's Indian

168 The Graphic (October 20, 1875): 8.

${ }^{169}$ Louis Rousselet, L'Inde des Rajahs: Voyage dans L'Inde Centrale et dans les Présidences de Bombay et du Bengale (Paris: Librairie Hachette et Co., 1877).

The English translation, published five years later, contains significantly fewer engravings based on IAPA photographs. Louis Rousselet, India and its Native Princes: Travels in Central India and in the Presidencies of Bombay and Bengal, ed. Lieut. Col. Buckle (London: Bickers \& Son, 1882). 
Pictures, Drawn With Pen and Pencil make extensive use of IAPA photographs as source material for their engravings. It should be noted that although the transformation of these photographs into engravings is basically faithful to the source imagery, the backgrounds and sundry details are often altered to make the scene look more rustic, forlorn, or decrepit [figures 52 and 53]. 


\section{Conclusion}

The rising interest in colonialist photography and the history of photography of British India over the past few decades has produced an environment ripe for an extensive discussion of The Indian Amateur's Photographic Album, which has been absent from scholarly literature. The intention of this thesis has been to provide a thorough description and analysis of the IAPA album found in George Eastman House's collection. By tracing the origins of the IAPA to the rise of amateur photographic societies and establishing connections to early subscription based photographic publications in Europe, the thesis has argued that the IAPA is an important publication providing a view of British India during a transitional time in its photographic history. By enabling a forum for amateur and emerging professional photographers to disseminate their imagery, the IAPA enabled a conscious mapping of the unfamiliar cultural terrain of India, and made it accessible to Western audiences. Historical research and a description of the material presented in the IAPA has helped to contextualize it within the framework of nineteenth century British photography in India, and as an important part of the extensive colonial visual record.

This project has resulted in an annotated catalogue of the entire GEH album, which represents the first twenty-four issues of the IAPA in its entirety, and provides a previously unavailable resource and guide to its content. Considering the texts within the album, both visual and written, and discussing them within the framework of British colonialist photography has enabled an analysis of the ways the IAPA used photography to produce touchstones of familiarity in a foreign environment. In producing ethnographic portraits of the local population the IAPA photographers used pre-existing visual conventions to produce and market images of the people of India. The British imperial project resulted in the expansion of their empire further into India, and the IAPA photographers produced cultural records of urban topography, previous empires, and territorial growth through the use of photography by documenting the city and the Presidency of Bombay.

One of the shortcomings of this project is that, as an analysis of the IAPA, it has been hampered by the incomplete nature of GEH's holdings. Although the material present in the first twenty-four issues is representative of the IAPA as a whole, its incomplete nature means that one third of the IAPA was not available for analysis and discussion. 
Nevertheless, I feel that the present analysis would be born out by the remaining twelve issues.

A comparison of the GEH album with a similar IAPA compilation at the Newberry library in Chicago revealed that the two were not identical, and this discrepancy between various editions of the IAPA suggests an area worthy of future research. A thorough comparison of the existing compilations of IAPA material in other collections, such as the Victoria and Albert Museum, and the British Library, would be a valuable contribution to knowledge about the IAPA by highlighting the similarities and differences. The scarcity of the IAPA has to date yielded only one examination of a complete set, and limits the possibilities for comparison.

Another area worth investigating is the connection between the IAPA and other publications that re-use its photographs in other contexts. Three later publications - Frith India Series vol. I, William Johnson's portfolio Views in Western India, and Johnson's The Oriental Races and Tribes, Residents and Visitors of Bombay-all contain images that originally appeared in the IAPA, and the connection between these works has not been thoroughly examined to date. In addition, if any commercial work by Johnson and Henderson produced in the 1850s could be unearthed, it would provide valuable insight into the development of the IAPA.

A brief discussion of the use of IAPA photographs within the visual culture of the nineteenth century has demonstrated that these images had a role that was not limited to their use in the IAPA. As part of how India was seen, viewed and perceived by the West, this suggests that the IAPA contributed to the formation of a Western idealized vision of India. Many of these photographs were disseminated through other media long after the IAPA ceased publication, and some of the photographers featured in the IAPA continued to produce and publish work. A more complete exploration of the role played by the IAPA in visual culture is needed.

Although this thesis traces the origins of the IAPA to the activities of amateur photographic societies and to photographic publications that used a similar subscription model, little is known about the actual distribution of the IAPA, its subscribers, and the extent of its circulation. Did it find an audience beyond India's borders? Where did the 
issues go? As a valuable historical object, the various trajectories of the other copies of this publication are worthy of investigation. 


\section{Appendix A Catalogue of Photographs in the GEH Album}

This catalogue documents the seventy-two photographs contained in The Indian Amateur's Photographic Album found in the George Eastman House (GEH) collection, Rochester NY. The album contains the first twenty-four issues of the IAPA, from November 1856 to October 1858. The GEH album was compiled and bound at some later date and contains many errors in its arrangement and labeling. This catalogue preserves the order of the GEH album, but has substituted the correct titles; for the original publication order of the IAPA, see Appendix B.

In this catalogue, titles and photographers are listed exactly as they appear in the accompanying letterpress. Information within square brackets has been supplied by the author, and reflects details missing from the letterpress. Publication Date corresponds to the issue in which the photograph was originally published. In many cases these appear out of sequence, reflecting the errors in arrangement that occurred at the binding stage of the album. Dimensions are of the image only and are given in millimeters with height preceding width. GEH indicates the George Eastman House accession numbers. Unless otherwise indicated, quotations in the Notes field are from the corresponding letterpress. 


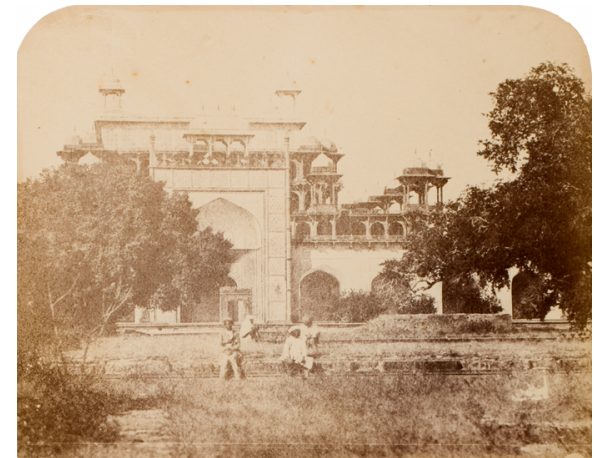

\section{Catalogue 1}

Title Acbar's Tomb, Agra

Photographer An Up-Country Amateur

Publication Date IAPA no. 1, November 1856

Medium Albumen silver print from a calotype negative.

Dimensions $194 \times 244 \mathrm{~mm}$

\section{GEH 1979.0065.0001}

Notes This view depicting the main entrance to the Tomb of Mughal Emperor Akbar the Great (1542-1605) located in Sikanadra (near Agra), is the only photograph in the GEH album made outside the Presidency, and one of the few made using paper negatives.

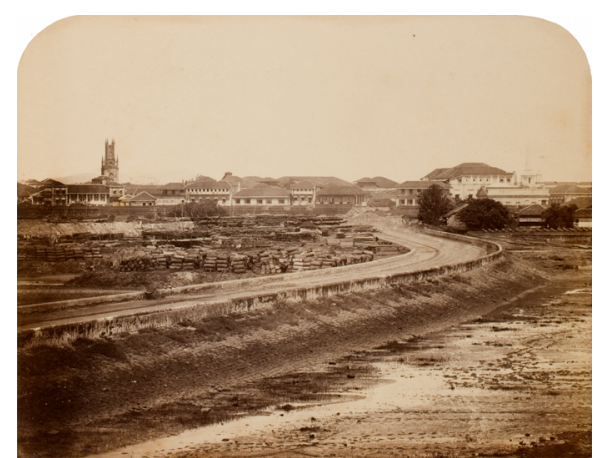

Catalogue 2

Title Bombay no. 11-Panoramic View of the Fort from Colaba

Photographer Johnson and Henderson
Publication Date IAPA no. 11, September 1857

Medium Albumen silver print from a wet collodion glass-plate negative.

Dimensions $188 \times 244 \mathrm{~mm}$

GEH 1979.0065.0002

Notes This panoramic view of the south end of the Fort from Lower Colaba depicts the Fort walls and moat, the vellard (Colaba Causeway), along with St. Thomas Cathedral (left) and St. Andrew's Church (right). The saluting battery is visible as a row of cannons on the far right. Cotton bales and stacks of teakwood (for shipbuilding) are visible in the middle ground.

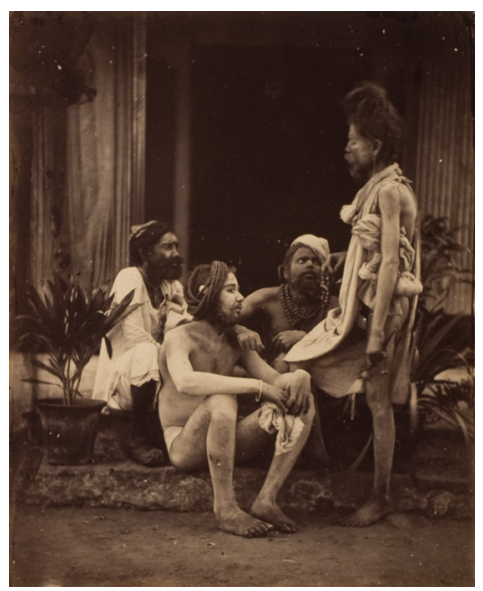

\section{Catalogue 3}

Title Costumes and Characters of Western India no. 1-The Gosayins

Photographer William Johnson

Publication Date IAPA no. 1, November 1856

Medium Albumen silver print from a wet collodion glass-plate negative.

Dimensions $195 \times 160 \mathrm{~mm}$

GEH 1979.0065.0003 


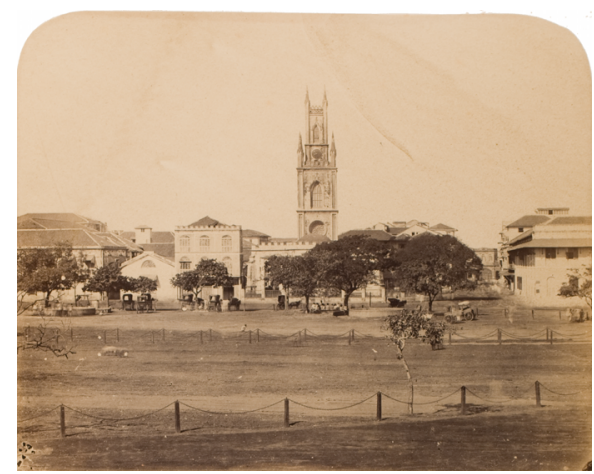

\section{Catalogue 4}

Title Bombay no. 2. -Bombay Green from the Town Hall

Photographer Johnson and Henderson

Publication Date IAPA no. 2, December 1856

Medium Albumen silver print from a wet collodion glass-plate negative.

\section{Dimensions $194 \times 243 \mathrm{~mm}$}

\section{GEH 1979.0065.0004}

Notes Catalogue 4 and 5 form a two-part, slightly overlapping panorama when viewed together, and were photographed from the Town Hall, where the Bombay Photographic Society held their meetings. Most of this area was destroyed to build Elphinstone Circle in the 1860s.

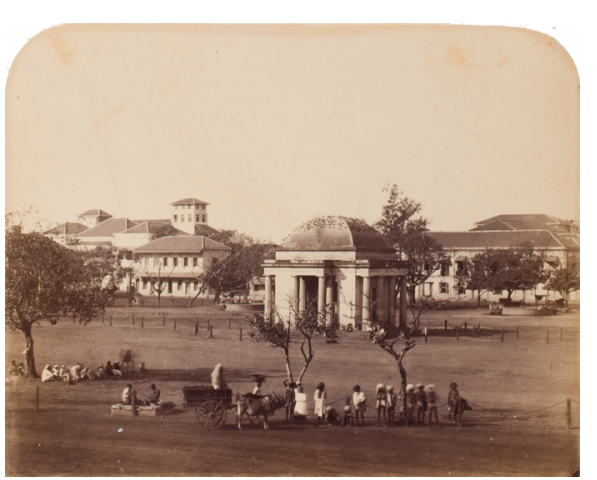

Catalogue 5

Title Bombay no. 3-Monument of the Late Marquis of Cornwallis, Governor General of India

Photographer A. Z. [Albert Zorn?]
Publication Date IAPA no. 2, December 1856

Medium Albumen silver print from a wet collodion glass-plate negative.

Dimensions $192 \times 244 \mathrm{~mm}$

\section{GEH 1979.0065.0005}

Notes A view of Bombay Green showing the monument to the former Governor General and Commander in Chief of India from 1786-1793, who was associated with the establishment and solidification of British rule in India. Catalogue 4 and 5 form a two-part, slightly overlapping panorama when viewed together, and were photographed from the town hall.

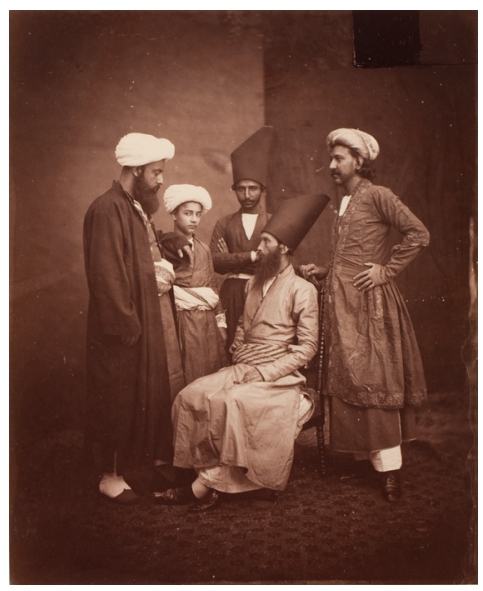

\section{Catalogue 6}

Title Costumes and Characters of Western India no. 2-A Group of Persians

Photographer Johnson and Henderson

Publication Date IAPA no. 2, December 1856

Medium Albumen silver print from a wet collodion glass-plate negative.

Dimensions $238 \times 194 \mathrm{~mm}$

\section{GEH 1979.0065.0006}

Notes Depicts prominent men and merchants of the Persian community, including the Persian Consul (centre), who had recently resigned his post in light of the emerging Anglo-Persian war. 


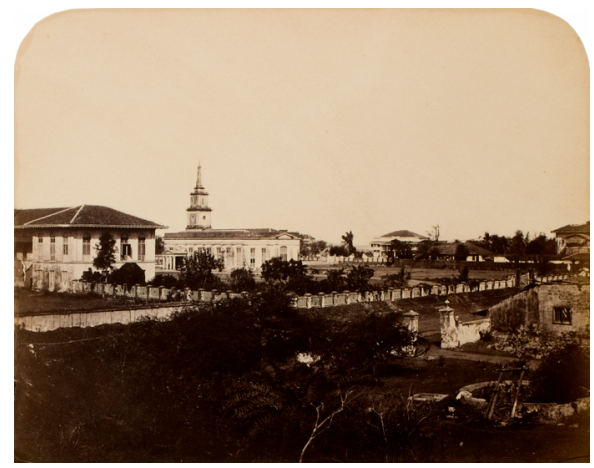

\section{Catalogue 7}

Title Bombay no. 4-Christ Church, Byculla

Photographer Henry H. Hinton

Publication Date IAPA no. 3, January 1857

Medium Albumen silver print from a wet collodion glass-plate negative.

\section{Dimensions $192 \times 244$ mm}

\section{GEH 1979.0065.0007}

Notes The Christ Church, erected in 1834, is enclosed in the grounds of the Schools of the Bombay Education Society, established at Byculla in 1815.

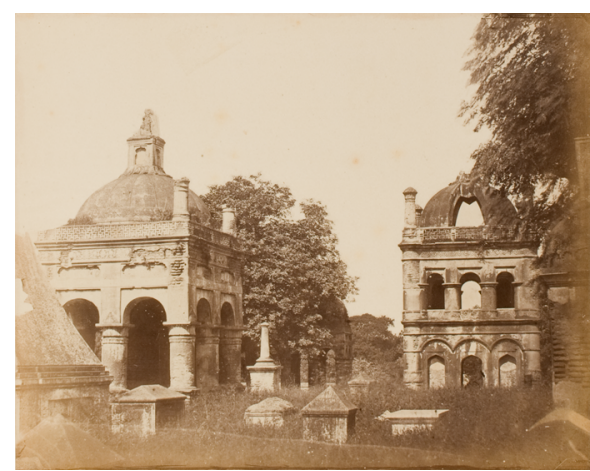

Catalogue 8

Title Surat. English Burial Ground

Photographer An Amateur

Publication Date IAPA no. 3, January 1857

Medium Albumen silver print from a wet collodion glass-plate negative.

\section{Dimensions $171 \times 215 \mathrm{~mm}$}

\section{GEH 1979.0065.0008}

Notes The English burial grounds at Surat are remnants of the seventeenth century trading factory established by the East India Company while the area was still firmly under the control of the Miughal Empire. The large scale of these tombs, along with the use of Indo-Islamic architectural styles, are indicative of the political aspirations of the East India Company officials and reflect the cultural interactions with the local ruling class. The European burial grounds at Surat are also documented in catalogues 65 and 69.

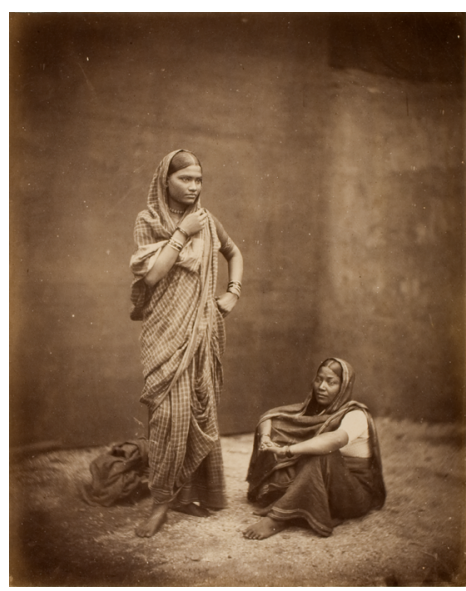

\section{Catalogue 9}

Title Costumes and Characters of Western India no. 3 - Parwari Women

Photographer Johnson and Henderson

Publication Date IAPA no. 3, January 1857

Medium Albumen silver print from a wet collodion glass-plate negative.

Dimensions $242 \times 193 \mathrm{~mm}$

GEH 1979.0065.0009

Notes Marathi women of the untouchable caste, likely employed in Bombay as household servants for Europeans. 


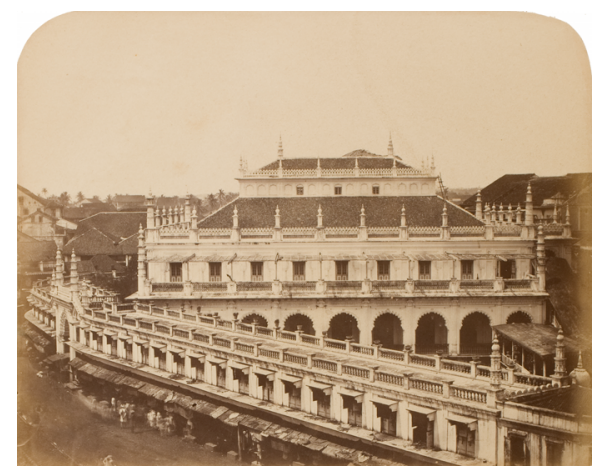

Catalogue 10

Title Bombay no. 5-Jooma Musjid

Photographer Henry H. Hinton

Publication Date IAPA no. 4, February 1857

Medium Albumen silver print from a wet collodion glass-plate negative.

Dimensions $191 \times 243 \mathrm{~mm}$

GEH 1979.0065.0010

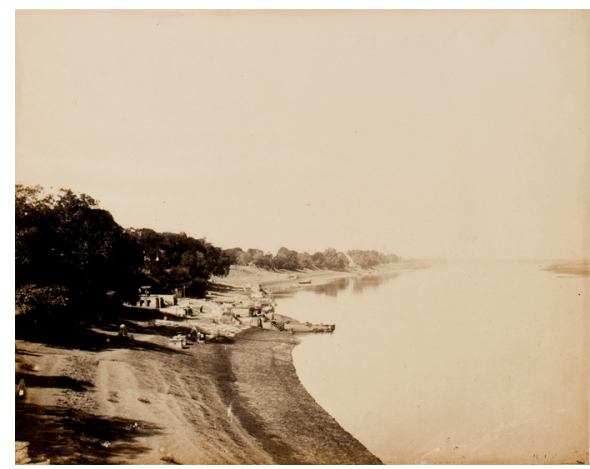

Catalogue 11

Title View on the Taptee River. The Site of the Proposed Railway Bridge Near Surat

Photographer Arthur A. Jacob

Publication Date IAPA no. 4, February 1857

Medium Albumen silver print from a wet collodion glass-plate negative.

Dimensions $166 \times 210 \mathrm{~mm}$

GEH 1979.0065.0011
Notes This view of the Taptee River is the proposed site of a railway bridge for the Bombay and Baroda line connecting the Presidency with Ahmadabad, then under construction.

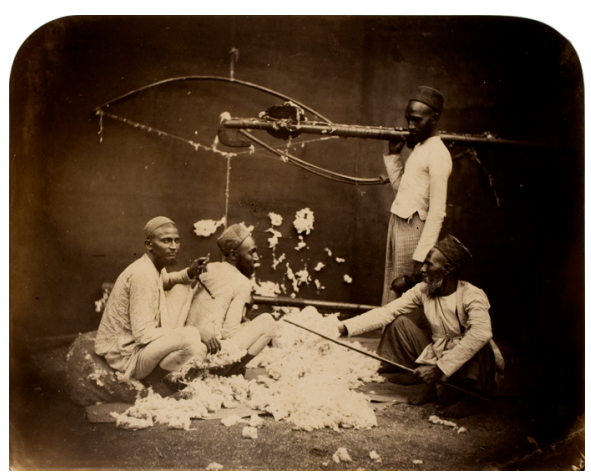

\section{Catalogue 12}

Title Costumes and Characters of Western India no. 4-Group of Pinjaras, or Cotton-Carders

Photographer Johnson and Henderson

Publication Date IAPA no. 4, February 1857

Medium Albumen silver print from a wet collodion glass-plate negative.

Dimensions $194 \times 244$ mm

GEH 1979.0065.0012

Notes A group of workers employed in the preparation of cotton, "the Pinjaras derive their name from their work (pinjawun), by which, through the aid of the instrument exhibited in this Photograph, they separate the fibres of the Cotton from one another, and this prepare it for being easily spun, or used in stuffing." 


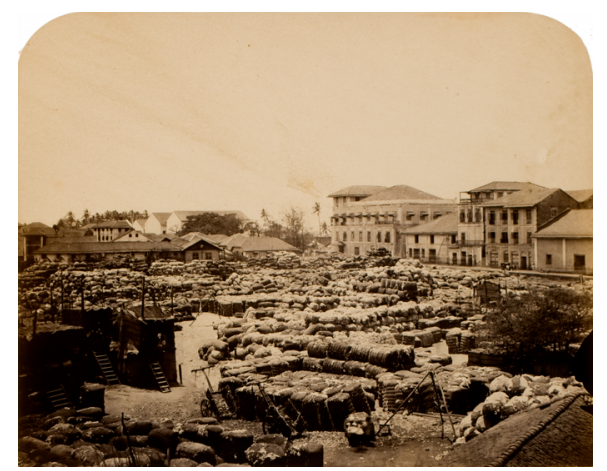

Catalogue 13

Title Bombay no. 6-The Cotton Ground, Colaba

Photographer Johnson and Henderson

Publication Date IAPA no. 5, March 1857

Medium Albumen silver print from a wet collodion glass-plate negative.

Dimensions $195 \times 244 \mathrm{~mm}$

\section{GEH 1979.0065.0013}

Notes In this view of the Cotton Ground the overflowing bales of cotton fill the courtyard defined by the surrounding buildings, while the large scales used for weighing the bales dot the landscape. The cotton grounds used to be located in Bombay Green, but the volume of cotton being traded increased beyond what could be contained there and the Cotton Green was moved to Colaba in $1844 .{ }^{170}$ The heyday of Bombay cotton, which eventually defined the city by transforming it economically, did not occur until the outbreak of the American Civil War stifled American exports, however this indicates that it was already a significant commodity in the 1850s, as "from about Christmas to the setting of the Monsoon rains, the bustle and uproar are seldom intermitted."

170 Dr. M.D. David, Bombay: The City of Dreams (A History of the First City in India) (Bombay: Himalaya Publishing House, 1995), 147.

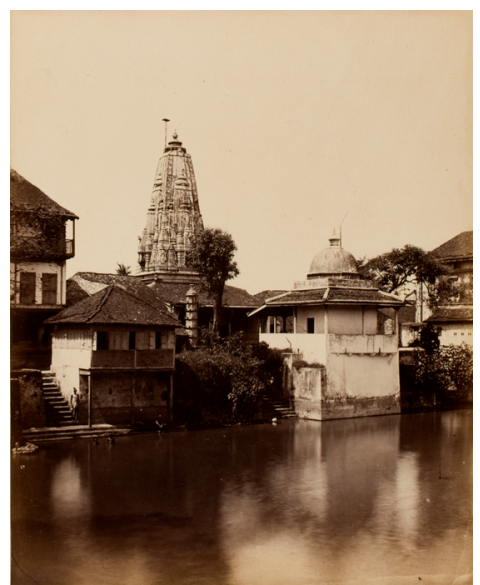

\section{Catalogue 14}

Title Bombay no. 18-Temple of Shiva at Walakeshwar

Photographer William Johnson

Publication Date IAPA no. 17, March 1858

Medium Albumen silver print from a wet collodion glass-plate negative.

Dimensions $241 \times 194 \mathrm{~mm}$

\section{GEH 1979.0065.0014}

Notes A view of the Shiva temple at Walakeshwar reflected in the Banganga Tank. The Walakeshwar temple complex is a 1715 reconstruction of an ancient set of temples destroyed either by Muslim or Portuguese invaders. This view depicts the Venkatesh Balaji Temple on the right (with the dome), and the Shiva Temple on the left (with the shikhara). Several devotees can be seen on the steps and in the water. The complex is also represented in catalogues 37 and 40 . 


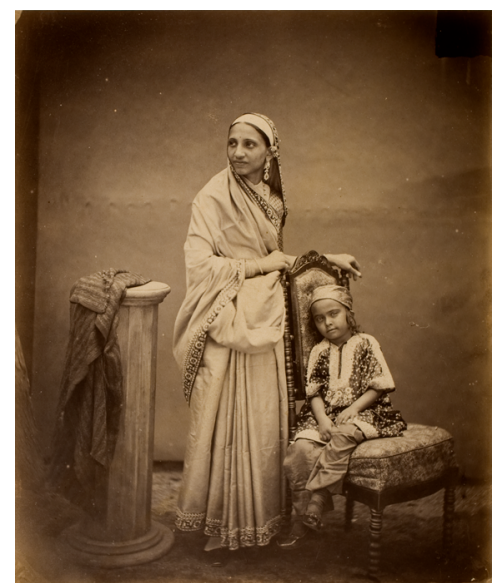

\section{Catalogue 15}

Title Costumes and Characters of Western India no. 5-Parsee Lady and Child

Photographer Johnson and Henderson

Publication Date IAPA no. 5, March 1857

Medium Albumen silver print from a wet collodion glass-plate negative.

Dimensions $234 \times 194 \mathrm{~mm}$

\section{GEH 1979.0065.0015}

Notes A variant to this print, in which the woman is posed with a different child, was obtained by the India Office at the 1867 Paris exhibition as part of an acquisition of the work of photographer Hurrichind Chintamon. The catalogue record for the variant photograph, currently held at the British Library, states "this photograph is probably by [William] Johnson, despite the crediting of the image to Chintamon."

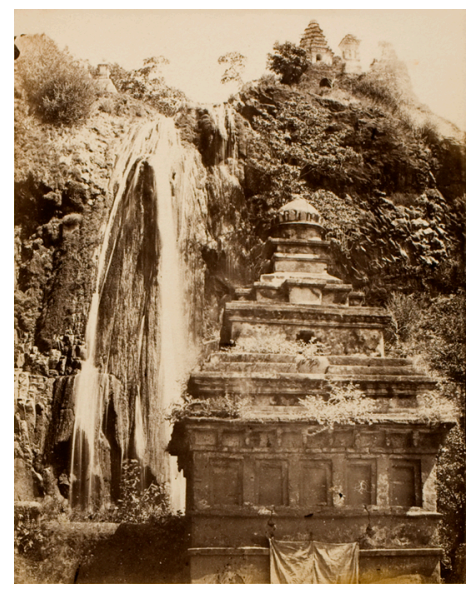

\section{Catalogue 16}

Title Falls of Mutlagherry, Near Ellichpoor, Northern Berar

Photographer Capt. Allan N. Scott

Publication Date IAPA no. 6, April 1857

Medium Albumen silver print from a wet collodion glass-plate negative.

Dimensions $185 \times 145 \mathrm{~mm}$

GEH 1979.0065.0016

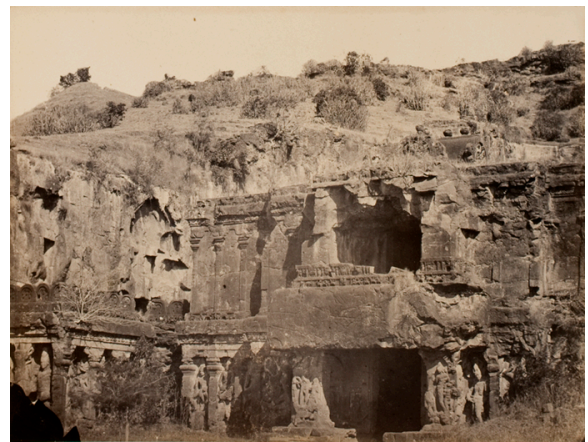

\section{Catalogue 17}

Title Entrance to the Monolithic Temple of Kailas at Elora

Photographer Capt. Allan N. Scott

Publication Date IAPA no. 18, April 1858

Medium Albumen silver print from a wet collodion glass-plate negative.

Dimensions $145 \times 193$ mm

GEH 1979.0065.0017 


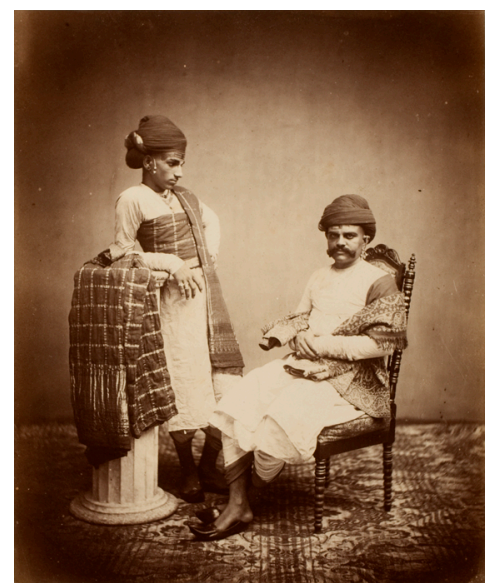

\section{Catalogue 18}

Title Costumes and Characters of Western India no. 6-Comfortable Gosavis

Photographer Johnson and Henderson

Publication Date IAPA no. 6, April 1857

Medium Albumen silver print from a wet collodion glass-plate negative.

Dimensions $244 \times 200 \mathrm{~mm}$

GEH 1979.0065.0018

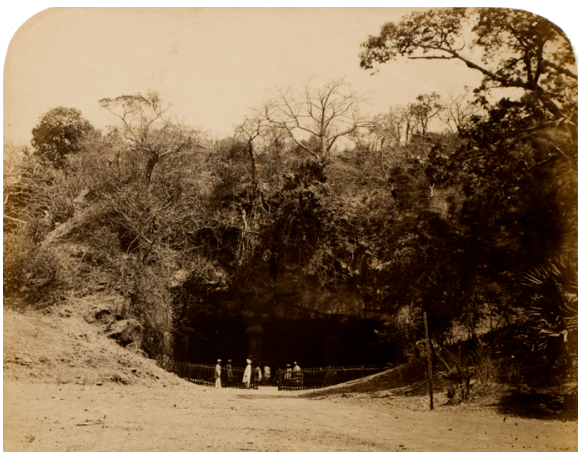

Catalogue 19

Title Elephanta. The Brahmanical Cave-Temple. no. 1-The Entrance

Photographer Johnson and Henderson

Publication Date IAPA no. 7, May 1857

Medium Albumen silver print from a wet collodion glass-plate negative.
Dimensions $189 \times 244 \mathrm{~mm}$

GEH 1979.0065.0019

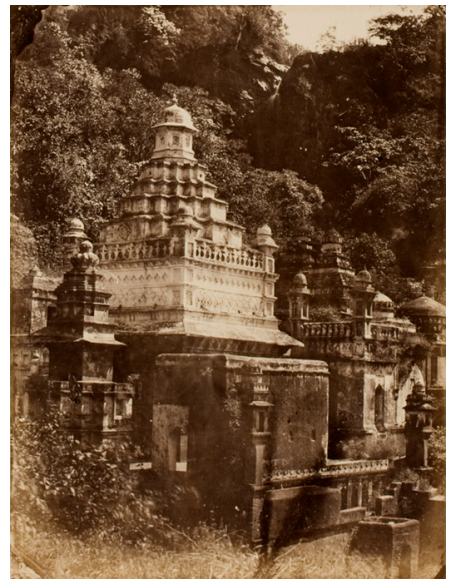

Catalogue 20

Title Elephanta. The Brahmanical Cave-Temple. no. 1-The Entrance

Photographer Johnson and Henderson

Publication Date IAPA no. 7, May 1857

Medium Albumen silver print from a wet collodion glass-plate negative.

Dimensions $195 \times 147 \mathrm{~mm}$

GEH 1979.0065.0020 
Appendix A Catalogue of Photographs in the GEH Album

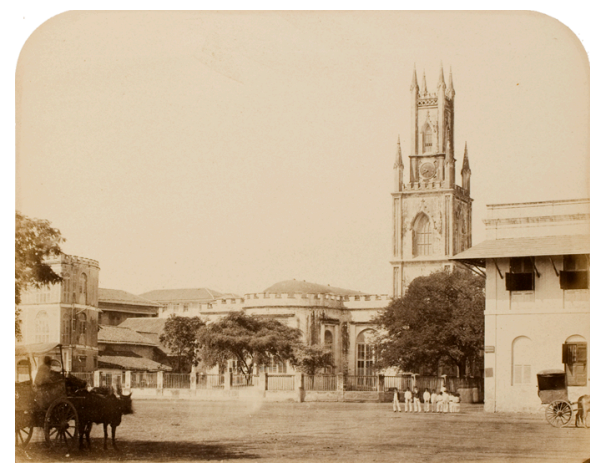

Catalogue 21

Title Bombay no. 7- The Cathedral

Photographer Johnson and Henderson

Publication Date IAPA no. 7, May 1857

Medium Albumen silver print from a wet collodion glass-plate negative.

Dimensions $190 \times 245 \mathrm{~mm}$

\section{GEH 1979.0065.0021}

Notes St. Thomas Cathedral was a common subject for members of the Bombay Photographic Society. One of the oldest buildings within the Fort, it was built in 1715, although the Gothic tower was a later construction, and dates from 1837. The Cathedral was felt to "eclips[e] the Churches of Bengal and Madras, as well as the Portuguese Churches of Bombay."

The cathedral is also clearly visible in catalogue 4, and its spire can be seen in catalogues 2 and 24 .

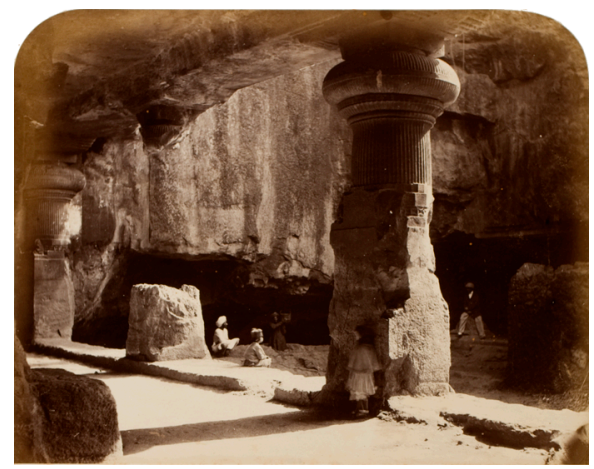

Catalogue 22

Title Elephanta. The Brahmanical Cave-Temple no. 2-Specimens of the Pillars
Photographer Johnson and Henderson

Publication Date IAPA no. 8, June 1857

Medium Albumen silver print from a wet collodion glass-plate negative.

Dimensions $190 \times 244$ mm

GEH 1979.0065.0022

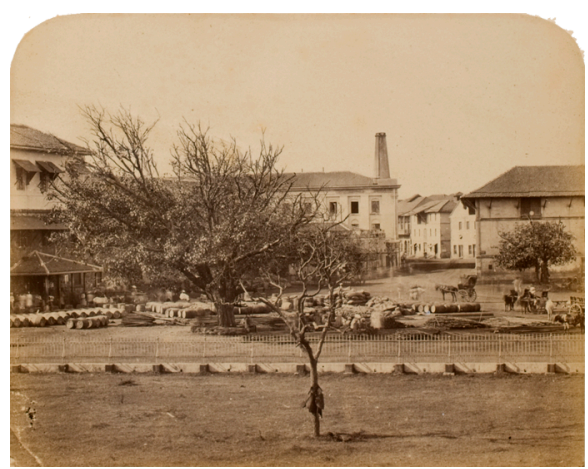

Catalogue 23

Title Bombay no. 8-View from the South-East Frontage of the Town Hall

Photographer Johnson and Henderson

Publication Date IAPA no. 8, June 1857

Medium Albumen silver print from a wet collodion glass-plate negative.

Dimensions $190 \times 240 \mathrm{~mm}$

GEH 1979.0065.0023

Notes This view across the Bombay Green depicts the Custom House (right) and opium warehouses (far left), with recently unloaded merchandise in piles. 


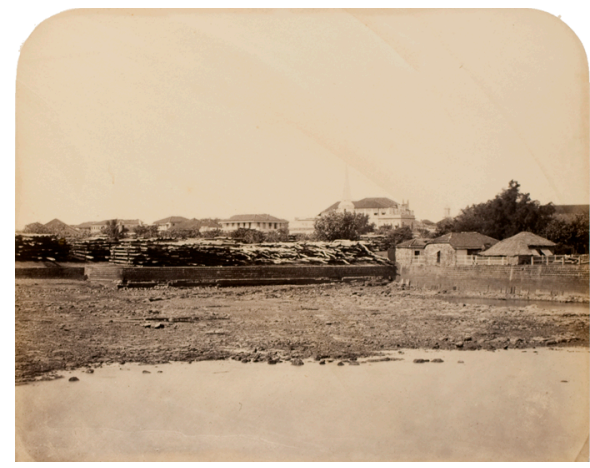

Catalogue 24

Title Bombay no. 20-The Fort of Bombay, From the Apollo Bunder

Photographer William Johnson

Publication Date IAPA no. 19, May 1858

Medium Albumen silver print from a wet collodion glass-plate negative.

Dimensions $190 \times 245 \mathrm{~mm}$

GEH 1979.0065.0024

Notes For hundreds of years Apollo Bunder was the main disembarking point for passengers arriving by ship. This view depicts the Fort walls, dockyard and the Engine Factory. The piles of timber are teakwood for shipbuilding.

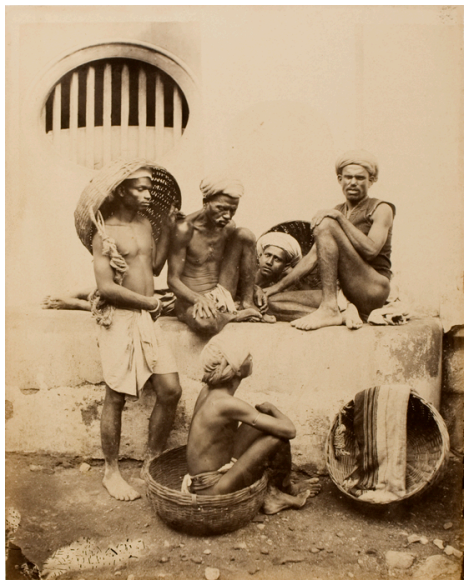

Catalogue 25

Title Costumes and Characters of Western India no. 7-Group of Maratha Ghatis
Photographer Johnson and Henderson

Publication Date IAPA no. 9, n. d.

Medium Albumen silver print from a wet collodion glass-plate negative.

Dimensions $250 \times 201 \mathrm{~mm}$

\section{GEH 1979.0065.0025}

Notes This group of lower caste day labourers, are "noted for their industry, to which men, women, and children alike devote themselves." These men are described as being the husbands of the women in catalogue 29.

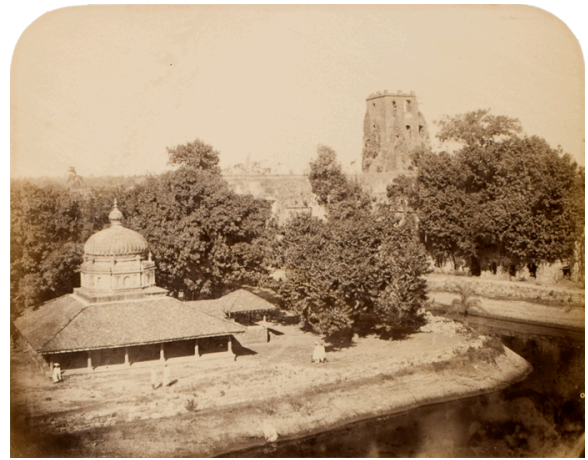

Catalogue 26

Title Bassein no. 4-The Hindoo Temple of Mahdeo

Photographer [Unidentified Photographer]

Publication Date IAPA no. 23, September 1858

Medium Albumen silver print from a wet collodion glass-plate negative.

Dimensions $190 \times 234 \mathrm{~mm}$

GEH 1979.0065.0026 


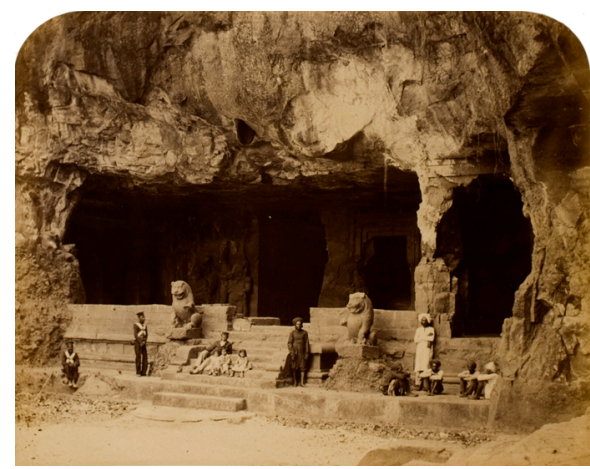

Catalogue 27

Title Elephanta. The Brahmanical Cave Temple no. 3-Entrance to the Northern Aisle

Photographer Johnson and Henderson

Publication Date IAPA no. 23, September 1858

Medium Albumen silver print from a wet collodion glass-plate negative.

Dimensions $190 \times 243 \mathrm{~mm}$

GEH 1979.0065.0027

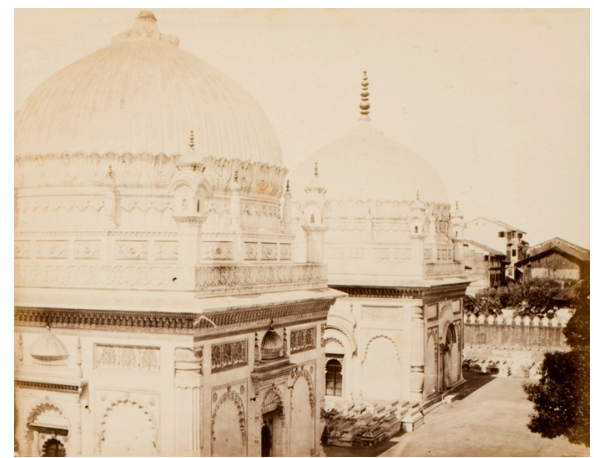

Catalogue 28

Title Tomb of the Moola of the Boras, Surat

Photographer [Unidentified Photographer]

Publication Date IAPA no. 10, n.d.

Medium Albumen silver print from a wet collodion glass-plate negative.

Dimensions $167 \times 214 \mathrm{~mm}$

GEH 1979.0065.0028

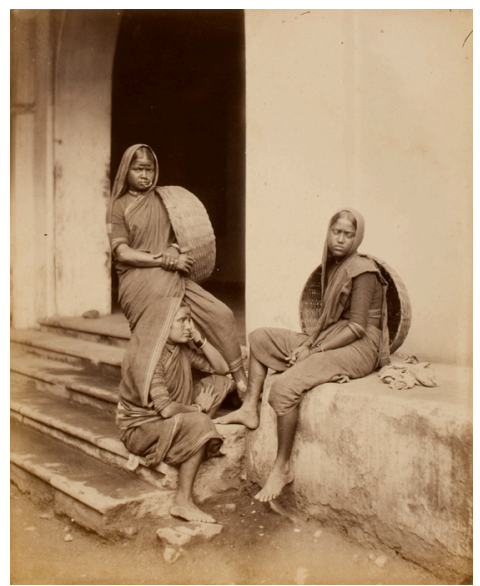

\section{Catalogue 29}

Title Costumes and Characters of Western India no. 8-Maratha Women of the Labouring Class

Photographer Johnson and Henderson

Publication Date IAPA no. 10, n.d.

Medium Albumen silver print from a wet collodion glass-plate negative.

Dimensions $239 \times 192 \mathrm{~mm}$

GEH 1979.0065.0029

Notes This group of lower caste workers, "laboriously co-operate with their husbands and brothers in Bombay, in the support of their families, and the accumulation of capital." These women are the wives of the men in catalogue 25 . 


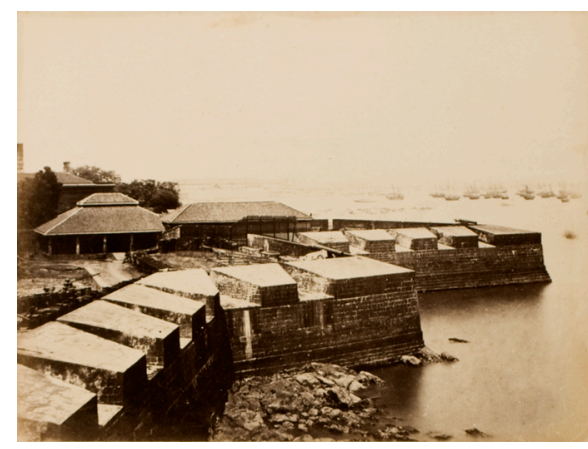

Catalogue 30

Title Bombay no. 9-A Wee Bit of the Castle

Photographer An Amateur

Publication Date IAPA no. 9, n.d.

Medium Albumen silver print from a wet collodion glass-plate negative.

Dimensions $156 \times 208 \mathrm{~mm}$

\section{GEH 1979.0065.0030}

Notes This view of the Castle walls looking North across Bombay Harbour shows the interior of Bombay Castle, the centre of government for the Bombay Presidency, with British ships moored in the distance. Built by the Portuguese, this structure predates the British occupation of Bombay, and outlasted their presence.

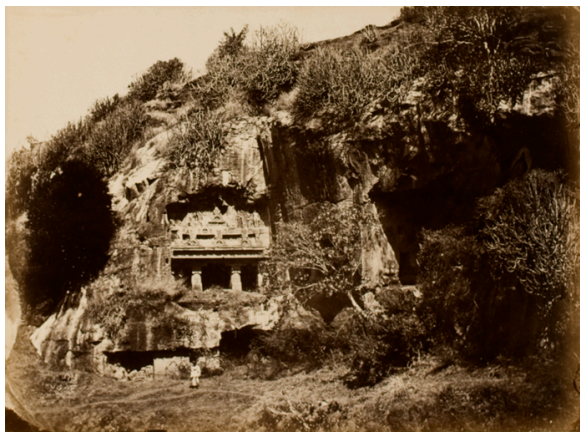

\section{Catalogue 31}

Title Entrance to one of the Smaller Excavations at Elora

Photographer Capt. Allan N. Scott

Publication Date IAPA no. 11, September 1857
Medium Albumen silver print from a wet collodion glass-plate negative.

Dimensions $145 \times 197 \mathrm{~mm}$

GEH 1979.0065.0031

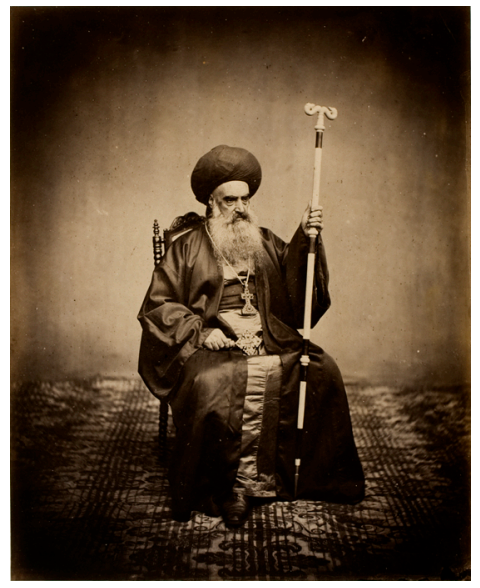

\section{Catalogue 32}

Title Costumes and Characters of Western India no. 9-An Eastern Bishop

Photographer Johnson and Henderson

Publication Date IAPA no. 11, September 1857

Medium Albumen silver print from a wet collodion glass-plate negative.

Dimensions $243 \times 194 \mathrm{~mm}$

\section{GEH 1979.0065.0032}

Notes This portrait of Mar Gregorius, the Metran, or Metropolitan Bishop of the Syrian church of Jerusalem was taken during a visit to India to visit the Syrian Christians of Kerala. 


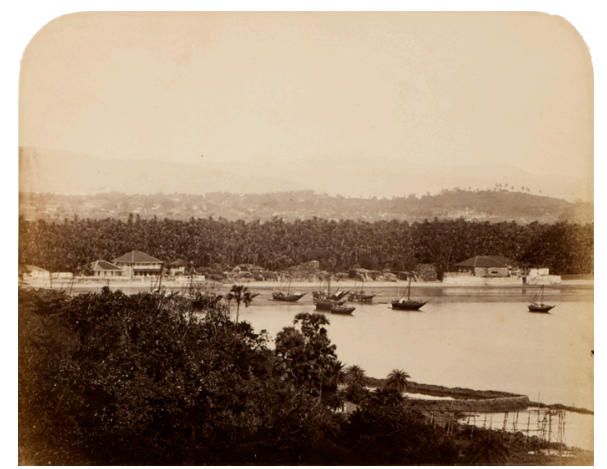

Catalogue 33

Title Bombay no. 12-Back Bay, from Malabar Hill

Photographer Johnson and Henderson

Publication Date IAPA no. 12, September 1857

Medium Albumen silver print from a wet collodion glass-plate negative.

Dimensions $190 \times 242 \mathrm{~mm}$

GEH 1979.0065.0033

Notes This view of the Back Bay facing east towards the city, with the Western Ghats in the background.

This photograph was made from a similar vantage point to catalogue 39, which illustrates the view looking west. These two complimentary images may have been made on the same day.

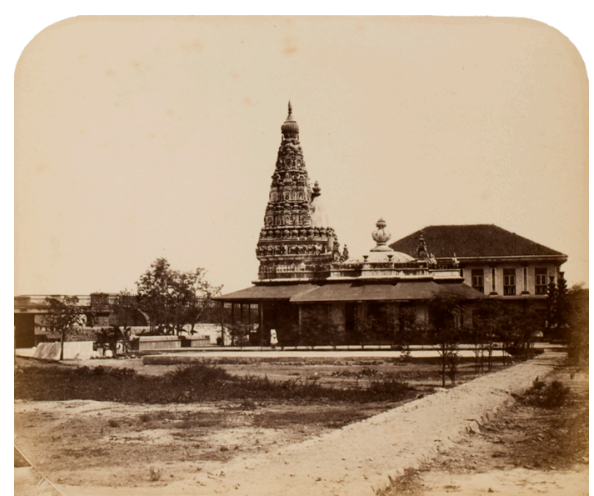

Catalogue 34

Title Bombay no. 10-Hindu Shrine by the Railway Station, Byculla

Photographer Johnson and Henderson
Publication Date IAPA no. 10, n.d.

Medium Albumen silver print from a wet collodion glass-plate negative.

\section{Dimensions $190 \times 230 \mathrm{~mm}$}

\section{GEH 1979.0065.0034}

Notes The Mankeshwar Temple was built in 1851, a few years before the Byculla station was constructed. The text in the IAPA notes that the temple "strikes the attention of the visitor to Bombay from its peculiar situation."

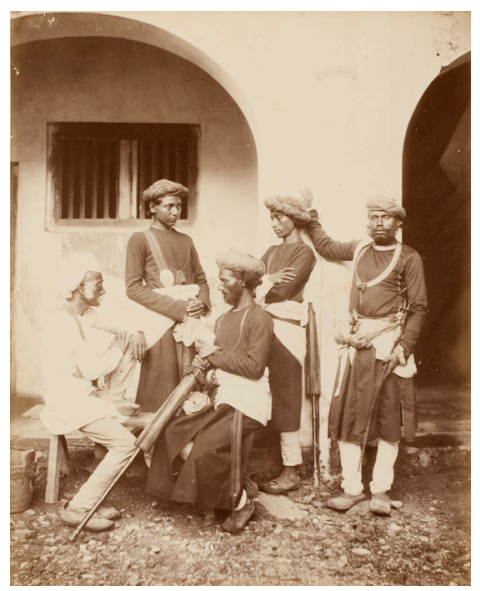

\section{Catalogue 35}

Title Costumes and Characters of Western India no. 10-Huzur Pattewallas

Photographer Johnson and Henderson

Publication Date IAPA no. 12, October 1857

Medium Albumen silver print from a wet collodion glass-plate negative.

Dimensions $240 \times 192 \mathrm{~mm}$

GEH 1979.0065.0035 


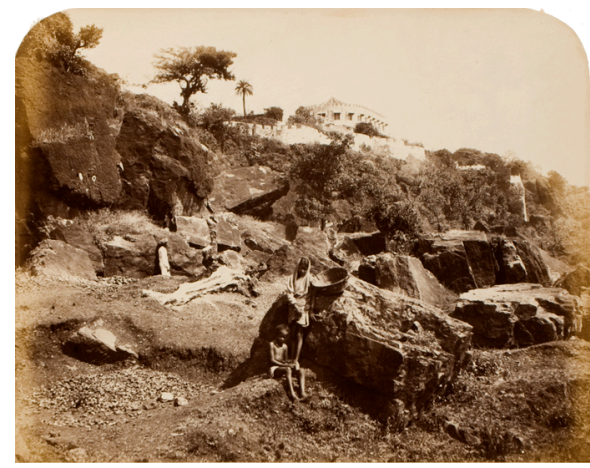

Catalogue 36

Title Bombay no. 13-A Bit of Malabar Hill

Photographer Johnson and Henderson

Publication Date IAPA no. 13, November 1857

Medium Albumen silver print from a wet collodion glass-plate negative.

Dimensions $190 \times 242$ mm

\section{GEH 1979.0065.0036}

Notes The workers in this photograph are breaking rocks and crushing stones for use in the construction of Bombay's macadamized roads.

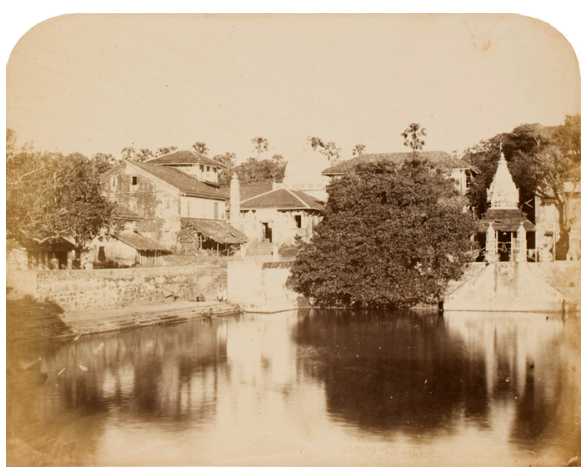

\section{Catalogue 37}

Title Bombay no. 14-Temples at Walkeshwar

Photographer Johnson and Henderson

Publication Date IAPA no. 13, November 1857

Medium Albumen silver print from a wet collodion glass-plate negative.

Dimensions $190 \times 242$ mm

\section{GEH 1979.0065.0037}

Notes The northeast corner of the Banganga Tank. The Walakeshwar temple complex is a 1715 reconstruction of an ancient set of temples destroyed either by Muslim or Portuguese invaders. This view depicts the Venkatesh Balaji Temple on the left (with the dome), and the Siddheshwar Temple on the right (with the spire). The complex is also represented in catalogues 14 and 40.

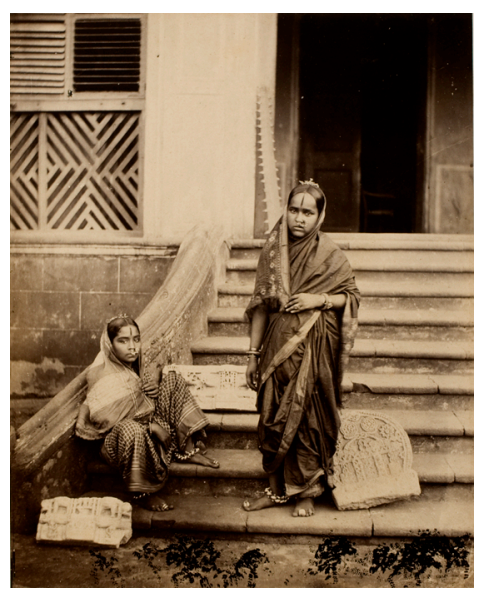

\section{Catalogue 38}

Title Costumes and Characters of Western India no. 11-Brahmani Ladies

Photographer Johnson and Henderson

Publication Date IAPA no. 13, November 1857

Medium Albumen silver print from a wet collodion glass-plate negative.

Dimensions $238 \times 192 \mathrm{~mm}$

\section{GEH 1979.0065.0038}

Notes These Brahmin ladies, Aralá Báí (left) and Lakshmí Bái (right) are the daughters of respected Maratha landowners who are "much distinguished in the judicial service of Government." They are in Bombay to study at the Ambrolie English School, a Christian Missionhouse founded and run by Scottish missionary Dr. John Wilson (1804-1875). Their husbands are photographed separately, and are the subjects of catalogue 41. 
William Johnson reused this image in The Oriental Races and Tribes, Residents and Visitors of Bombay vol. 2 under the heading "Marathi Brahmin women," where they are not identified by name. The photograph later appeared in J. Forbes Watson's 1866 The Textile Manufactures and the Costumes of the People of India as part of an illustration of female attire. ${ }^{171}$

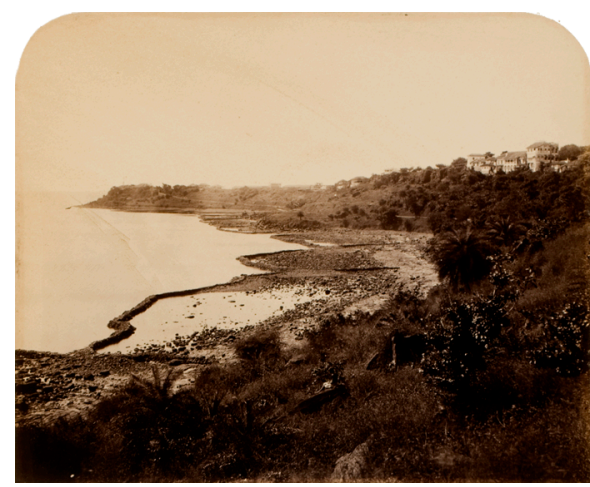

\section{Catalogue 39}

Title Bombay no. 15-Malabar Point

Photographer Johnson and Henderson

Publication Date IAPA no. 14, December 1857

Medium Albumen silver print from a wet collodion glass-plate negative.

Dimensions $190 \times 234 \mathrm{~mm}$

\section{GEH 1979.0065.0039}

Notes In this view of Malabar Point, looking west from the Back Bay, the residence of the Governor of Bombay can be faintly seen to the left. The large bungalow on the right is a private residence. The dykes visible in the foreground are used for catching fish at low tide.

This photograph was made from a similar vantage point to catalogue 33, which illustrates the view looking east. These two complimentary images may have been made on the same day.

$171 \mathrm{~J}$. Forbes Watson, The Textile Manufactures and the Costumes of the People of India (London: George Edward Eyre and William Spottiswoode, for the India Office, 1866), 51.

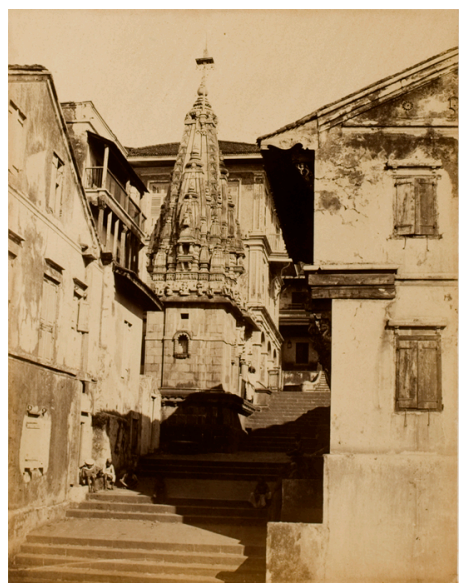

\section{Catalogue 40}

Title Bombay no. 16-A Second View of the Walkeshwar Temples

Photographer Johnson and Henderson

Publication Date IAPA no. 14, December 1857

Medium Albumen silver print from a wet collodion glass-plate negative.

Dimensions $242 \times 189 \mathrm{~mm}$

GEH 1979.0065.0040

Notes A view of the Shiva temple at Walakeshwar. The Walakeshwar temple complex is a 1715 reconstruction of an ancient set of temples destroyed either by Muslim or Portuguese invaders. The complex is also represented in catalogues 14 and 37 . 


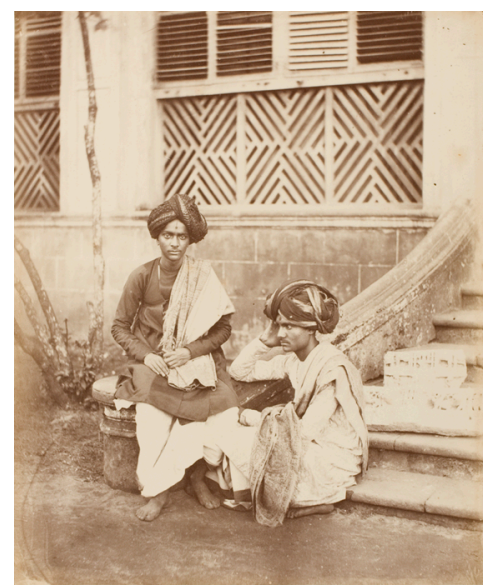

Catalogue 41

Title Costumes and Characters of Western India no. 12-Brahmin Students of English Literature

Photographer Johnson and Henderson

Publication Date IAPA no. 14, December 1857

Medium Albumen silver print from a wet collodion glass-plate negative.

Dimensions $240 \times 195 \mathrm{~mm}$

\section{GEH 1979.0065.0041}

Notes The two men in this photograph are the husbands of the women in catalogue 38 , however, unlike the women, the men are not named. They are students of English at the Free General Assembly's Institution, founded by Dr. John Wilson, and now called Wilson College.

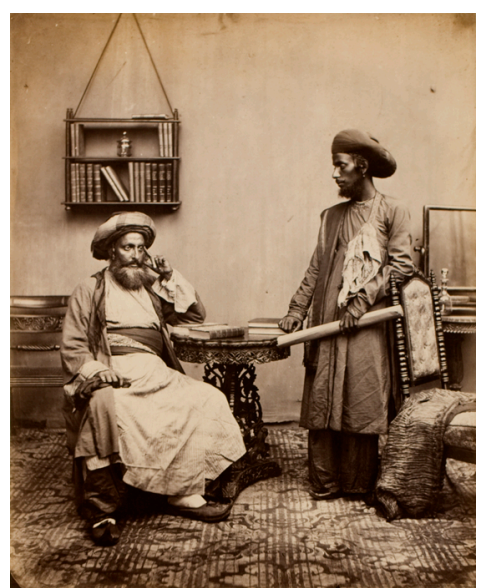

\section{Catalogue 42}

Title Costumes and Characters of Western India no. 13-Bene-Israel Teachers

Photographer Johnson and Henderson

Publication Date IAPA no. 15, January 1858

Medium Albumen silver print from a wet collodion glass-plate negative.

Dimensions $239 \times 194 \mathrm{~mm}$

\section{GEH 1979.0065.0042}

Notes The Bene-Israel are Indian Jews, likely descended from a community who escaped persecution in Galilee and arrived in India when their ship sank off the coast of India in the 2nd century BC. In the 1850s there was a community of 8000-10 000 Bene-Israel living in Bombay or its vicinity.

These men are teachers, the man on the left at a "vernacular school of the Free Church of Scotland's mission," and the man on the right in the "Jewish English School supported by Mr. David Sasún [David Sassoon (1792-1864)], the Jewish patriot and patriarch of the Western Capital of India." 


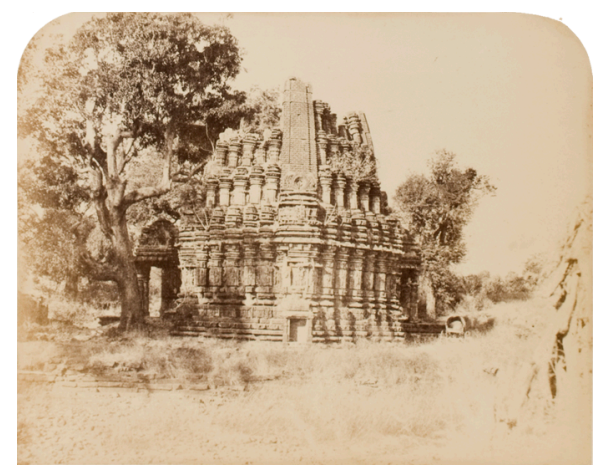

Catalogue 43

Title The Temple of Amarnath

Photographer Archibald Robertson

Publication Date IAPA no. 15, January 1858

Medium Albumen silver print from a waxed paper negative.

Dimensions $192 \times 244$ mm

\section{GEH 1979.0065.0043}

Notes The temple at Amarnath dates from the tenth century and is dedicated to Shiva. The letterpress indicates that two photographs of this temple were intended to be included in the month's publication, however both the GEH and Newberry albums contain a single print only. These prints are slight variants, and the Newberry version contains human figures for staffage.

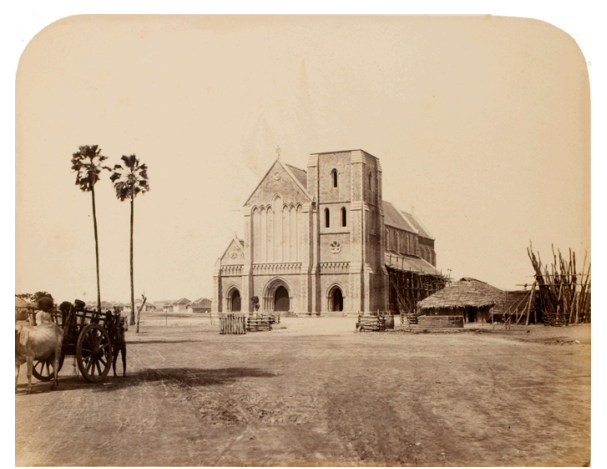

Catalogue 44

Title Bombay no. 17-The Colaba Memorial Church

Photographer William Johnson
Publication Date IAPA no. 16, February 1858

Medium Albumen silver print from a wet collodion glass-plate negative.

Dimensions $190 \times 245 \mathrm{~mm}$

GEH 1979.0065.0044

Notes The Colaba Memorial Church, also known as the Afghan church, commemorates the soldiers who died in the Afghan Conflict of 1839-1841. Consecrated in 1857, the spire was not completed until 1865.

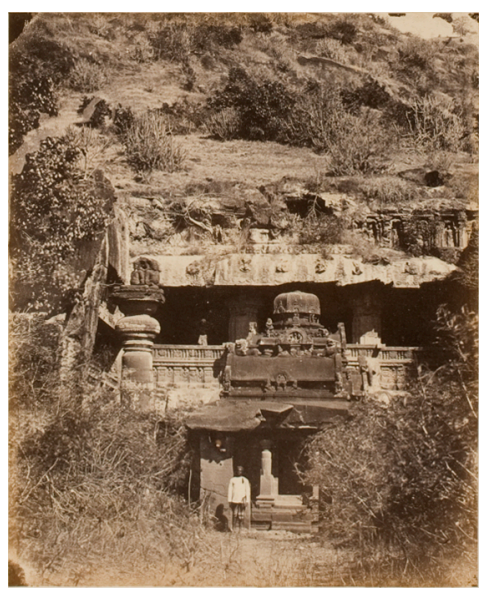

\section{Catalogue 45}

Title Temple Excavation at Elora

Photographer Capt. Allan N. Scott

Publication Date IAPA no. 16, February 1858

Medium Albumen silver print from a wet collodion glass-plate negative.

Dimensions $147 \times 120 \mathrm{~mm}$

\section{GEH 1979.0065.0045}

Notes This photograph illustrates the entrance to a Jain temple, Chota Kailasa (cave 32), at Ellora. 


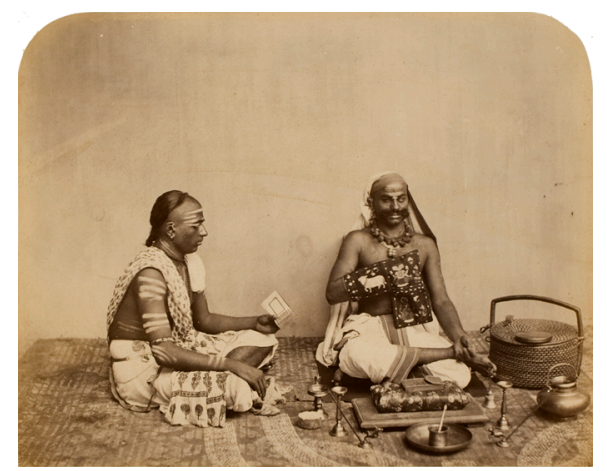

Catalogue 46

Title Costumes and Characters of Western India no. 14-Smarta Brahmans

Photographer William Johnson

Publication Date IAPA no. 16, February 1858

Medium Albumen silver print from a wet collodion glass-plate negative.

Dimensions $192 \times 244$ mm

GEH 1979.0065.0046

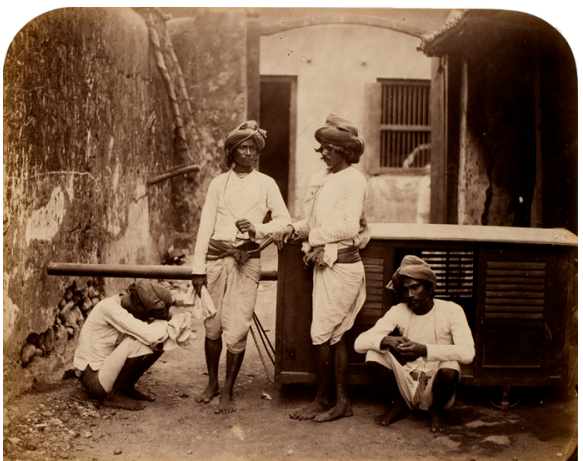

Catalogue 47

Title Costumes and Characters of Western India no. 15-Bengali Hamals

Photographer William Johnson

Publication Date IAPA no. 17, March 1858

Medium Albumen silver print from a wet collodion glass-plate negative.

Dimensions $190 \times 244 \mathrm{~mm}$

GEH 1979.0065.0047

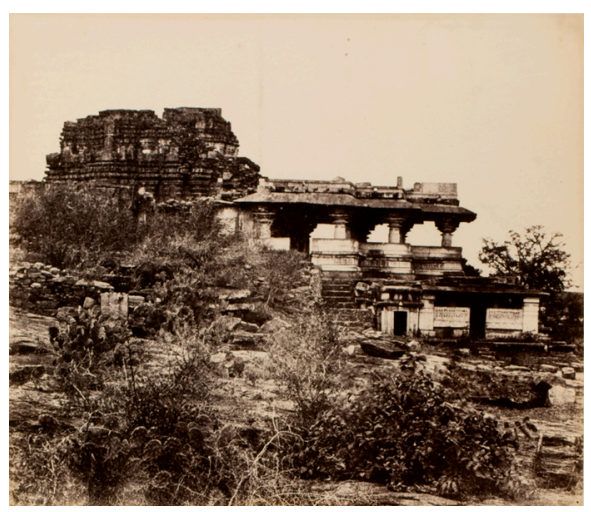

Catalogue 48

Title Ancient Temple at Gokak

Photographer A.Z. [Albert Zorn?]

Publication Date IAPA no. 17, March 1858

Medium Albumen silver print from a wet collodion glass-plate negative.

Dimensions $182 \times 211 \mathrm{~mm}$

GEH 1979.0065.0048

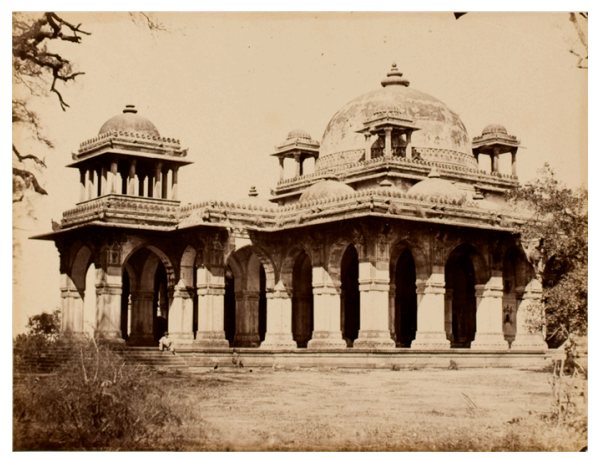

Catalogue 49

Title [Tomb of Mubarak Sayyid, near Mahmudabad]

Photographer [Unidentified Photographer]

Publication Date Unknown

Medium Albumen silver print from a wet collodion glass-plate negative.

Dimensions $164 \times 214 \mathrm{~mm}$

GEH 1979.0065.0049 


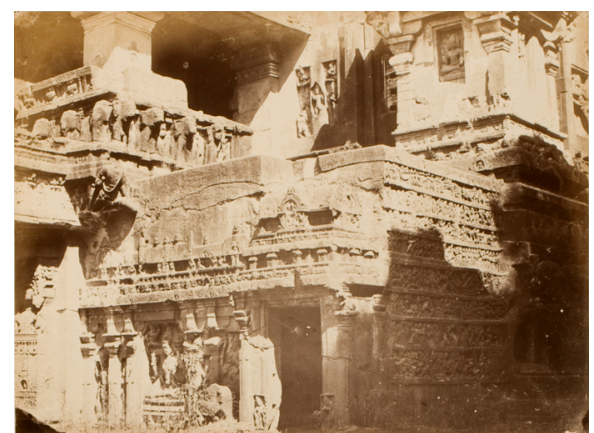

Catalogue 50

Title Portion of the Monolithic Temple of Kailas at Elora

Photographer Capt. Allan N. Scott

Publication Date IAPA no. 12, October 1857

Medium Albumen silver print from a wet collodion glass-plate negative.

Dimensions $144 \times 195 \mathrm{~mm}$

GEH 1979.0065.0050

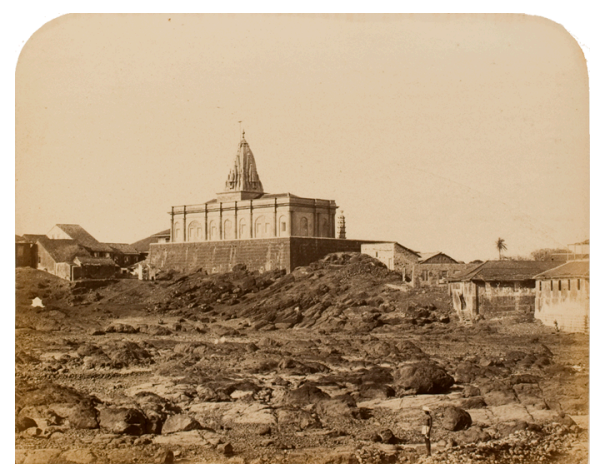

Catalogue 51

Title Bombay no. 21-Temple of Dhakaleshwar at Breach Candy

Photographer [Unidentified Photographer]

Publication Date IAPA no. 18, April 1858

Medium Albumen silver print from a wet collodion glass-plate negative.

Dimensions $191 \times 245 \mathrm{~mm}$

GEH 1979.0065.0051
Notes This photograph provides a view of the Dhakleshwar Mahadeo Mandir on the west side of Bombay, seen from the sea and looking towards the city. Although not visible in this photograph, the Dhakleshwar temple is very closely situated to the Mahalaxmi temple, dedicated to the Goddess of Wealth and perhaps Mumbai's most famous temple. Built by a prominent local businessman at least fifty years before the Mahalaxmi temple, its style of architecture is "partly native and partly European." The IAPA describes a temple "seldom visited by any worshipers," whose "annual festival attracts but little attention."

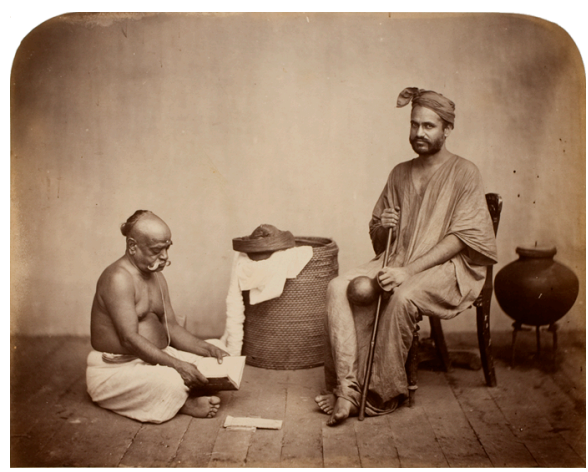

Catalogue 52

Title Costumes and Characters of Western India no. 17-The Brahmachari Bawa, Vishnu Bhiku

Photographer [Unidentified Photographer]

Publication Date IAPA no. 18, April 1858

Medium Albumen silver print from a wet collodion glass-plate negative.

Dimensions $192 \times 244$ mm

GEH 1979.0065.0052 


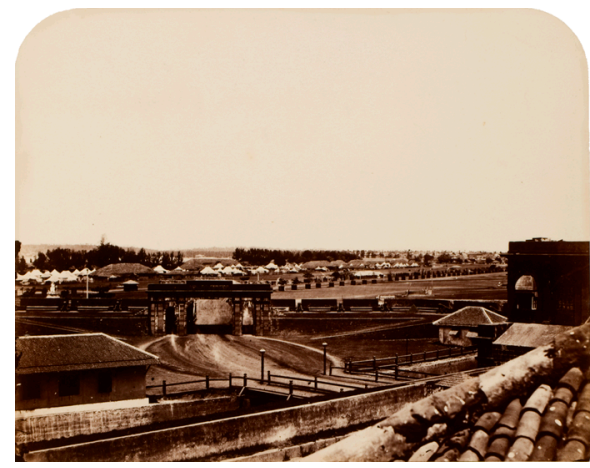

Catalogue 53

Title Bombay no. 1 -Bird's-eye View of the Church Gate and Esplanade, from the Bank of Bombay

Photographer Dr. George R. Ballingall

Publication Date IAPA no. 1, November 1856

Medium Albumen silver print from a wet collodion glass-plate negative.

Dimensions $190 \times 245 \mathrm{~mm}$

\section{GEH 1979.0065.0053}

Notes This view of the ramparts of Bombay Fort looking northwest across Church Gate clearly illustrates the confines of the Bombay fort and the green space beyond it, showing the moat and the cannons that were part of the Fort's defensive strategy. The Esplanade (today's Maidan), visible beyond the Fort's walls, is littered with military tents. Beyond the Esplanade and far into the distance, the heights of Malabar Hill can be seen to the left, while the buildings of the "Native Town" are visible on the right.

A probable variant to Catalogue 53, by $\operatorname{Dr}$. Ballingall depicting "the thoroughfare at the Church Gate Entrance to the Fort, and the Esplanade beyond" was displayed at the general meeting of the Bombay Photographic Society on July 10, 1855, where it was noted, "carriages, horses, and the crowds passing to and fro, were clearly and distinctly delineated." 172

172 "General Meeting," Journal of the Photographic Society of Bombay no. 7 (August 1855): 114.

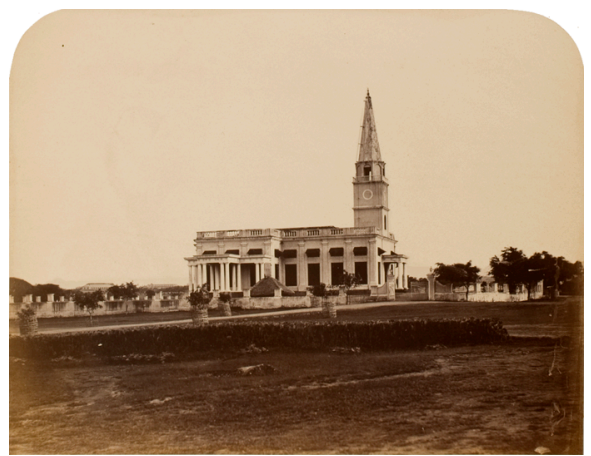

\section{Catalogue 54}

Title Saint Mary's Church, Poona

Photographer Henry H. Hinton

Publication Date IAPA no. 19, May 1858

Medium Albumen silver print from a wet collodion glass-plate negative.

Dimensions $187 \times 245 \mathrm{~mm}$

GEH 1979.0065.0054

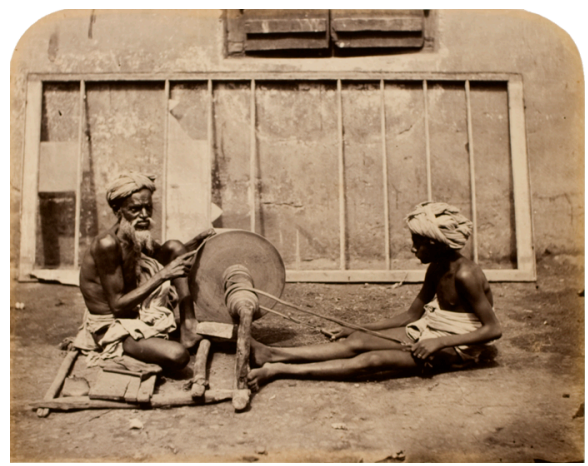

Catalogue 55

Title Costumes and Characters of Western India no. 16-The Native Knife Grinder and His Assistant

Photographer William Johnson

Publication Date IAPA no. 19, May 1858

Medium Albumen silver print from a wet collodion glass-plate negative.

Dimensions $190 \times 244 \mathrm{~mm}$

GEH 1979.0065.0055 


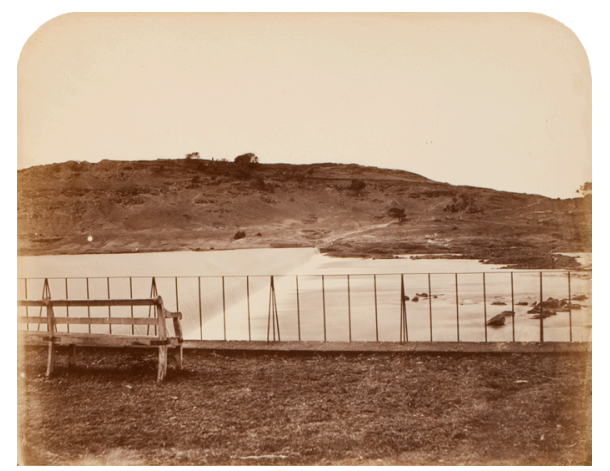

Catalogue 56

Title Poona no. 2-The Jamsetjee Bund

Photographer Henry H. Hinton

Publication Date IAPA no. 20, June 1858

Medium Albumen silver print from a wet collodion glass-plate negative.

Dimensions $190 \times 244 \mathrm{~mm}$

\section{GEH 1979.0065.0056}

Notes Documents the construction of a dike to control the flooding of the Mula and Mutha rivers. The sluices depicted here were funded by prominent Parsi businessman Jamsetjee Jeejeebhoy.

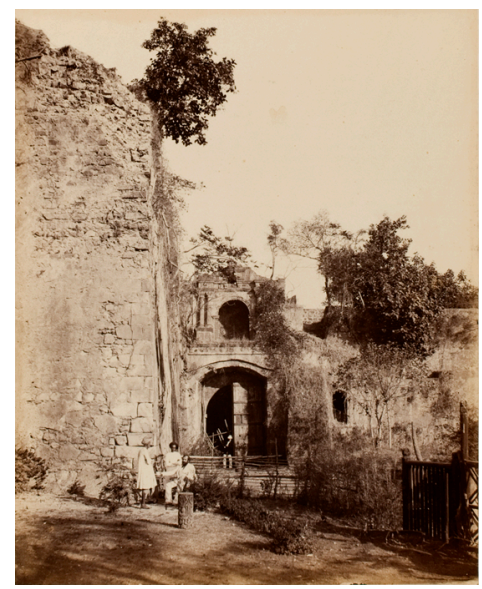

\section{Catalogue 57}

Title Bassein no. 1-The Eastern Gateway

Photographer [Unidentified Photographer]
Publication Date IAPA no. 20, June 1858

Medium Albumen silver print from a wet collodion glass-plate negative.

Dimensions $242 \times 194 \mathrm{~mm}$

GEH 1979.0065.0057

Notes Bassein (now Vasai), located fifty kilometers north of Bombay, was an important Portuguese settlement for roughly 200 years from 1535 until it was sacked by the Marathas in 1737(39?). This view shows the ruinous and overgrown state of the eastern gateway to the fort.

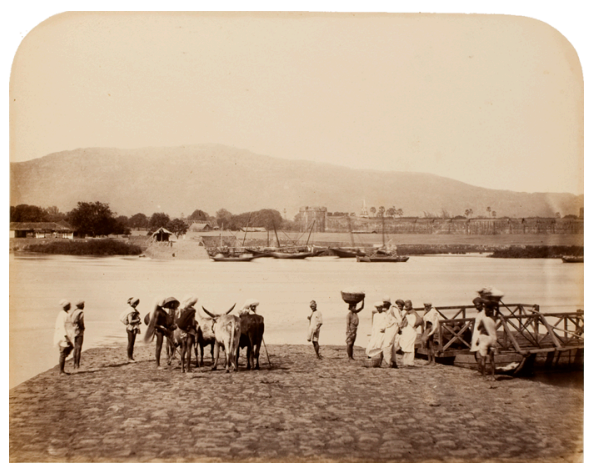

\section{Catalogue 58}

Title Tanna no. 1-The Ferry

Photographer [Unidentified Photographer]

Publication Date IAPA no. 20, June 1858

Medium Albumen silver print from a wet collodion glass-plate negative.

Dimensions $190 \times 244 \mathrm{~mm}$

GEH 1979.0065.0058 


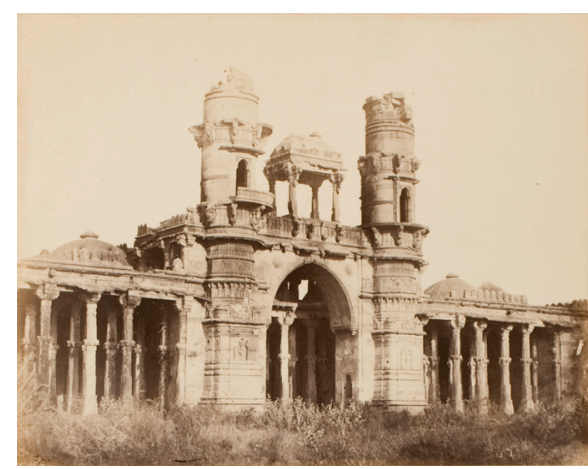

Catalogue 59

Title Ahmadabad no. 1-The Masjid of Alimpura

Photographer H.D. Rae

Publication Date IAPA no. 21, July 1858

Medium Albumen silver print from a wet collodion glass-plate negative.

Dimensions $168 \times 214 \mathrm{~mm}$

GEH 1979.0065.0059

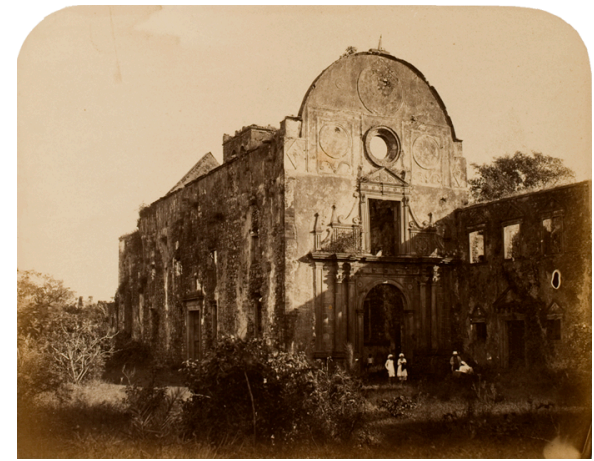

Catalogue 60

Title Bassein no. 2-The Church of St. Paul

Photographer William Johnson

Publication Date IAPA no. 21, July 1858

Medium Albumen silver print from a wet collodion glass-plate negative.

Dimensions $190 \times 244 \mathrm{~mm}$

GEH 1979.0065.0060

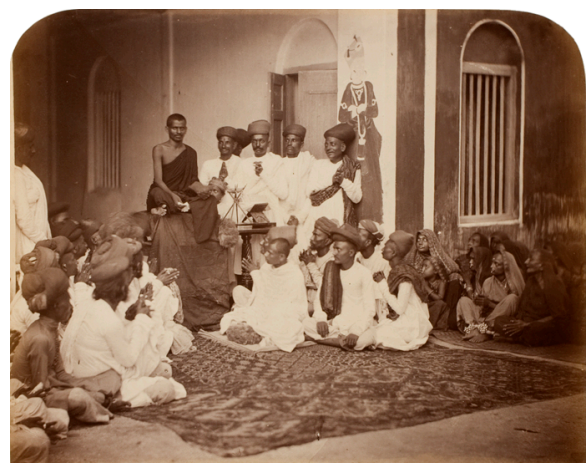

Catalogue 61

Title Costumes and Characters of Western India no. 18-A Jaina Priest Instructing his Disciples

Photographer William Johnson

Publication Date IAPA no. 21, July 1858

Medium Albumen silver print from a wet collodion glass-plate negative.

Dimensions $190 \times 243 \mathrm{~mm}$

GEH 1979.0065.0061

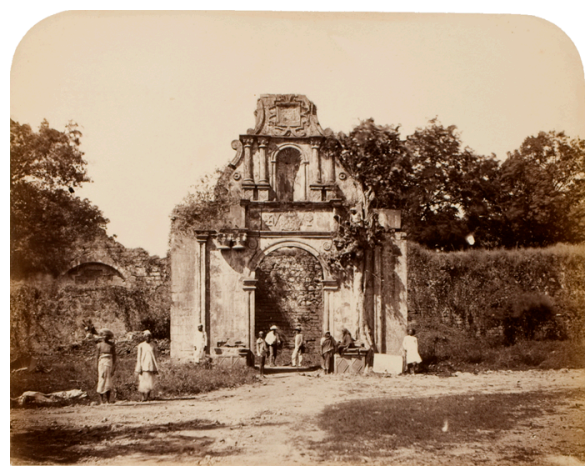

Catalogue 62

Title Bassein no. 3-The Main Entrance into the Inner Fort

Photographer William Johnson

Publication Date IAPA no. 22, August 1858

Medium Albumen silver print from a wet collodion glass-plate negative.

Dimensions $188 \times 244 \mathrm{~mm}$

GEH 1979.0065.0062 


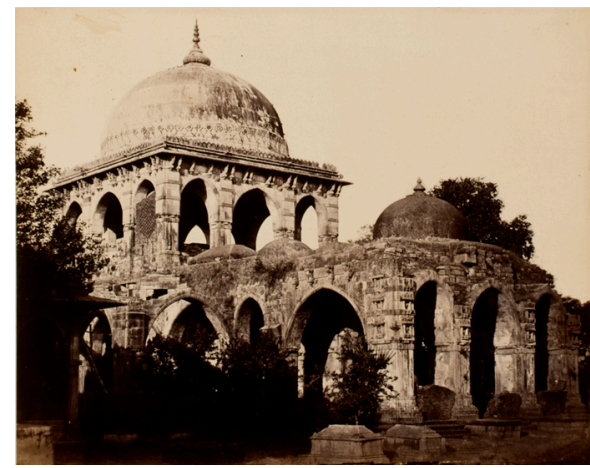

Catalogue 63

Title Ahmadabad no. 2-The Gambaj of Ganj Bakshi

Photographer H.D. Rae

Publication Date IAPA no. 22, August 1858

Medium Albumen silver print from a wet collodion glass-plate negative.

Dimensions $169 \times 212 \mathrm{~mm}$

GEH 1979.0065.0063

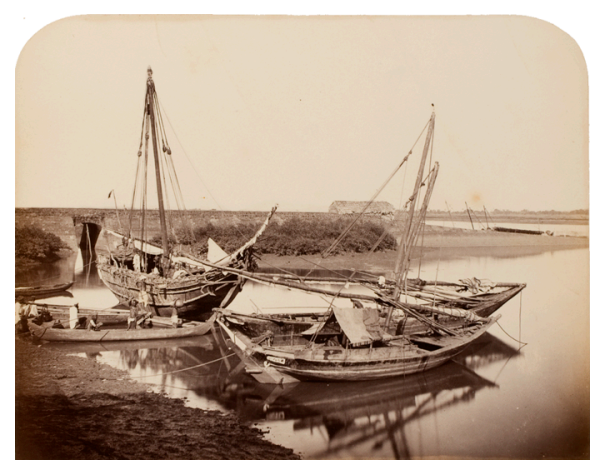

Catalogue 64

Title Tanna no. 2-Native Boats in the Creek

Photographer William Johnson

Publication Date IAPA no. 22, August 1858

Medium Albumen silver print from a wet collodion glass-plate negative.

Dimensions $186 \times 244 \mathrm{~mm}$

GEH 1979.0065.0064

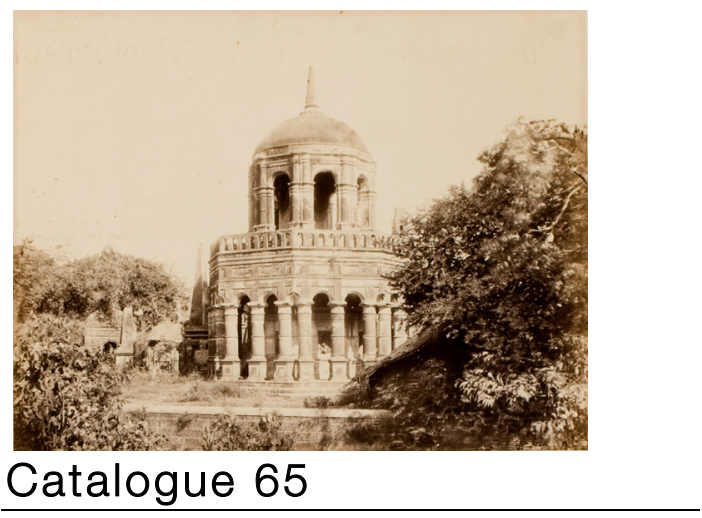

Title Dutch Tombs, Surat

Photographer Arthur A. Jacob

Publication Date IAPA no. 5, March 1857

Medium Albumen silver print from a wet collodion glass-plate negative.

Dimensions $163 \times 213 \mathrm{~mm}$

\section{GEH 1979.0065.0065}

Notes This photograph documents the tomb of Hendrik Adriaan van Rheede (1636-1691), administrator of the Dutch East India Company. Van Reede was also the author of Hortus Malabaricus, a comprehensive treatise dealing with local medicinal plants.

The European burial grounds at Surat, remnants of some of the earliest trading settlements in India, are also documented in catalogues 8 and 69 . 


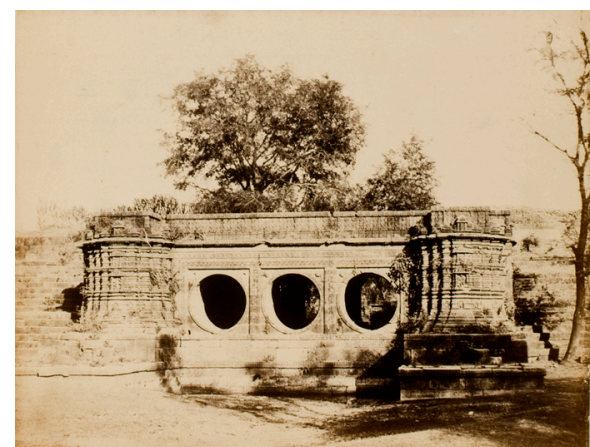

Catalogue 66

Title Ahmadabad no. 3-The Sluice Gates of the Hoza Kutbe or Kankrya Talao

Photographer H.D. Rae

Publication Date IAPA no. 23, September 1858

Medium Albumen silver print from a wet collodion glass-plate negative.

Dimensions $167 \times 216 \mathrm{~mm}$

GEH 1979.0065.0066

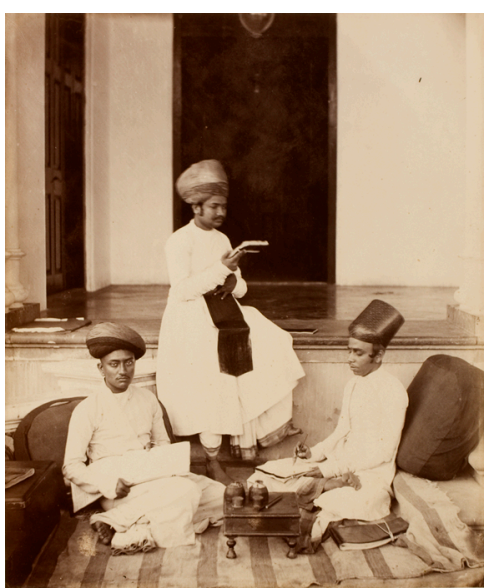

Catalogue 67

Title Costumes and Characters of Western India no. 19-Mehtas, or Native Writers

Photographer [Unidentified Photographer]

Publication Date IAPA no. 23, September 1858

Medium Albumen silver print from a wet collodion glass-plate negative.
Dimensions $241 \times 201 \mathrm{~mm}$

GEH 1979.0065.0067

Notes A group of Gujarati accountants, all of the Bania caste.

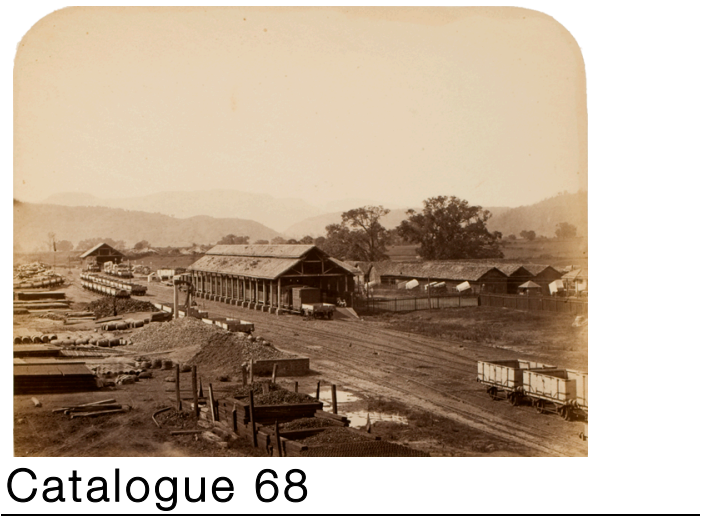

Title Campoolee

Photographer [Unidentified Photographer]

Publication Date IAPA no. 24, October 1858

Medium Albumen silver print from a wet collodion glass-plate negative.

Dimensions $190 \times 244 \mathrm{~mm}$

GEH 1979.0065.0068 


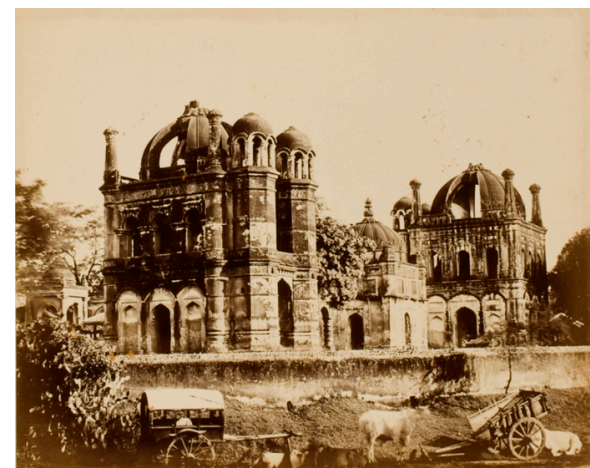

Catalogue 69

Title The Oldest English Tombs in Western India

Photographer H.D. Rae

Publication Date IAPA no. 24, October 1858

Medium Albumen silver print from a wet collodion glass-plate negative.

Dimensions $172 \times 213 \mathrm{~mm}$

\section{GEH 1979.0065.0069}

Notes Seventeenth century English mausoleums for three early Presidents of the Factory at Surat, Sir George Oxinden, Bartholomew Harris, and Francis Breton, dating from 1649 to 1695.

The European burial grounds at Surat are also documented in catalogues 8 and 65.

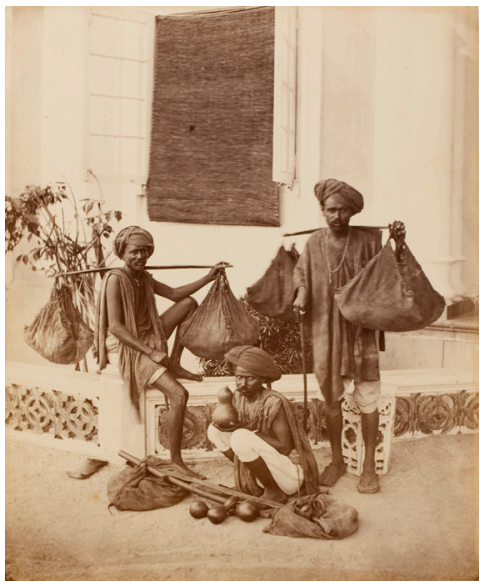

\section{Catalogue 70}

Title Costumes and Characters of Western India no. 20-Naka-Dole Waidyas
Photographer [Unidentified Photographer]

Publication Date IAPA no. 24, October 1858

Medium Albumen silver print from a wet collodion glass-plate negative.

Dimensions $243 \times 202$ mm

\section{GEH 1979.0065.0070}

Notes A group of wandering medicine men, seemingly known more for their untrustworthiness than their healing skills.

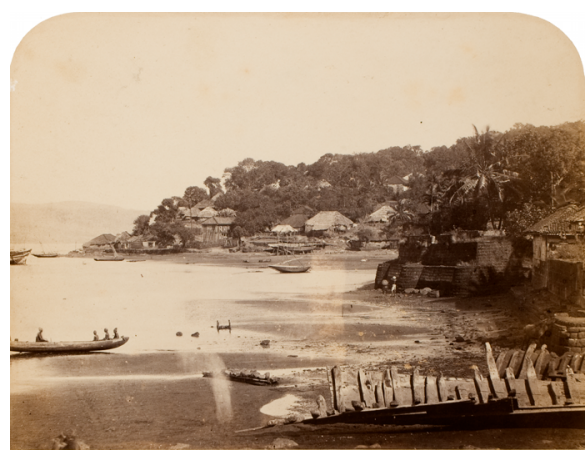

Catalogue 71

Title Bankot. From the Custom House

Photographer [Unidentified Photographer]

Publication Date Unknown

Medium Albumen silver print from a wet collodion glass-plate negative.

Dimensions $184 \times 144$ mm

GEH 1979.0065.0071 


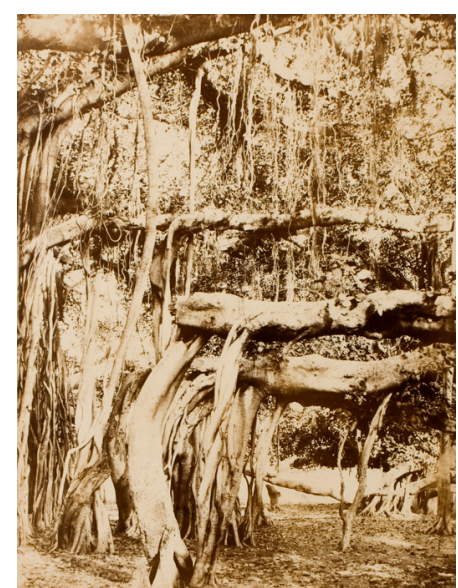

Catalogue 72

Title The Banyan Tree

Photographer [Unidentified Photographer]

Publication Date IAPA no. 6, April 1857

Medium Albumen silver print from a wet collodion glass-plate negative.

Dimensions $210 \times 160 \mathrm{~mm}$

GEH 1979.0065.0072 


\section{Appendix B The IAPA by Issue Number}

This table lists the photographs published in each of the first twenty-four issues of the IAPA, based on the examination of the compilations found in the collections of George Eastman House, Rochester NY and the Newberry Library, Chicago, IL. In this table, photograph titles and photographers are listed exactly as they appear in the issue's letterpress. Information within square brackets has been supplied by the author, and reflects details missing from the letterpress. In certain cases discrepancies exist between the two collections, which have been indicated.

\begin{tabular}{|c|c|c|}
\hline Issue & Photograph Title & Photographer \\
\hline \multirow{3}{*}{$\begin{array}{l}\text { IAPA no. } 1 \\
\text { November } 1856\end{array}$} & Acbar's Tomb, Agra (Catalogue 1) & An Up-Country Amateur \\
\hline & $\begin{array}{l}\text { Costumes and Characters of Western India no. 1-The } \\
\text { Gosayins (Catalogue } 3 \text { ) }\end{array}$ & William Johnson \\
\hline & $\begin{array}{l}\text { Bombay no. 1-Bird's-eye View of the Church Gate and } \\
\text { Esplanade, from the Bank of Bombay (Catalogue 53) }\end{array}$ & Dr. George R. Ballingal \\
\hline \multirow[t]{3}{*}{$\begin{array}{l}\text { IAPA no. } 2 \\
\text { December } 1856\end{array}$} & $\begin{array}{l}\text { Bombay no. 2-Bombay Green from the Town Hall } \\
\text { (Catalogue 4) }\end{array}$ & Johnson and Henderson \\
\hline & $\begin{array}{l}\text { Costumes and Characters of Western India no. 2-A } \\
\text { Group of Persians (Catalogue 6) }\end{array}$ & Johnson and Henderson \\
\hline & $\begin{array}{l}\text { Bombay no. 3-Monument of the Late Marquis of } \\
\text { Cornwallis, Governor General of India (Catalogue 5) }\end{array}$ & A. Z. [Albert Zorn?] \\
\hline \multirow{3}{*}{$\begin{array}{l}\text { IAPA no. } 3 \\
\text { January } 1857\end{array}$} & Bombay no. 4-Christ Church, Byculla (Catalogue 7) & Henry H. Hinton \\
\hline & Surat. English Burial Ground (Catalogue 8) & An Amateur \\
\hline & $\begin{array}{l}\text { Costumes and Characters of Western India no. } 3 \text { - } \\
\text { Parwari Women (Catalogue 9) }\end{array}$ & Johnson and Henderson \\
\hline \multirow{3}{*}{$\begin{array}{l}\text { IAPA no. } 4 \\
\text { February } 1857\end{array}$} & Bombay no. 5-Jooma Musjid (Catalogue 10) & Henry H. Hinton \\
\hline & $\begin{array}{l}\text { View on the Taptee River. The Site of the Proposed } \\
\text { Railway Bridge Near Surat (Catalogue 11) }\end{array}$ & Arthur A. Jacob \\
\hline & $\begin{array}{l}\text { Costumes and Characters of Western India no. 4-Group } \\
\text { of Pinjaras, or Cotton-Carders (Catalogue 12) }\end{array}$ & Johnson and Henderson \\
\hline \multirow[t]{3}{*}{$\begin{array}{l}\text { IAPA no. } 5 \\
\text { March } 1857\end{array}$} & $\begin{array}{l}\text { Bombay no. 6-The Cotton Ground, Colaba (Catalogue } \\
\text { 13) }\end{array}$ & Johnson and Henderson \\
\hline & $\begin{array}{l}\text { Costumes and Characters of Western India no. 5- } \\
\text { Parsee Lady and Child }{ }^{173} \text { (Catalogue 15) }\end{array}$ & Johnson and Henderson \\
\hline & Dutch Tombs, Surat (Catalogue 65) & Arthur A. Jacob \\
\hline \multirow[t]{4}{*}{$\begin{array}{l}\text { IAPA no. } 6 \\
\text { April } 1857\end{array}$} & $\begin{array}{l}\text { Falls of Mutlagherry, Near Ellichpoor, Northern Berar } \\
\text { (Catalogue 16) }\end{array}$ & Capt. Allan N. Scott \\
\hline & $\begin{array}{l}\text { Costumes and Characters of Western India no. 6- } \\
\text { Comfortable Gosavis (Catalogue 18) }\end{array}$ & Johnson and Henderson \\
\hline & GEH: Ruins in the Citadel of Bijapur & An Up-Country Amateur \\
\hline & Newberry: The Banyan Tree (Catalogue 72) & [Unidentified Photographer] \\
\hline
\end{tabular}

${ }^{173}$ In the GEH copy of the album the descriptive text for this photograph appears on a separate letterpress sheet as an appendix, which appears to have been published at a later date. In the Newberry copy of the album the descriptive text for all three photographs of IAPA no. 5 is compiled into a single letterpress sheet. 
Appendix B The IAPA by Issue Number

\begin{tabular}{|c|c|c|}
\hline \multirow[t]{3}{*}{$\begin{array}{l}\text { IAPA no. } 7 \\
\text { May } 1857\end{array}$} & $\begin{array}{l}\text { Elephanta. The Brahmanical Cave-Temple. no. 1-The } \\
\text { Entrance (Catalogue 19) }\end{array}$ & Johnson and Henderson \\
\hline & $\begin{array}{l}\text { Temples at Mutlagherry, Near Ellichpoor, Northern Berar } \\
\text { (Catalogue 20) }\end{array}$ & Capt. Allan N. Scott \\
\hline & Bombay no. 7- The Cathedral (Catalogue 21) & Johnson and Henderson \\
\hline \multirow[t]{4}{*}{$\begin{array}{l}\text { IAPA no. } 8 \\
\text { June } 1857\end{array}$} & $\begin{array}{l}\text { Elephanta. The Brahmanical Cave-Temple. no. 2- } \\
\text { Specimens of the Pillars (Catalogue 22) }\end{array}$ & Johnson and Henderson \\
\hline & $\begin{array}{l}\text { GEH: Bombay no. 8-View from the South-East } \\
\text { Frontage of the Town Hall (Catalogue 23) }\end{array}$ & Johnson and Henderson \\
\hline & Newberry: Bombay no. 8-St. Andrew's Church & [Unidentified Photographer] \\
\hline & A Scene on the Bombay and Baroda Line of Railway & Arthur A. Jacob \\
\hline \multirow[t]{3}{*}{$\begin{array}{l}\text { IAPA no. } 9 \\
\text { no date }\end{array}$} & $\begin{array}{l}\text { Costumes and Characters of Western India no. 7-Group } \\
\text { of Maratha Ghatis (Catalogue 25) }\end{array}$ & Johnson and Henderson \\
\hline & Bombay no. 9-A Wee Bit of the Castle (Catalogue 30) & An Amateur \\
\hline & $\begin{array}{l}\text { Elephanta. The Brahmanical Cave-Temple. no. 3- } \\
\text { Entrance to the Northern Aisle (Catalogue 27) }\end{array}$ & Johnson and Henderson \\
\hline \multirow{3}{*}{$\begin{array}{l}\text { IAPA no. } 10 \\
\text { no date }\end{array}$} & Tomb of the Moola of the Boras, Surat (Catalogue 28) & [Unidentified Photographer] \\
\hline & $\begin{array}{l}\text { Costumes and Characters of Western India no. 8- } \\
\text { Maratha Women of the Labouring Class (Catalogue 29) }\end{array}$ & Johnson and Henderson \\
\hline & $\begin{array}{l}\text { Bombay no. 10-Hindu Shrine by the Railway Station, } \\
\text { Byculla (Catalogue 34) }\end{array}$ & Henry H. Hinton \\
\hline \multirow[t]{3}{*}{$\begin{array}{l}\text { IAPA no. } 11 \\
\text { September } 1857\end{array}$} & $\begin{array}{l}\text { Bombay no. 11-Panoramic View of the Fort from } \\
\text { Colaba (Catalogue 2) }\end{array}$ & Johnson and Henderson \\
\hline & $\begin{array}{l}\text { Entrance to one of the Smaller Excavations at Elora } \\
\text { (Catalogue 31) }\end{array}$ & Capt. Allan N. Scott \\
\hline & $\begin{array}{l}\text { Costumes and Characters of Western India no. 9-An } \\
\text { Eastern Bishop (Catalogue 32) }\end{array}$ & Johnson and Henderson \\
\hline \multirow[t]{3}{*}{$\begin{array}{l}\text { IAPA no. } 12 \\
\text { October } 1857\end{array}$} & $\begin{array}{l}\text { Bombay no. 12-Back Bay, from Malabar Hill (Catalogue } \\
\text { 33) }\end{array}$ & Johnson and Henderson \\
\hline & $\begin{array}{l}\text { Portion of the Monolithic Temple of Kailas at Elora } \\
\text { (Catalogue 50) }\end{array}$ & Capt. Allan N. Scott \\
\hline & $\begin{array}{l}\text { Costumes and Characters of Western India no. 10- } \\
\text { Huzur Pattewallas (Catalogue 35) }\end{array}$ & Johnson and Henderson \\
\hline \multirow[t]{3}{*}{$\begin{array}{l}\text { IAPA no. } 13 \\
\text { November } 1857\end{array}$} & Bombay no. 13-A Bit of Malabar Hill (Catalogue 36) & Johnson and Henderson \\
\hline & $\begin{array}{l}\text { Costumes and Characters of Western India no. 11- } \\
\text { Brahmani Ladies (Catalogue 38) }\end{array}$ & Johnson and Henderson \\
\hline & Bombay no. 14-Temples at Walkeshwar (Catalogue 37) & Johnson and Henderson \\
\hline \multirow{3}{*}{$\begin{array}{l}\text { IAPA no. } 14 \\
\text { December } 1857\end{array}$} & Bombay no. 15-Malabar Point (Catalogue 39) & Johnson and Henderson \\
\hline & $\begin{array}{l}\text { Costumes and Characters of Western India no. 12- } \\
\text { Brahmin Students of English Literature (Catalogue 41) }\end{array}$ & Johnson and Henderson \\
\hline & $\begin{array}{l}\text { Bombay no. 16-A Second View of the Walkeshwar } \\
\text { Temples (Catalogue 40) }\end{array}$ & Johnson and Henderson \\
\hline \multirow[t]{2}{*}{$\begin{array}{l}\text { IAPA no. } 15 \\
\text { January } 1858\end{array}$} & $\begin{array}{l}\text { Costumes and Characters of Western India no. 13- } \\
\text { Bene-Israel Teachers (Catalogue 42) }\end{array}$ & Johnson and Henderson \\
\hline & $\begin{array}{l}\text { The Temple of Amarnath (Two Photographs) (Catalogue } \\
\text { 43) }\end{array}$ & Archibald Robertson \\
\hline \multirow[t]{3}{*}{$\begin{array}{l}\text { IAPA no. } 16 \\
\text { February } 1858\end{array}$} & $\begin{array}{l}\text { Bombay no. 17-The Colaba Memorial Church } \\
\text { (Catalogue 44) }\end{array}$ & William Johnson \\
\hline & $\begin{array}{l}\text { Costumes and Characters of Western India no. 14- } \\
\text { Smarta Brahmans (Catalogue 46) }\end{array}$ & William Johnson \\
\hline & Temple Excavation at Elora (Catalogue 45) & Capt. Allan N. Scott \\
\hline
\end{tabular}


Appendix B The IAPA by Issue Number

\begin{tabular}{|c|c|c|}
\hline \multirow[t]{3}{*}{$\begin{array}{l}\text { IAPA no. } 17 \\
\text { March } 1858\end{array}$} & $\begin{array}{l}\text { Costumes and Characters of Western India no. 15- } \\
\text { Bengali Hamals (Catalogue 1) }\end{array}$ & William Johnson \\
\hline & Ancient Temple at Gokak (Catalogue 48) & A. Z. [Albert Zorn?] \\
\hline & $\begin{array}{l}\text { Bombay no. 18-Temple of Shiva at Walakeshwar } \\
\text { (Catalogue 14) }\end{array}$ & William Johnson \\
\hline \multirow[t]{3}{*}{$\begin{array}{l}\text { IAPA no. } 18 \\
\text { April } 1858\end{array}$} & $\begin{array}{l}\text { Entrance to the Monolithic Temple of Kailas at Elora } \\
\text { (Catalogue 17) }\end{array}$ & $\begin{array}{l}\text { J. N. S. } \\
\text { [Capt. Allan N. Scott?] }\end{array}$ \\
\hline & $\begin{array}{l}\text { Costumes and Characters of Western India no. 17-The } \\
\text { Brahmachari Bawa, Vishnu Bhiku (Catalogue 52) }\end{array}$ & [Unidentified Photographer] \\
\hline & $\begin{array}{l}\text { Bombay no. 21-Temple of Dhakaleshwar at Breach } \\
\text { Candy (Catalogue 51) }\end{array}$ & [Unidentified Photographer] \\
\hline \multirow[t]{3}{*}{$\begin{array}{l}\text { IAPA no. } 19 \\
\text { May } 1858\end{array}$} & $\begin{array}{l}\text { Bombay no. 20-The Fort of Bombay, From the Apollo } \\
\text { Bunder (Catalogue 24) }\end{array}$ & William Johnson \\
\hline & $\begin{array}{l}\text { Costumes and Characters of Western India no. 16-The } \\
\text { Native Knife Grinder and His Assistant (Catalogue 55) }\end{array}$ & William Johnson \\
\hline & Saint Mary's Church, Poona (Catalogue 54) & Henry $\mathrm{H}$. Hinton \\
\hline \multirow{3}{*}{$\begin{array}{l}\text { IAPA no. } 20 \\
\text { June } 1858\end{array}$} & Poona no. 2-The Jamsetjee Bund (Catalogue 56) & Henry H. Hinton \\
\hline & Bassein no. 1-The Eastern Gateway (Catalogue 57) & [Unidentified Photographer] \\
\hline & Tanna no. 1-The Ferry (Catalogue 58) & [Unidentified Photographer] \\
\hline \multirow[t]{3}{*}{$\begin{array}{l}\text { IAPA no. } 21 \\
\text { July } 1858\end{array}$} & $\begin{array}{l}\text { Ahmadabad no. 1-The Masjid of Alimpura (Catalogue } \\
\text { 59) }\end{array}$ & H. D. Rae \\
\hline & $\begin{array}{l}\text { Costumes and Characters of Western India no. 18-A } \\
\text { Jaina Priest Instructing his Disciples (Catalogue 61) }\end{array}$ & William Johnson \\
\hline & Bassein no. 2-The Church of St. Paul (Catalogue 60) & William Johnson \\
\hline \multirow[t]{3}{*}{$\begin{array}{l}\text { IAPA no. } 22 \\
\text { August } 1858\end{array}$} & $\begin{array}{l}\text { Bassein no. 3-The Main Entrance into the Inner Fort } \\
\text { (Catalogue 62) }\end{array}$ & William Johnson \\
\hline & $\begin{array}{l}\text { Ahmadabad no. 2-The Gambaj of Ganj Bakshi } \\
\text { (Catalogue 63) }\end{array}$ & H. D. Rae \\
\hline & Tanna no. 2-Native Boats in the Creek (Catalogue 64) & William Johnson \\
\hline \multirow[t]{3}{*}{$\begin{array}{l}\text { IAPA no. } 23 \\
\text { September } 1858\end{array}$} & $\begin{array}{l}\text { Bassein no. 4-The Hindoo Temple of Mahdeo } \\
\text { (Catalogue 26) }\end{array}$ & [Unidentified Photographer] \\
\hline & $\begin{array}{l}\text { Costumes and Characters of Western India no. 19- } \\
\text { Mehtas, or Native Writers (Catalogue 67) }\end{array}$ & [Unidentified Photographer] \\
\hline & $\begin{array}{l}\text { Ahmadabad no. 3-The Sluice Gates of the Hoza Kutbe } \\
\text { or Kankrya Talao (Catalogue 66) }\end{array}$ & H. D. Rae \\
\hline \multirow{3}{*}{$\begin{array}{l}\text { IAPA no. } 24 \\
\text { October } 1858\end{array}$} & Campoolee (Catalogue 68) & [Unidentified Photographer] \\
\hline & $\begin{array}{l}\text { Costumes and Characters of Western India no. 20- } \\
\text { Naka-Dole Waidyas (Catalogue 70) }\end{array}$ & [Unidentified Photographer] \\
\hline & $\begin{array}{l}\text { The Oldest English Tombs in Western India (Catalogue } \\
\text { 69) }\end{array}$ & H. D. Rae \\
\hline
\end{tabular}




\section{Appendix $\mathrm{C}$ The IAPA by Series}

This table lists the photographic series published in each of the first twenty-four issues of the IAPA, based on the examination of the compilations found in the collections of George Eastman House, Rochester NY and the Newberry Library, Chicago, IL. In this table, titles and photographers are listed exactly as they appear in the issue's letterpress. Although the series title often forms part of the photograph title, e.g. Costumes and Characters of Western India, the photographs in an individual series are grouped together, and the series title is not repeated. Information within square brackets has been supplied by the author, and reflects details missing from the letterpress. In certain cases discrepancies exist between the two collections, which have been indicated.

\section{Title}

\section{Bombay}

No. 1-Bird's-eye View of the Church Gate and Esplanade, from the Bank of Bombay (Catalogue 53)

No. 2-Bombay Green from the Town Hall (Catalogue 4)

No. 3-Monument of the Late Marquis of Cornwallis, Governor General of India (Catalogue 5)

No. 4-Christ Church, Byculla (Catalogue 7)

No. 5-Jooma Musjid (Catalogue 10)

No. 6-The Cotton Ground, Colaba (Catalogue 13)

No. 7-The Cathedral (Catalogue 21)

GEH: No. 8-View from the South-East Frontage of the Town Hall (Catalogue 23)

Newberry: No. 8-St. Andrew's Church

No. 9-A Wee Bit of the Castle (Catalogue 30)

No. 10-Hindu Shrine by the Railway Station, Byculla (Catalogue 34)

No. 11-Panoramic View of the Fort from Colaba (Catalogue 2)

No. 12-Back Bay, from Malabar Hill (Catalogue 33)

No. 13-A Bit of Malabar Hill (Catalogue 36)

No. 14-Temples at Walkeshwar (Catalogue 37)

No. 15-Malabar Point (Catalogue 39)

No. 16-A Second View of the Walkeshwar Temples (Catalogue 40)

No. 17-The Colaba Memorial Church (Catalogue 44)

No. 18-Temple of Shiva at Walakeshwar (Catalogue 14)

No. 20-The Fort of Bombay, From the Apollo Bunder (Catalogue 24)

No. 21-Temple of Dhakaleshwar at Breach Candy (Catalogue 51)

\section{Costumes and Characters of Western India}

No. 1-The Gosayins (Catalogue 3)

No. 2-A Group of Persians (Catalogue 6)

No. 3 - Parwari Women (Catalogue 9)

No. 4-Group of Pinjaras, or Cotton-Carders (Catalogue 12)

No. 5-Parsee Lady and Child (Catalogue 15)

No. 6-Comfortable Gosavis (Catalogue 18)

\section{IAPA Photographer}

no. 1 Dr. George R. Ballingal

no. 2 Johnson and Henderson

no. 2 A. Z. [Albert Zorn?]

no. 3 Henry H. Hinton

no. 4 Henry $\mathrm{H}$. Hinton

no. 5 Johnson and Henderson

no. 7 Johnson and Henderson

no. 8 Johnson and Henderson

no. 8 [Unidentified Photographer]

no. 9 An Amateur

no. 10 Henry H. Hinton

no. 11 Johnson and Henderson

no. 12 Johnson and Henderson

no. 13 Johnson and Henderson

no. 13 Johnson and Henderson

no. 14 Johnson and Henderson

no. 14 Johnson and Henderson

no. 16 William Johnson

no. 17 William Johnson

no. 19 William Johnson

no. 18 [Unidentified Photographer]

no. 1 William Johnson

no. 2 Johnson and Henderson

no. 3 Johnson and Henderson

no. 4 Johnson and Henderson

no. 5 Johnson and Henderson

no. 6 Johnson and Henderson 


No. 7 -Group of Maratha Ghatis (Catalogue 25)
No. 8 -Maratha Women of the Labouring Class (Catalogue 29)
No. 9 -An Eastern Bishop (Catalogue 32)
No. 10 -Huzur Pattewallas (Catalogue 35)
No. $11-$ Brahmani Ladies (Catalogue 38)
No. $12-$ Brahmin Students of English Literature (Catalogue 41)
No. $13-$ Bene-Israel Teachers (Catalogue 42)
No. $14-$ Smarta Brahmans (Catalogue 46)
No. $15-$ Bengali Hamals (Catalogue 47 )
No. $16-$ The Native Knife Grinder and His Assistant (Catalogue 55)
No. $17-$ The Brahmachari Bawa, Vishnu Bhiku (Catalogue 52)
No. $18-$ A Jaina Priest Instructing his Disciples (Catalogue 61)
No. $19-$ Mehtas, or Native Writers (Catalogue 67)
No. $20-$ Naka-Dole Waidyas (Catalogue 70)

\section{[Surat]}

English Burial Ground (Catalogue 8)

View on the Taptee River. The Site of the Proposed Railway Bridge

Near Surat (Catalogue 11)

Dutch Tombs, Surat (Catalogue 65)

A Scene on the Bombay and Baroda Line of Railway

Tomb of the Moola of the Boras, Surat (Catalogue 28)

The Oldest English Tombs in Western India (Catalogue 69)

\section{[Ellichpoor]}

Falls of Mutlagherry, Near Ellichpoor, Northern Berar (Catalogue 16)

Temples at Mutlagherry, Near Ellichpoor, Northern Berar (Catalogue 20)

\section{Elephanta. The Brahmanical Cave-Temple}

No. 1-The Entrance (Catalogue 19)

No. 2-Specimens of the Pillars (Catalogue 22)

No. 3-Entrance to the Northern Aisle (Catalogue 27)

\section{[Elora]}

Entrance to one of the Smaller Excavations at Elora (Catalogue 31)

Portion of the Monolithic Temple of Kailas at Elora (Catalogue 50)

Temple Excavation at Elora (Catalogue 45)

Entrance to the Monolithic Temple of Kailas at Elora (Catalogue 31)

\section{Poona}

[No. 1]-Saint Mary's Church, Poona (Catalogue 54)

No. 2-The Jamsetjee Bund (Catalogue 56)

\section{Bassein}

No. 1-The Eastern Gateway (Catalogue 57)

No. 2-The Church of St. Paul (Catalogue 60)

No. 3-The Main Entrance into the Inner Fort (Catalogue 62)

No. 4-The Hindoo Temple of Mahdeo (Catalogue 26) no. 9 Johnson and Henderson

no. 10 Johnson and Henderson

no. 11 Johnson and Henderson

no. 12 Johnson and Henderson

no. 13 Johnson and Henderson

no. 14 Johnson and Henderson

no. 15 Johnson and Henderson

no. 16 William Johnson

no. 17 William Johnson

no. 19 William Johnson

no. 18 [Unidentified Photographer]

no. 21 William Johnson

no. 23 [Unidentified Photographer]

no. 24 [Unidentified Photographer]

\section{no. 3 An Amateur}

no. 4 Arthur A. Jacob

no. 5 Arthur A. Jacob

no. 8 Arthur A. Jacob

no. 10 [Unidentified Photographer]

no. 24 H. D. Rae

no. 6 Capt. Allan N. Scott

no. 7 Capt. Allan N. Scott

no. 7 Johnson and Henderson

no. 8 Johnson and Henderson

no. 9 Johnson and Henderson 
Appendix C The IAPA by Series

\begin{tabular}{|c|c|c|}
\hline \multicolumn{3}{|l|}{ Tanna } \\
\hline No. 1-The Ferry (Catalogue 58) & no. 20 & [Unidentified Photographer] \\
\hline No. 2-Native Boats in the Creek (Catalogue 64) & no. 22 & William Johnson \\
\hline \multicolumn{3}{|l|}{ Ahmadabad } \\
\hline No. 1-The Masjid of Alimpura (Catalogue 59) & no. 21 & H. D. Rae \\
\hline No. 2-The Gambaj of Ganj Bakshi (Catalogue 63) & no. 22 & H. D. Rae \\
\hline $\begin{array}{l}\text { No. } 3 \text { - The Sluice Gates of the Hoza Kutbe or Kankrya Talao } \\
\text { (Catalogue 66) }\end{array}$ & no. 23 & H. D. Rae \\
\hline \multicolumn{3}{|l|}{ Bankot } \\
\hline Bankot. From the Custom House (Catalogue 71) & [???] & [Unidentified Photographer] \\
\hline
\end{tabular}




\section{Bibliography and Works Consulted}

\section{Nineteenth Century Illustrated Works}

Daniell, Thomas and William Daniell. Oriental Scenery: Part First Containing Twenty-Four Views of the Architecture, Antiquities, and Landscape Scenery of Hindoostan. London: Longman, Hurst, Rees, Orme, and Brown, 1812.

Hinton, Henry. The Ruins of Beejapoor, in a Series of Nineteen Views from Collodion Negatives. Bombay, 1860.

Johnson, William and William Henderson. The Indian Amateur's Photographic Album nos. 1-36 (November 1856-October 1859).

Johnson, William. The Oriental Races and Tribes, Residents and Visitors of Bombay. 2 vols. London: W. J. Johnson, Bolton and Barnitt, 1863, 1866.

_. Photographs of Western India. 3 vols. Bombay, 1860 or later.

Rousselet, Louis. L'Inde des Rajahs: Voyage dans L'Inde Centrale et dans les Présidences de Bombay et du Bengale. Paris: Librairie Hachette et Co., 1877.

- India and its Native Princes: Travels in Central India and in the Presidencies of Bombay and Bengal. Edited by Lieut.-Col. Buckle. London: Bickers \& Son, 1882.

Scott, Capt. Allan N. Sketches in India: Taken at Hyderabad and Secunderbad, in the Madras Presidency. Edited by Charles Richard Weld. London: Lovell Reeve, 1862.

The Stereoscopic Magazine: A Gallery of Landscape, Scenery, Architecture, Antiquities, and Natural History, Accompanied with Descriptive Articles by Writers of Eminence. 5 vols. London: Lovell Reeve 1858-59, 1862-63, and 1865.

Urwick, Rev. W. Indian Pictures, Drawn With Pen and Pencil. London: Religious Tract Society, 1881.

Watson, J. Forbes. The Textile Manufactures and the Costumes of the People of India. London: George Edward Eyre and William Spottiswoode, 1866.

Watson, J. Forbes and Sir John William Kaye, ed. The People of India: A Series of Photographic Illustrations, with Descriptive Letterpress, of the Races and Tribes of Hindustan. 8 vols. London: Wm. H. Allen \& Co., 1868-1874.

Wilson, John. The Caves of Karla Illustrated: in a Series of Photographs, by W. Johnson, F.L.P.S. with Descriptive and Historical Remarks on the Buddhist Excavations of Western India. Bombay: Exchange Press, 1861.

\section{Nineteenth Century Periodicals}

“Amateur's Photographic Album.” Photographic Notes 1, no. 1 (January 1, 1856): 12. 
"At a Meeting of the Photographic Society, held at the School of Arts on the $7^{\text {th }}$ April 1859." Madras Journal of Literature and Science 21 (1859-60): 174-202.

Bombay Calendar and Almanac for 1856. Bombay: Times' Press, 1856.

"Exhibition of Photographs at Bombay." Humphrey's Journal of the Daguerreotype and Photographic Arts, and the Sciences and Arts Pertaining to Heliography 8, no. 15 (December 1, 1856): 233-235.

"The Hindoo Money Changer," The Illustrated London News, October 8, 1859, 342.

Journal of the Photographic Society of Bombay nos. 1-17 (January 15, 1855-June 1856).

"List of Works on India and the East Published During the Quarter." The Calcutta Review: 33 (July-Dec. 1859): xxxviii.

"Photography in Western India." The Photographic News 1, no. 23 (February 11, 1859): 265-266.

"Proclamation of the Queen's Rule in India," The Illustrated London News, January 1, 1859, 17.

"Surat-Its Past and Present." Calcutta Review 9 (1848): 103 - 137.

\section{Twentieth and Twenty-first Century Sources}

Archer, Mildred. Company Paintings: Indian Paintings of the British Period. London: Victoria and Albert Museum with Mapin, Ahmedabad, 1992.

Bayly, Christopher Alan, ed., Brian Allen, Rajnarayan Chandavarkar, John Falconer, P.J. Marshall, Partha Mitter, Christopher Pinney, Francis Robinson, G.H.R. Tillotson. The Raj: India and the British 1600-1947. London: National Portrait Gallery Publications, 1990.

Bethel, Denise. "At Auction and in the Book Trade: Sources for the Photography Historian." History of Photography 21, no. 2 (Summer 1997): 117-128.

Bonhams. India in Books, Photographs, Maps and Manuscripts. London: Bonhams, 2006.

Carter, Mia and Barbara Harlow, eds. Archives of Empire Volume 1: From the East India Company to the Suez Canal. Durham NC: Duke University Press, 2003.

Christies. $19^{\text {th }}$ Century Indian Photographs from the Kanwardip Gujral Collection. London: Christies, Sept. 272001.

David, Dr. M.D. Bombay: The City of Dreams (A History of the First City in India). Bombay: Himalaya Publishing House, 1995.

Dehejia, Vidya, ed. India Though the Lens: Photography 1840-1911. Washington DC: Freer Gallery of Art and Arthur M. Sackler Gallery with Mapin, Ahmedabad, 2000. 
Desmond, Ray. "Photography in India During the $19^{\text {th }}$ Century." The Photographic Journal 115, no. 1 (January 1975): 40-41.

_- "Photography in India During the Nineteenth Century." In India Office Library and Records, Annual Report for the Year 1974, 5-36. London: Her Majesty's Stationary Office, 1976. 317.

Dewan, Janet. "Delineating Antiquities and Remarkable Tribes: Photography for the Bombay and Madras Governments 1855-70." History of Photography 16 (1992): 302317.

_. "Sun Pictures from the City of Gold: Early Photography in Bombay." In Bombay to Mumbai: Changing Perspectives, edited by Pratapaditya Pal, 112-127. Mumbai: Marg Publications, 1997.

- The Photographs of Linnaeus Tripe: A Catalogue Raisonée. Toronto: Art Gallery of Ontario, 2003.

Edwards, Elizabeth. "Photographic "Types": The Pursuit of Method." Visual Anthropology 3, no. 2 (1990): 235-258.

—. Raw Histories: Photographs, Anthropology and Museums. Oxford: Berg, 2001.

Eskind, Andrew H., ed. International Photography: George Eastman House Index to Photographers, Collections. $3^{\text {rd }}$ ed. Greg Drake, Kirsti Ringerr, Lynne Rumney, assoc. ed. New York: G.K. Hall \& Co., 1998.

Falconer, John. "The Photograph Collection of The Royal Commonwealth Society." The Photographic Collector 2, no. 1 (1981): 34-53.

_. "Ethnographical Photography in India 1850-1900." The Photographic Collector 5, no. 1 (1984): 16-46.

_. "Photography in Nineteenth-Century India." In The Raj: India and the British 16001947, edited by C. A. Bayly, 264-277. London: National Portrait Gallery Publications, 1990.

_ . "A Passion for Documentation: Architecture and Ethnography." In India Though the Lens: Photography 1840-1911, edited by Vidya Dehejia, 69-85. Washington DC: Freer Gallery of Art and Arthur M. Sackler Gallery with Mapin, Ahmedabad, 2000.

—. India: Pioneering Photographers 1850-1900. London: The British Library, 2001.

Fergusson, James. History of Indian \& Eastern Architecture. $2^{\text {nd }}$ ed. London: John Murray, 1910.

Gernsheim, Helmut. "Cuthbert Bede (The Rev. Edward Bradley, 1827-1889), Robert Hunter F.R.S. (1807-1887), and Thomas Sutton (1819-1875)." In One Hundred Years of 
Photographic History: Essays in Honor of Beaumont Newhall, edited by Van Deren Coke, 59-67. Albuquerque: University of New Mexico Press, 1975.

- Incunabula of British Photographic Literature: A Bibliography of British Photographic Literature 1839-75, and British Books Illustrated with Original Photographs. London: Scholar Press, 1984.

Gutman, Judith Mara. Through Indian Eyes: $19^{\text {th }}$ and Early $20^{\text {th }}$ Century Photographs from India. New York: International Center of Photography, 1982.

Hahn, Hazel H. "Indian Princes, Dancing Girls, and Tigers: The Prince of Wales' Tour of India and Ceylon, 1875-1876." Postcolonial Studies 12, no. 2 (2009): 173-192.

Hartsuiker, Dolf. Sadhus: Holy Men of India. London: Thames and Hudson, 1993.

Hannavy, John, ed. Encyclopedia of Nineteenth-Century Photography. New York: Routledge, 2008.

Hight, Eleanor M. and Gary D. Sampson, eds. Colonialist Photography: Imag(in)ing Race and Place. London: Routledge, 2002.

Jammes, Isabelle. Blanquart-Evrard et les Origines de L'édition Photographique Française: Catalogue Raisonné des Albums Photographique Édités 1851-1855. Genève: Librairie Droz SA, 1981.

Johnson, William S. Nineteenth Century Photography: An Annotated Bibliography, 18391879. Boston: G.K. Hall, 1990.

McCauley, Elizabeth Anne. "Evasion in Victorian Landscape Photography: The Amateur Photographic Association Album." Bulletin, University of New Mexico Art Museum 12 (1978-1979): 3-13.

McKenzie, Ray. "'The laboratory of Mankind': John McCosh and the Beginnings of Photography in British India." History of Photography, 11, no. 2 (April-June 1987): 109118.

Mehta, Suketu. Maximum City: Bombay Lost and Found. New York: Vintage Books, 2004.

Mitchell, W. J. T., ed. Landscape and Power. Chicago: University of Chicago Press, 1994.

Mitter, Partha. The Artful Pose: Early Studio Photography in Mumbai, c. 1855-1940. Ahmedabad: Mapin Publishing, 2010.

Morris, Rosalind C., ed. Photographies East: The Camera and Its Histories in East and Southeast Asia. Durham NC: Duke University Press, 2009.

Nordström, Alison Devine. "Persistent Images: Photographic Archives in Ethnographic Collections." Continuum: The Australian Journal of Media \& Culture 6, no. 2 (1991): 208212.

Pal, Pratapaditya, ed. Bombay to Mumbai: Changing Perspectives. Mumbai: Marg Publications, 1997. 
Patel, Divia. "The Formation of an Imperial Vision: The Indian Amateur's Photographic Album." The Asian Arts Society of Australia Review 17, no. 3 (Sept. 2008): 4-6.

Pelizzari, Maria Antonella, ed. Traces of India: Photography, Architecture, and the Politics of Representation, 1850-1900. New Haven: Yale University Press, 2003.

Pinney, Christopher. "Classification and Fantasy in the Photographic Construction of Caste and Tribe." Visual Anthropology 3, no. 2 (1990): 259-288.

- "Colonial Photography in the 'Laboratory of Mankind.'” In The Raj: India and the British 1600-1947, edited by C. A. Bayly, 252-263. London: National Portrait Gallery Publications, 1990.

- Camera Indica: The Social Life of Indian Photographs. Chicago: The University of Chicago Press, 1997.

- "Notes from the Surface of the Image: Photography, Postcolonialism, and Vernacular Modernism." In Photography's Other Histories, edited by Christopher Pinney and Nicholas Peterson, 202-220. Durham NC: Duke University Press, 2003.

—. The Coming of Photography in India. London: The British Library, 2008.

Pratt, Mary Louise. "Arts of the Contact Zone." Profession 91(1991): 33-40.

Ranganathan, Murali, ed. and trans. Govind Narayan's Mumbai: An Urban Biography from 1863. London: Anthem Press, 2008.

Ricketts, Howard. "Early Indian Photographs at the Graves Art Gallery, Sheffield: From the Howard Ricketts Collection." Creative Camera 208 (April 1982): 476-484.

Rosenblum, Naomi. A World History of Photography. New York: Abbeville Press, 1984.

Ryan, James R. Picturing Empire: Photography and the Visualization of the British Empire. London: Reaktion Books, 1997.

Scarre, Chris and Judith Roberts. "The English Cemetery at Surat: Pre-Colonial Cultural Encounters in Western India." The Antiquarian Journal 85 (2005): 250 -291.

Schwartz, Joan M. "'Records of Simple Truth and Precision': Photography, Archives, and the Illusion of Control." Archivaria 50: 1-40.

Sieberling, Grace. Amateurs, Photography, and the Mid-Victorian Imagination. Chicago: University of Chicago Press, 1986.

Swann Auction Galleries. Photography: A Panoramic History of the Art of Photography as Applied to Book Illustration, from its Inception up to Date; The Important Collection of the Late Albert E. Marshall of Providence, R. I. Sold by the Executors, the Estate of Albert E. Marshall. New York: Swann Auction Galleries, 1952.

Tadgell, Christopher. The History of Architecture in India. London: Phaidon, 1990. 
Taylor, Roger. Impressed by Light: British Photographs from Paper Negatives, 1849-1860. New York: The Metropolitan Museum of Art, 2007.

Thomas, G. "Photography and the Elphinstone Institution of Bombay." History of Photography 5 (1981): 245-247.

- "The Madras Photographic Society 1856-61." History of Photography 16, no. 4 (Winter 1992): 299-301.

Tindall, Gillian. City of Gold. London: Temple Smith, 1982.

Worswick, Clark and Ainslee Embree, ed. The Last Empire: Photography in British India, 1855-1911. Millerton NY: Aperture, 1976. 